\title{
Kapitel- und Musterübersicht ${ }^{\star}$
}

\begin{abstract}
Alle Muster auch auf der CD-ROM am hinteren Buchdeckel.
Seite

Vorwort $\ldots \ldots \ldots \ldots \ldots \ldots \ldots \ldots \ldots \ldots \ldots \ldots \ldots \ldots \ldots \ldots \ldots \ldots \ldots \ldots$ VII

Allgemeines Literaturverzeichnis $\ldots \ldots \ldots \ldots \ldots \ldots \ldots \ldots \ldots \ldots \ldots \ldots \ldots \ldots \ldots \ldots \ldots$

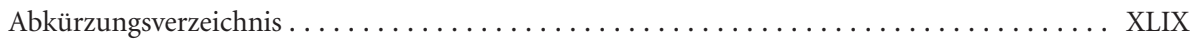

\section{A. Zivil- und Wirtschaftsrecht}

Erster Teil. Vereine und Stiftungen

\section{Abschnitt. Vereine}

Kap. 1 Vereine Fleckenstein/Schröders $\ldots \ldots \ldots \ldots \ldots \ldots \ldots \ldots \ldots \ldots \ldots \ldots \ldots \ldots \ldots$

M $1.1 \quad$ Niederschrift über die Gründungsversammlung eines Vereins . . . . . . . . . 2

M 1.2 Satzung eines Sportvereins e.V. $\ldots \ldots \ldots \ldots \ldots \ldots \ldots \ldots \ldots \ldots \ldots \ldots \ldots \ldots \ldots$

M 1.3 Antrag auf Bestellung eines Notvorstands für den Verein $\ldots \ldots \ldots \ldots \ldots \ldots \ldots$

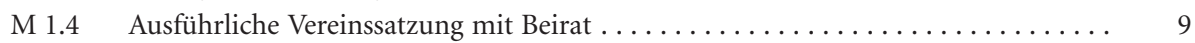

M 1.5 Anmeldung eines Vereins zur Eintragung in das Vereinsregister. . . . . . . . . . . 13

M 1.6 Einladung zwecks Einberufung einer Mitgliederversammlung des Vereins . . . . . 14

M 1.7 Niederschrift einer Mitgliederversammlung mit Veränderungen im Vorstand und

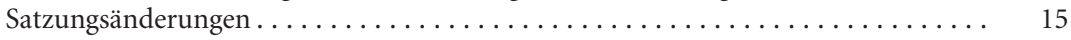

M 1.8 Anmeldung von Veränderungen im Vereinsvorstand und Satzungsänderungen . . 16

M 1.9 Beschluss der Mitgliederversammlung zur Auflösung des Vereins . . . . . . . . . 17

M 1.10 Antrag auf Entziehung der Rechtsfähigkeit des Vereins . . . . . . . . . . . 18

M 1.11 Anmeldung der Auflösung des Vereins und Anmeldung der Liquidatoren . . . . . 19

M 1.12 Zuwendungsbestätigung: inländische juristische Personen des öffentlichen Rechts

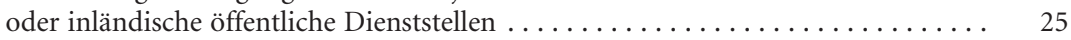

M 1.13 Zuwendungsbestätigung: in $\$ 5$ Abs. 1 Nr. 9 KStG bezeichnete Körperschaften, Personenvereinigungen oder Vermögensmassen $\ldots \ldots \ldots \ldots \ldots \ldots \ldots \ldots \ldots \ldots \ldots$

M 1.14 Erläuterungen zu der Erklärung zur Körperschaftsteuer und Gewerbesteuer von Körperschaften, die gemeinnützigen, mildtätigen oder kirchlichen Zwecken dienen

\section{Abschnitt. Stiftungen}

Kap. 2 Stiftungen Fleckenstein/Schröders $\ldots \ldots \ldots \ldots \ldots \ldots \ldots \ldots \ldots \ldots \ldots \ldots \ldots \ldots \ldots$

M 2.1 Errichtung einer Stiftung unter Lebenden, Stiftungsgeschäft und einfache

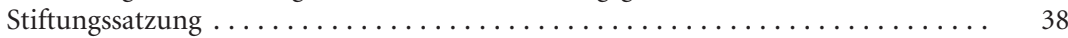

M 2.1a Errichtung einer Verbrauchsstiftung unter Lebenden . . . . . . . . . . . . 40

M 2.2 Errichtung einer rechtsfähigen Stiftung unter Lebenden, Stiftungsgeschäft und

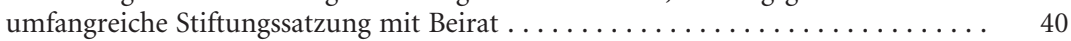

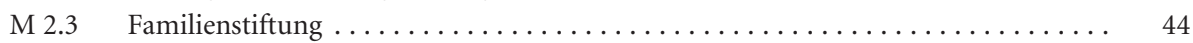

M 2.4 Errichtung einer Stiftung, Stiftungsgeschäft durch Testament $\ldots \ldots \ldots \ldots \ldots$

M $2.5 \quad$ Antrag auf Anerkennung der Stiftung $\ldots \ldots \ldots \ldots \ldots \ldots \ldots \ldots \ldots \ldots \ldots \ldots \ldots \ldots \ldots \ldots$

* Ausführliche Inhaltsverzeichnisse finden sich jeweils am Anfang der einzelnen Kapitel. 
M 2.6 Nicht rechtsfähige (unselbständige) Stiftung, Errichtung durch Vermächtnis . ... 47

M 2.7 Nicht rechtsfähige Stiftung, Errichtung durch Verwaltungstreuhand ......... 47

M 2.8 Zuwendungsbestätigung: inländische Stiftung des öffentlichen Rechts . . . . . . 51

M 2.9 Zuwendungsbestätigung: inländische Stiftung des privaten Rechts $\ldots \ldots \ldots \ldots \ldots 2$

Zweiter Teil. Allgemeines Schuldrecht

\section{Abschnitt. Handeln, Vertretung, Form}

Kap. 3 Rechtsfähigkeit und Handlungsfähigkeit Götte/Schröders ................ 54

M $3.1 \quad$ Antrag auf Todeserklärung aufgrund allgemeiner Verschollenheit . . . . . . . . 58

Kap. 4 Vertretung und Vollmacht Götte/Schröders ....................... 59

M $4.1 \quad$ Einfache Vollmacht (Spezialvollmacht) ....................... 63

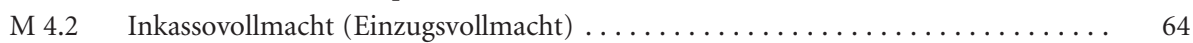

M 4.3 Zwangsversteigerungsvollmacht einschließlich Ermächtigung zum Bieten....... 64

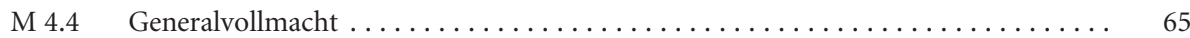

M $4.5 \quad$ Kraftloserklärung einer Vollmacht ........................... 68

M 4.6 Genehmigung einer ohne Vertretungsmacht abgegebenen Willenserklärung ..... 70

Kap. 5 Gesetzliche und vereinbarte Form Götte .................... 70

M 5.1 Öffentliche Unterschriftsbeglaubigung durch den Notar $\ldots \ldots \ldots \ldots \ldots \ldots \ldots$

M 5.2 Notarielle Beurkundung von Willenserklärungen .................. 75

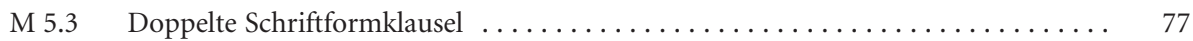

2. Abschnitt. Das Rechtsgeschäft

Kap. 6 Willenserklärungen und Vertragsabschluss Götte $\ldots \ldots \ldots \ldots \ldots \ldots \ldots \ldots \ldots$

Kap. 7 Erlöschen von Schuldverhältnissen, Vergleich Götte/Schröders ............ 82

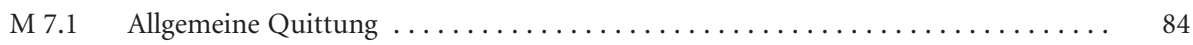

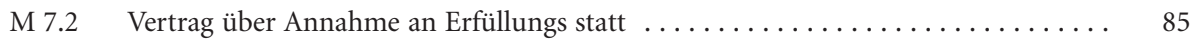

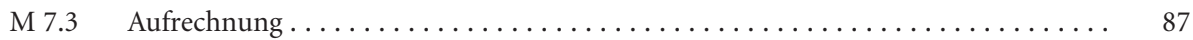

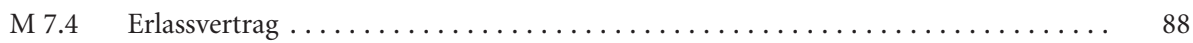

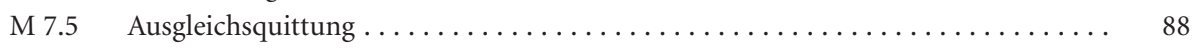

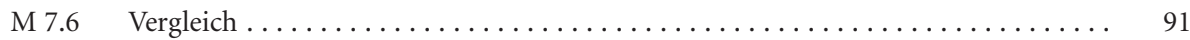

Kap. 8 Fehlerhafte Rechtsgeschäfte Götte/Schröders.................. 91

\section{Abschnitt. Allgemeine Schuldverhältnisse}

Kap. 9 Beteiligung Dritter am Schuldverhältnis Götte/Schröders $\ldots \ldots \ldots \ldots \ldots \ldots .98$

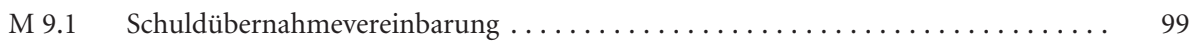

M 9.2 Aufforderung an den Gläubiger zur Genehmigung der Schuldübernahme ...... 99

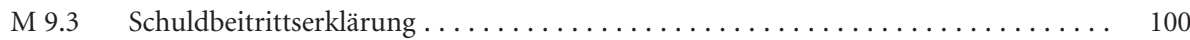

M 9.4 Vertragsübernahmevertrag zwischen scheidender und neuer Partei ......... 101

M 9.5 Vertragsübernahme - Schreiben der neuen Partei an den Vertragspartner....... 102

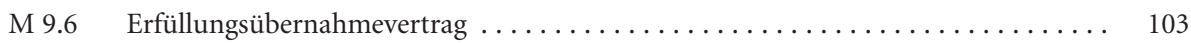

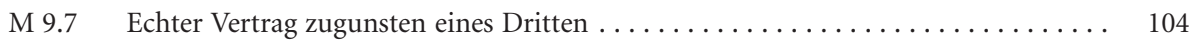

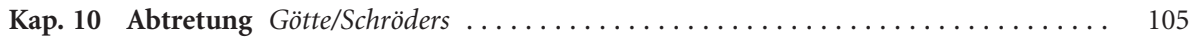

M 10.1 Abtretungsvertrag . . . . . . . . . . . . . . . . . . . . . . . . . . 107

M 10.2 Abtretungsanzeige durch den Zedenten ....................... 107

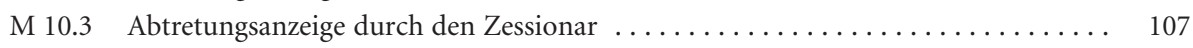




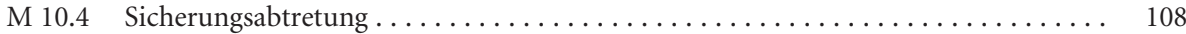

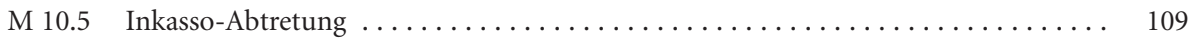

M 10.6 Einziehungsermächtigung (Vertragsklausel) $\ldots \ldots \ldots \ldots \ldots \ldots \ldots \ldots \ldots \ldots \ldots \ldots$

M 10.7 Abtretung einer Gehaltsforderung $\ldots \ldots \ldots \ldots \ldots \ldots \ldots \ldots \ldots \ldots \ldots \ldots \ldots \ldots \ldots$

Kap. 11 Vertragsstrafe, Verjährung, Verzug und Mahnung Götte .............. 114

M 11.1 Vertragsstrafeversprechen (Unterlassung einer Äußerung) . . . . . . . . . . 116

M 11.2 Verjährungseinredeverzicht $\ldots \ldots \ldots \ldots \ldots \ldots \ldots \ldots \ldots \ldots \ldots \ldots \ldots \ldots \ldots \ldots$

M 11.3 Mahnschreiben zur Verzugsauslösung beim Schuldner . . . . . . . . . . . . . . . . . 119

M 11.4 Mahnschreiben zum Annahmeverzug . . . . . . . . . . . . . . . . . . . 120

Dritter Teil. Schuldrechtliche Verträge des BGB

\section{Abschnitt. Allgemeine Geschäftsbedingungen, Kauf}

Kap. 12 Allgemeine Geschäftsbedingungen Fleckenstein ................. 121

M 12.1 AGB für den Gebrauchtwagenverkauf - Verkauf von Privat . . . . . . . . . . . . 128

M 12.2 AGB für den Gebrauchtwagenverkauf - Verkauf durch einen Unternehmer . . . . . 129

M 12.3 AGB für die Lieferung neuer Verbrauchsgüter $\ldots \ldots \ldots \ldots \ldots \ldots \ldots \ldots$

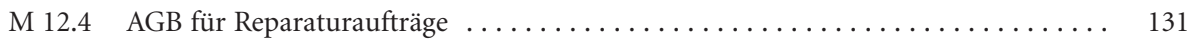

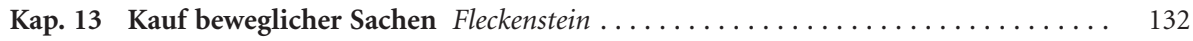

M $13.1 \quad$ Kaufvertrag über ein gebrauchtes Kraftfahrzeug . . . . . . . . . . . . . . . . . 143

M 13.2 Veräußerungsanzeige bei Kfz-Verkauf, Mitteilungsschreiben für die Kfz-Zulas-

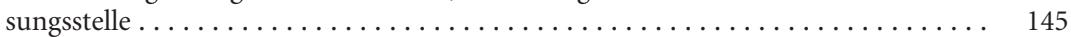

M 13.3 Veräußerungsanzeige bei Kfz-Verkauf, Mitteilung an die Haftpflichtversicherung

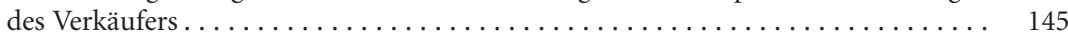

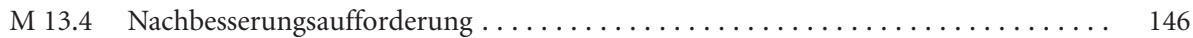

M 13.5 Rücktritt durch den Käufer . . . . . . . . . . . . . . . . . . . . . . . . . 146

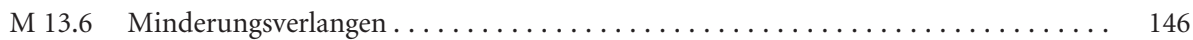

M 13.7 Mängelrüge beim Handelskauf $\ldots \ldots \ldots \ldots \ldots \ldots \ldots \ldots \ldots \ldots \ldots \ldots \ldots \ldots$

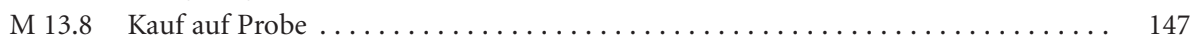

M 13.9 Vorkaufsrechtsvereinbarung . . . . . . . . . . . . . . . . . . . . . . . . 148

M 13.10 Mitteilung des Eintritts eines Vorkaufsfalls an den Vorkaufsberechtigten . . . . . . 149

\section{Abschnitt. Versand- und Onlinehandel}

Kap. 14 Versand- und Onlinehandel Scholz . . . . . . . . . . . . . . . . . . . . . . . . 149

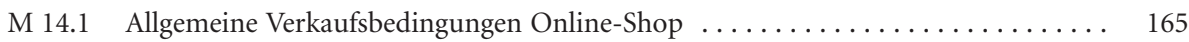

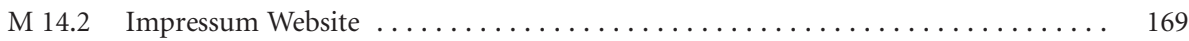

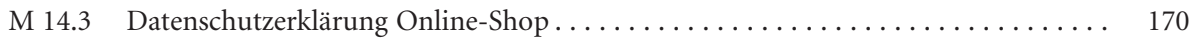

M 14.4 Einwilligungserklärung E-Mail- und Telefonwerbung . . . . . . . . . . . . 172

\section{Abschnitt. Schenkung}

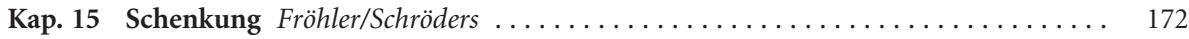

M 15.1 Schenkung einer Geldrente . . . . . . . . . . . . . . . . . . . . . . . . . . 179

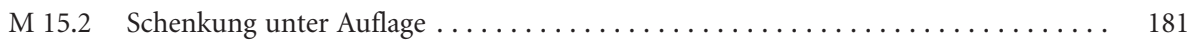

M 15.3 Vereinbarung zwischen Schenker und Bank bei Vertrag zu Gunsten eines Dritten auf den Todesfall (Schenkung eines Sparguthabens) . . . . . . . . . . . 185

M 15.4 Bestimmung der Bezugsberechtigung aus einem Lebensversicherungsvertrag . . . . 185

M 15.5 Lediglich rechtlich vorteilhafter Rückübertragungsvorbehalt . . . . . . . . . . . . . 189 
M 15.6 Lediglich rechtlich vorteilhafte Bestimmung einer Pflichtteilsanrechnung . . . . . . 191

M 15.7 Widerruf einer Schenkung wegen groben Undanks . . . . . . . . . . . . . . 192

\section{Abschnitt. Miete, Pacht, Landpacht}

Kap. 16 Wohnraummiete Engel/Schröders ......................... 198

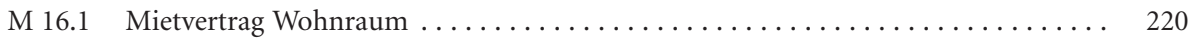

M 16.2 Übergabeprotokoll (Einzug) Wohnraum ........................ 226

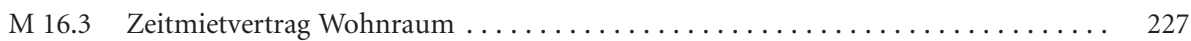

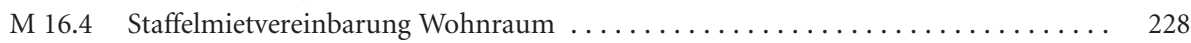

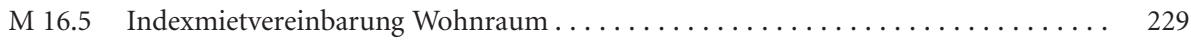

M 16.6 Mieterhöhung Wohnraum bis zur ortsüblichen Vergleichsmiete . . . . . . . . . . 229

M 16.7 Modernisierungsankündigung bei Wohnraum .................. 231

M 16.8 Mieterhöhung wegen Modernisierung von Wohnraum .............. 232

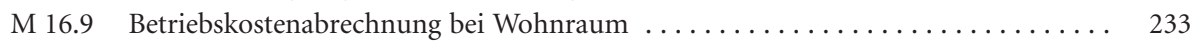

M 16.10 Anpassung der Betriebskostenvorauszahlungen bei Wohnraum ............ 234

M 16.11 Mietminderung wegen Mängeln bei Wohnraum .................. 235

M 16.12 Ordentliche Kündigung des Vermieters von Wohnraum wegen Pflichtverletzung .. 236

M 16.13 Erleichterte Kündigung des Vermieters bei Einliegerwohnung/Wohnraum im vom

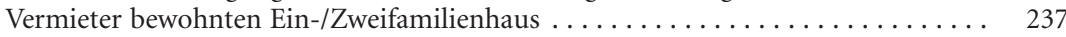

M 16.14 Fristlose Kündigung des Vermieters von Wohnraum bei Zahlungsverzug . . . . . . 238

M 16.15 Abmahnung des Mieters von Wohnraum wegen vertragswidrigen Verhaltens ..... 239

M 16.16 Fristlose Kündigung des Vermieters von Wohnraum wegen Pflichtverletzung ..... 239

M 16.17 Kündigungswiderspruch des Mieters von Wohnraum ................. 240

M 16.18 Fristlose Kündigung des Mieters von Wohnraum wegen Gesundheitsgefährdung .. 241

M 16.19 Mietaufhebungsvertrag über Wohnraum .................... 241

M 16.20 Fristsetzung zur Vornahme von Schönheitsreparaturen bei Wohnraum nach Ver-

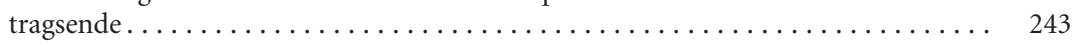

Kap. 17 Gewerberaummiete und Miete anderer Sachen Engel ................ 244

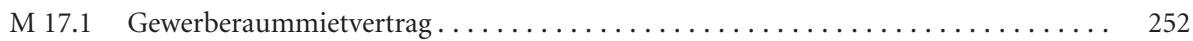

M 17.2 Konkurrenzschutzklausel bei Gewerberaum .................. 261

M 17.3 Echte Ersatzmieterklausel bei Gewerberaum .................... 262

M 17.4 „Harte“ Patronatserklärung bei Gewerberaum .................. 262

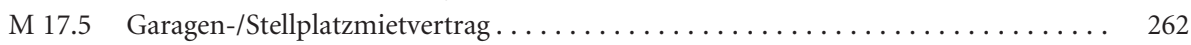

Kap. 18 Pacht (einschließlich Landpacht) Engel/Schröders ................. 265

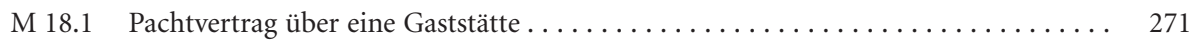

M 18.2 Pachtvertrag über einen Hof (Landpachtvertrag) $\ldots \ldots \ldots \ldots \ldots \ldots \ldots \ldots \ldots \ldots \ldots \ldots \ldots$

\section{Abschnitt. (Bau-)Werkvertrag und VOB-Verträge}

Kap. 19 Werkvertragsrecht Schill/Schröders $\ldots \ldots \ldots \ldots \ldots \ldots \ldots \ldots \ldots \ldots \ldots \ldots$

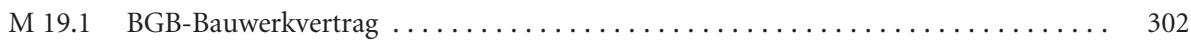

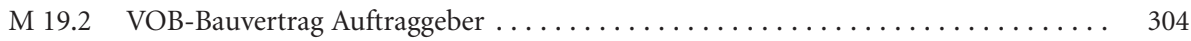

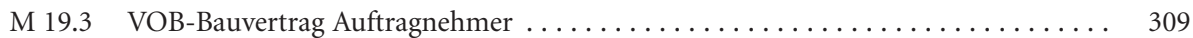

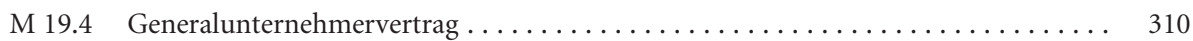

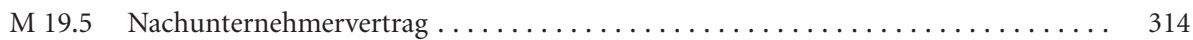

M 19.6 Anforderung der Sicherheitsleistung nach $₫ 648$ a B B $\ldots \ldots \ldots \ldots \ldots \ldots \ldots . \ldots \ldots$

M 19.7 Außerordentliche Kündigung nach fruchtloser Aufforderung zur Sicherheitsleis-

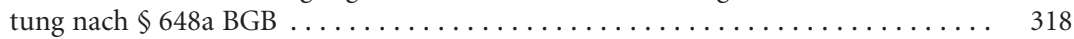




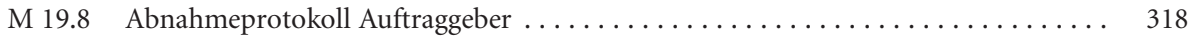

M 19.9 Abnahmeprotokoll Auftragnehmer . . . . . . . . . . . . . . . . . . . . . . . 319

M 19.10 Aufforderung zur Mängelbeseitigung unter Fristsetzung . . . . . . . . . . . 319

Kap. 20 Bauträgervertrag (mit Bauträgermerkblatt) Schill ................ 325

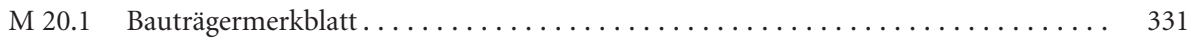

M 20.2 Bauträgervertrag (Ersterwerb Wohngebäude) $\ldots \ldots \ldots \ldots \ldots \ldots \ldots \ldots \ldots \ldots \ldots \ldots$

M 20.3 Bauträgervertrag (Ersterwerb Wohnungseigentum) . . . . . . . . . . . . 349

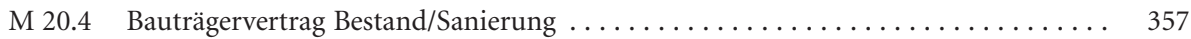

Kap. 21 Architektenvertrag und Verträge mit Sonderfachleuten Wolber ........... 364

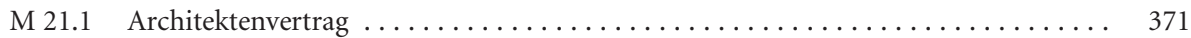

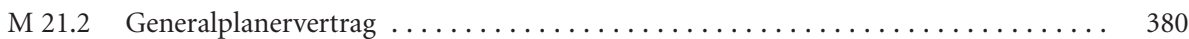

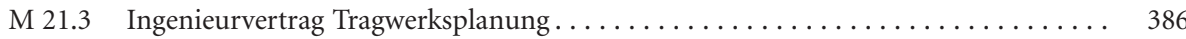

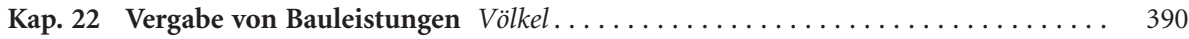

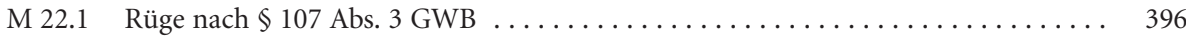

M 22.2 Antrag auf Durchführung eines Nachprüfungsverfahrens . . . . . . . . . . . . . 398

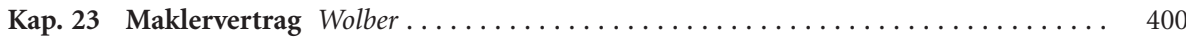

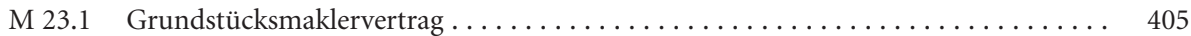

M 23.2 Muster einer Widerrufsbelehrung für den Maklervertrag . . . . . . . . . . . . . . . 407

\section{Abschnitt. Darlehen, Bürgschaft, Schuldanerkenntnis}

Kap. 24 Darlehensrecht $G e h l \ldots \ldots \ldots \ldots \ldots \ldots \ldots \ldots \ldots \ldots \ldots \ldots \ldots \ldots \ldots \ldots$

M $24.1 \quad$ Einfacher Darlehensvertrag unter Verwandten . . . . . . . . . . . . . . . 412

M 24.2 Darlehen zwischen Arbeitnehmer und Arbeitgeber . . . . . . . . . . . . . . . . . 413

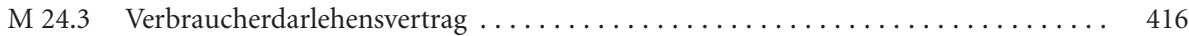

M 24.4 Umwandlung einer auf einem anderen Rechtsgrund beruhenden Schuld in ein Darlehen ....................................... 418

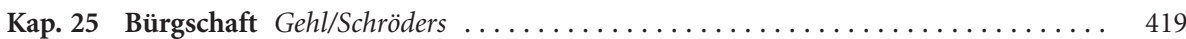

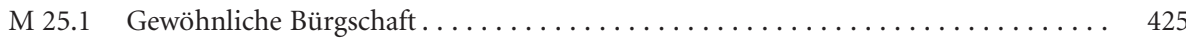

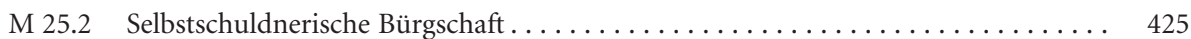

M 25.3 Höchstbetragsbürgschaft $\ldots \ldots \ldots \ldots \ldots \ldots \ldots \ldots \ldots \ldots \ldots \ldots \ldots \ldots \ldots \ldots \ldots$

M 25.4 Selbstschuldnerische Höchstbetragsbürgschaft zur Sicherung eines Bankkredits . . 426

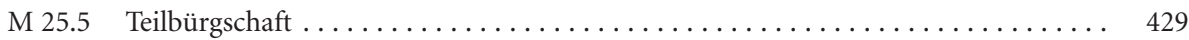

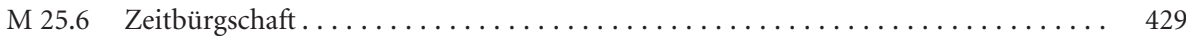

M 25.7 Ausfallbürgschaft $\ldots \ldots \ldots \ldots \ldots \ldots \ldots \ldots \ldots \ldots \ldots \ldots \ldots \ldots \ldots \ldots \ldots \ldots$

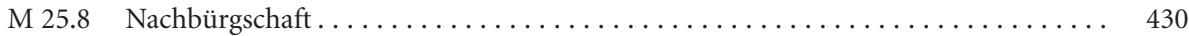

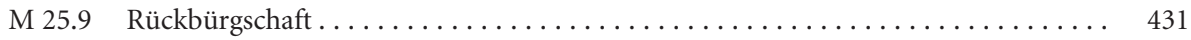

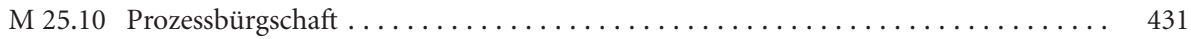

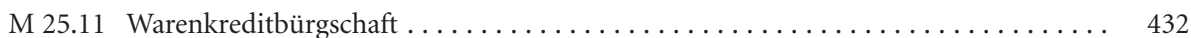

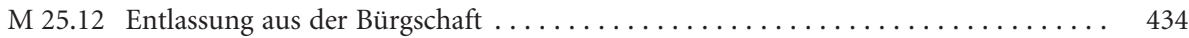

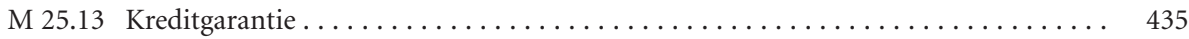

M 25.14 „Harte“ Patronatserklärung . . . . . . . . . . . . . . . . . . . . . . 436

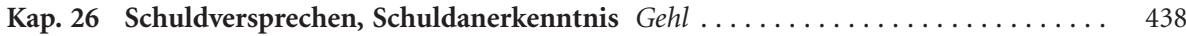

M 26.1 Schuldanerkenntnis mit Unterwerfung unter die sofortige Zwangsvollstreckung . . 441

M 26.2 Schuldanerkenntnis mit Ratenzahlungsvereinbarung . . . . . . . . . . . . . . 442

M 26.3 Besserungsschein nach außergerichtlichem Vergleich . . . . . . . . . . . . . . 443 


\section{Abschnitt. Unerlaubte Handlung}

Kap. 27 Unerlaubte Handlung Schmidt/Schröders ..................... 444

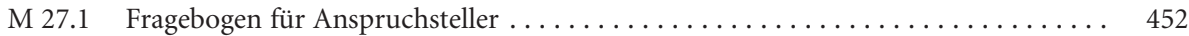

M 27.2 Geltendmachung von Ansprüchen aus Verkehrsunfall gegenüber dem Schädiger .. 453

M 27.3 Meldung von Schäden aus Verkehrsunfall gegenüber dem Haftpflichtversicherer

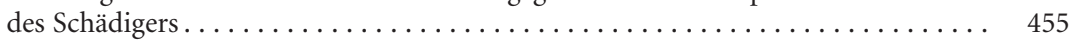

M 27.4 Geltendmachung von Schäden aus einem Verkehrsunfall gegenüber dem Haft-

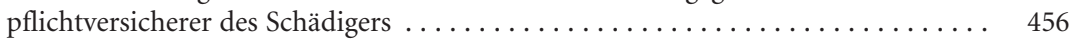

M 27.5 Kostendeckungsanfrage an Rechtsschutzversicherer ................ 456

8. Abschnitt. Verpfändung, Eigentumsvorbehalt und Sicherungsgeschäfte

Kap. 28 Pfandrecht an beweglichen Sachen und Rechten Schmidt/Schröders ........ 457

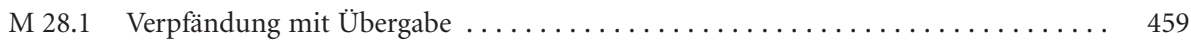

M 28.2 Verpfändung durch Abtretung des Herausgabeanspruchs . . . . . . . . . . . . . . 462

M 28.3 Pfandrecht an beweglichen Sachen ohne Besitzübertragung ............. 463

M 28.4 Verpfändung eines Sparguthabens . . . . . . . . . . . . . . . . . . . . . . . . . 464

M 28.5 Verpfändung von Wertpapieren . . . . . . . . . . . . . . . . . . . . . . . 464

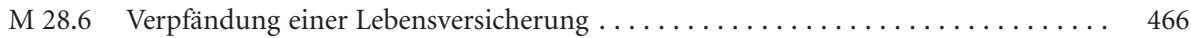

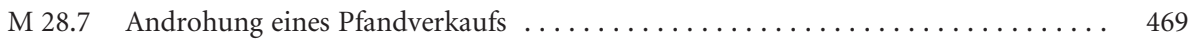

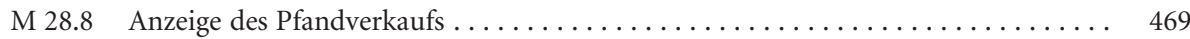

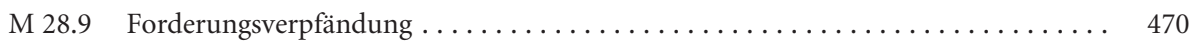

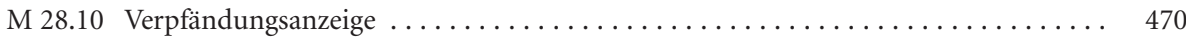

Kap. 29 Eigentumsvorbehalt, Sicherungsübereignung und andere Sicherungsgeschäfte

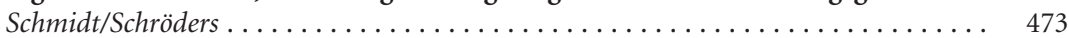

M 29.1 Kaufvertrag mit Ratenzahlung und Eigentumsvorbehalt $\ldots \ldots \ldots \ldots \ldots \ldots \ldots \quad 478$

M 29.2 Kontokorrentvorbehalt ............................... 479

M 29.3 Erweiterter und verlängerter Eigentumsvorbehalt im kaufmännischen Verkehr ... 481

M 29.4 Weitergeleiteter Eigentumsvorbehalt . . . . . . . . . . . . . . . . . . . . . . 483

M 29.5 Nachgeschalteter Eigentumsvorbehalt mit Vorausabtretungsklausel........... 483

M 29.6 Anzeige an den Versicherer von der Erledigung eines Kfz-Sicherungsscheins . . . . 485

M 29.7 Sicherungsübereignung eines Warenlagers.................... 491

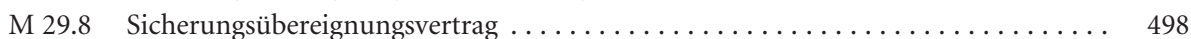

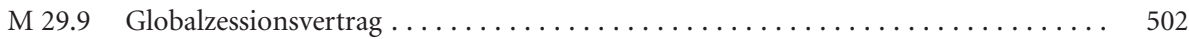

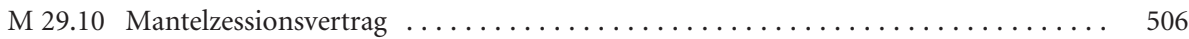

\section{Vierter Teil. Wirtschaftsrechtliche Verträge}

\section{Abschnitt. Leasing}

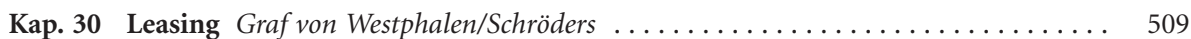

M 30.1 Vollamortisationsvertrag Kaufleute/Unternehmer - gewerblich/beruflich ....... 521

M 30.2 Vollamortisationsvertrag Verbraucher ...................... 528

M 30.3 Vollamortisationsvertrag mit Kaufoption Kaufleute/Unternehmer - gewerblich/

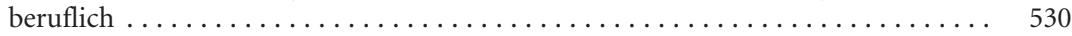

M 30.4 Vollamortisationsvertrag mit Kaufoption Verbraucher ................ 531

M 30.5 Teilamortisationsvertrag mit Andienungsrecht des Leasinggebers Kaufleute/Unter-

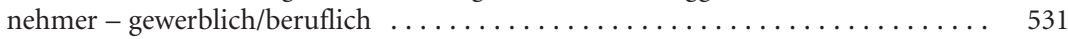

M 30.6 Teilamortisationsvertrag mit Andienungsrecht des Leasinggebers Verbraucher .... 
M 30.7 Teilamortisationsvertrag - Mehrerlösbeteiligung des Leasingnehmers Kaufleute/ Unternehmer - gewerblich/beruflich $\ldots \ldots \ldots \ldots \ldots \ldots \ldots \ldots \ldots \ldots \ldots \ldots \ldots \ldots \ldots \ldots \ldots$

M 30.8 Teilamortisationsvertrag - Mehrerlösbeteiligung des Leasingnehmers Verbraucher . 532

M 30.9 Kündbarer Teilamortisationsvertrag mit Abschlusszahlung des Leasingnehmers Kaufleute/Unternehmer - gewerblich/beruflich $\ldots \ldots \ldots \ldots \ldots \ldots \ldots$

M 30.10 Kündbarer Teilamortisationsvertrag mit Abschlusszahlung des Leasingnehmers Verbraucher ................................. 534

M 30.11 Kfz-Leasingvertrag für Privatwagen - Privatauto-Leasing-Bestellung . . . . . . . . 535

\section{Abschnitt. Factoring, Forfaitierung}

Kap. 31 Factoring Grafvon Westphalen/Schröders.................... 541

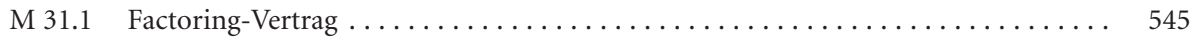

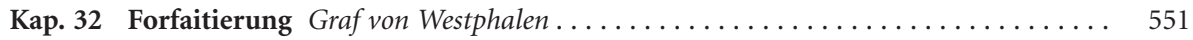

M 32.1 Forfaitierungs-Vertrag von Buchforderungen (Export) . . . . . . . . . . . . 552

M 32.2 Rahmenvertrag über Forderungsverkauf - Forfaitierung - Leasing . . . . . . . . . 555

3. Abschnitt. Handelsvertreter, Kommission, Vertragshändler

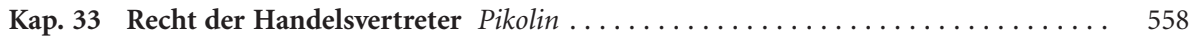

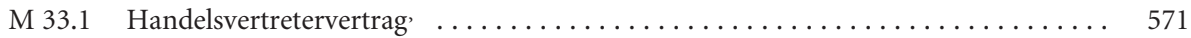

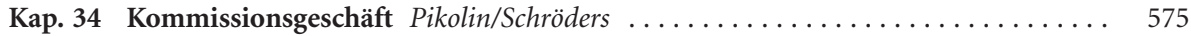

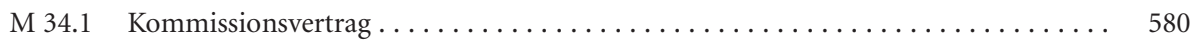

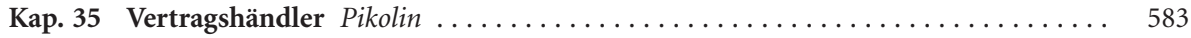

M $35.1 \quad$ Vertragshändlervertrag . . . . . . . . . . . . . . . . . . . . . . . . . 590

4. Abschnitt. Franchising

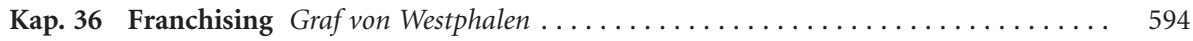

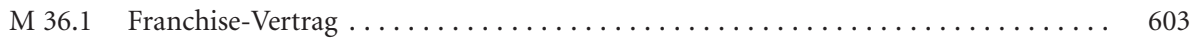

5. Abschnitt. Software-Überlassungsverträge

Kap. 37 Software-Überlassungsverträge Graf von Westphalen . . . . . . . . . . . . . . 615

M 37.1 Softwareüberlassung auf Dauer - Kaufleute . . . . . . . . . . . . . . . 626

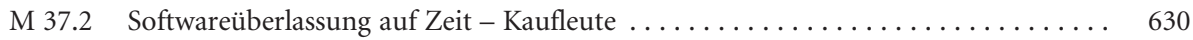

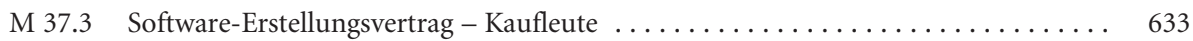

\section{Abschnitt. Internetverträge}

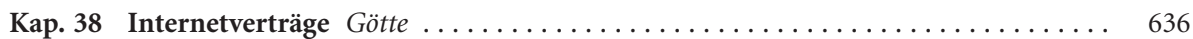

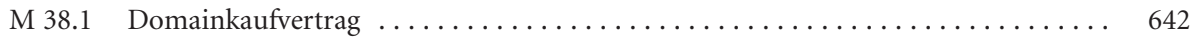

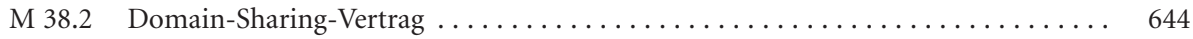

M 38.3 Webdesign-Vertrag . . . . . . . . . . . . . . . . . . . . . . . . . . . . . . . . . 649

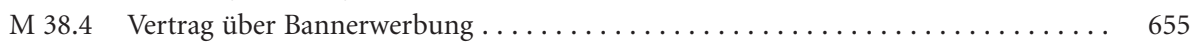

7. Abschnitt. Markenrecht, Gewerblicher Rechtsschutz

Kap. 39 Markenrecht, Gewerblicher Rechtsschutz Götte . . . . . . . . . . . . . . . 659

M 39.1 Kauf und Übertragung einer Marke. . . . . . . . . . . . . . . . . . . . . 670

M 39.2 Übertragung einer noch nicht eingetragenen Marke gegen Kostenerstattung . . . 672

M 39.3 Abgrenzungsvereinbarung $\ldots \ldots \ldots \ldots \ldots \ldots \ldots \ldots \ldots \ldots \ldots \ldots \ldots \ldots \ldots \ldots \ldots . \ldots \ldots 3$

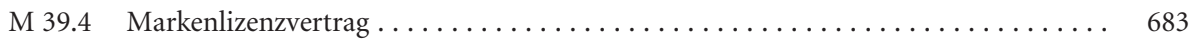




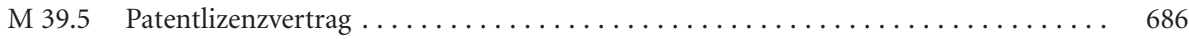

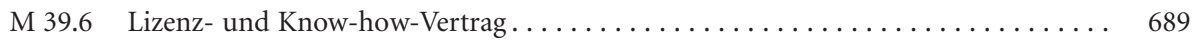

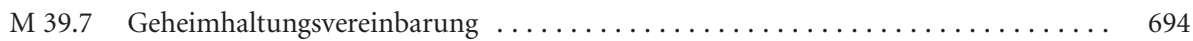

8. Abschnitt. Urheber- und Künstlerverträge

Kap. 40 Urheber- und Künstlerverträge Götte ...................... 697

M $40.1 \quad$ Prioritätserklärung und Hinterlegungsprotokoll . . . . . . . . . . . . . . . . 711

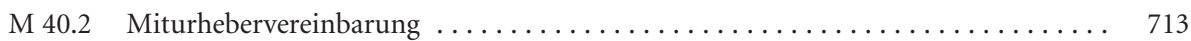

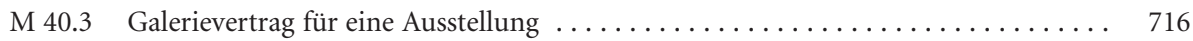

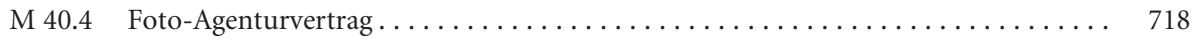

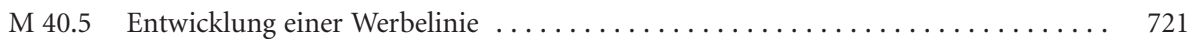

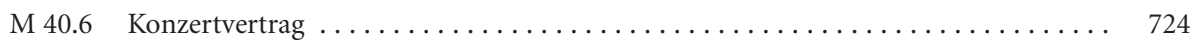

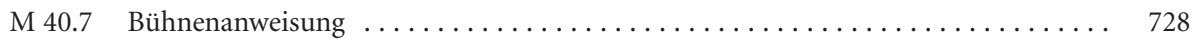

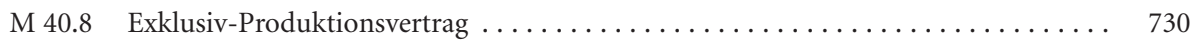

Fünfter Teil. Wettbewerbsrecht

Kap. 41 Die vorgerichtliche Streiterledigung Riegger ................... 738

M 41.1 Abmahnung wegen intransparenter Werbung für Verkaufsförderungsmaßnahmen 751

M 41.2 Verpflichtungserklärung (weit gefasst) zur Abmahnung nach Muster M 41.1 . . . 752

M 41.3 Abmahnung wegen irreführender Werbung ( $\$ \$ 3,5$ Abs. 1 UWG) $\ldots \ldots \ldots \ldots . . . .652$

M 41.4 Verpflichtungserklärung (konkret gefasst) zur Abmahnung nach Muster M 41.3 .. 753

M 41.5 Abmahnung wegen Verstoßes gegen gesetzliche Vorschriften, die das Marktverhal-

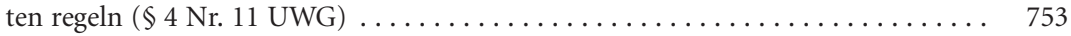

M 41.6 Verpflichtungserklärung zur Abmahnung nach Muster M 41.5 - Vertragsstrafe

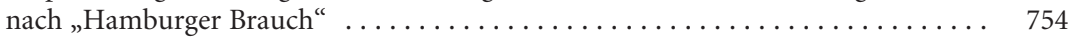

M 41.7 Eilige Abmahnung wegen Verstoßes gegen das Ladenschlussgesetz, $\$ 3$ Nr. 1

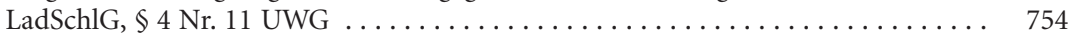

M 41.8 Verpflichtungserklärung zur Abmahnung nach Muster M $41.7 \ldots \ldots \ldots \ldots \ldots . \ldots 755$

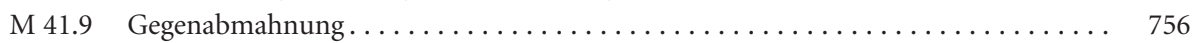

Kap. 42 Verhalten des Unterlassungsschuldners nach der Unterwerfung oder

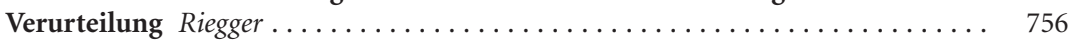

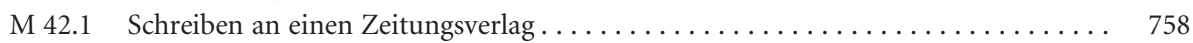

M 42.2 Abschlussschreiben nach Beschlussverfügung .................... 760

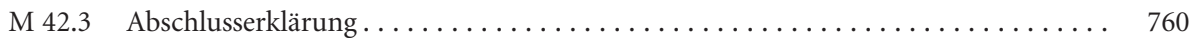

M 42.4 Abschlussschreiben nach Urteilsverfügung $\ldots \ldots \ldots \ldots \ldots \ldots \ldots \ldots \ldots \ldots$

\section{B. Liegenschaftsrecht}

\section{Erster Teil. Immobilienverträge}

\section{Abschnitt. Grundstückskauf, Grundstückstausch}

Kap. 43 Grundstückskauf, Grundstückstausch Leitzen/Schröders ............. 763

M 43.1 Grundstückskaufvertrag mit Direktzahlung durch den Käufer, deklaratorischer Fälligkeitsmitteilung durch den Notar sowie Umschreibungssperre . . . . . . . . 787

M 43.2 Grundstückskaufvertrag mit Abwicklung über Notaranderkonto............ 793

M 43.3 Grundstückskaufvertrag ohne beiderseitige Absicherung . . . . . . . . . . . 797 
M 43.4 Pfandrechts- oder/und Schuldübernahme im Rahmen eines Kaufvertrags _..... 801

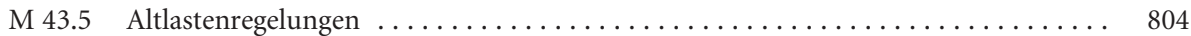

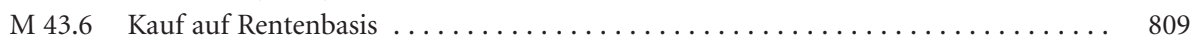

M 43.7 Grundstückskaufvertrag (noch nicht vermessene Teilfläche) $\ldots \ldots \ldots \ldots \ldots \ldots 811$

M 43.8 Vollzugserklärung zu M 43.7 (nach erfolgter Vermessung) . . . . . . . . . . 815

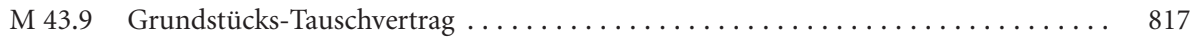

M 43.10 Angebot zum Abschluss eines Grundstückskaufvertrags (Verkäuferangebot) . . . 820

M 43.11 Annahme eines Angebots auf Abschluss eines Grundstückskaufvertrags

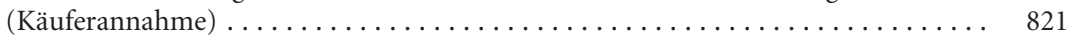

M 43.12 Angebot zum Abschluss eines Grundstückskaufvertrags (Käuferangebot) ...... 823

M 43.13 Annahme eines Angebots auf Abschluss eines Grundstückskaufvertrags

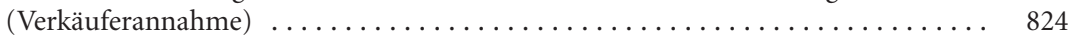

M 43.14 Vertragsangebot an noch zu benennende Dritte $\ldots \ldots \ldots \ldots \ldots \ldots \ldots \ldots \ldots$

M 43.15 Bedingte Kaufverpflichtung (flankierend zu M 43.14) .............. 828

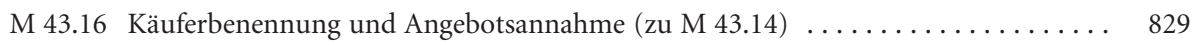

M 43.17 Angebotsvertrag (Alternative zu Verkäuferangebot M 43.10) ............ 831

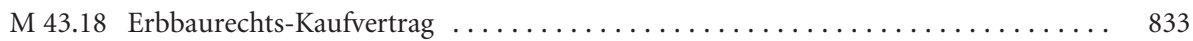

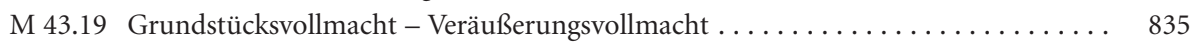

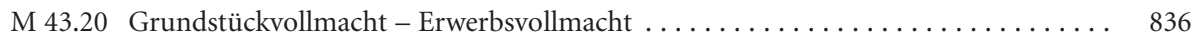

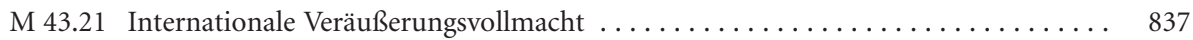

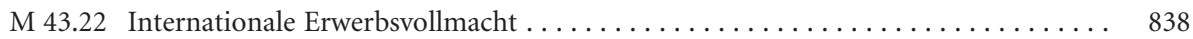

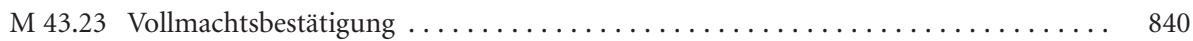

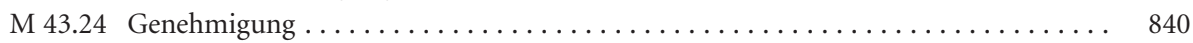

\section{Abschnitt. Andere Grundstücksveräußerungen}

Kap. 44 Unentgeltliche Grundstücksveräußerungen Oertel/Schröders ............ 840

M $44.1 \quad$ Schenkung von Grundbesitz ohne Vorbehalte und Auflagen . . . . . . . . . . . . 843

M 44.2 Übertragung im Wege vorweggenommer Erbfolge unter Vorbehalt des
Rückforderungsrechts und des Nießbrauchs

M 44.3 Pflichtteilsrechtliche Vereinbarungen ........................ 855

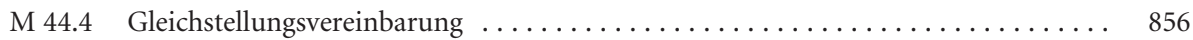

M 44.5 Vertrag einer Familien-Grundstücksgesellschaft $\ldots \ldots \ldots \ldots \ldots \ldots \ldots \ldots \ldots . \ldots 57$

M 44.6 Übergabe eines Hofes mit Alterssicherungsvorbehalten und Gleichstellung der Geschwister.......................................... 864

M 44.7 Übergabe von landwirtschaftlichen Grundstücken an mehrere Kinder mit

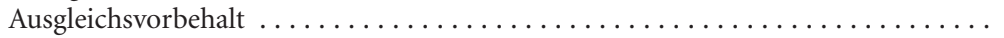

3. Abschnitt. Änderung, Aufhebung und Rückabwicklung von Grundstücksverträgen

Kap. 45 Änderung, Aufhebung und Rückabwicklung von Grundstücksverträgen Leitzen $/$ Schröders .................................. 871

M 45.1 Änderung eines Grundstückskaufvertrags . . . . . . . . . . . . . . . . . . . 876

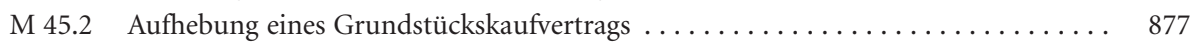

M 45.3 Grundbucherklärung nach privatschriftlicher Aufhebung eines Grundstücks-

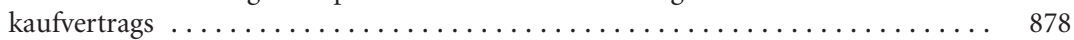

M 45.4 Rückabwicklung eines Grundstücksveräußerungsvertrags $\ldots \ldots \ldots \ldots \ldots \ldots \ldots$ 


\section{Zweiter Teil. Eigentumserwerb, Eigentumsverschaffung und -verzicht}

Kap. 46 Erwerb und Verlust von Grundstückseigentum Oertel/Schröders .......... 882

M 46.1 Auflassung eines Grundstücks aufgrund Kaufvertrags $\ldots \ldots \ldots \ldots \ldots \ldots \ldots . \quad 887$

M 46.2 Auflassung durch Erbengemeinschaft zur Erfüllung letztwilliger Verfügung ..... 888

M 46.3 Auflassung nach einem Widerrufsvergleich ........................ 889

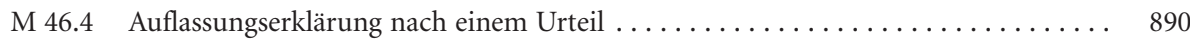

M 46.5 Verpfändung eines Eigentumsverschaffungsanspruchs (zur Sicherung eines

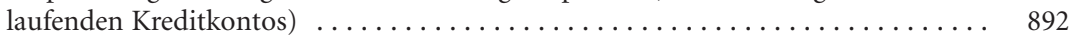

M 46.6 Abtretung eines Eigentumsverschaffungsanspruchs (zur Vermögensauseinander-

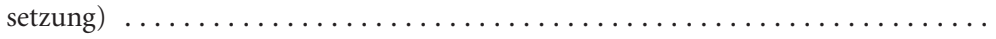

M 46.7 Abtretung eines Anwartschaftsrechts aus einem Kaufvertrag mit Auflassung

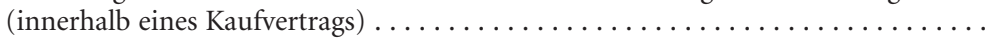

M 46.8 Verzicht auf das Eigentum an einem Grundstück . . . . . . . . . . . . . . . .

M 46.9 Grundbuchberichtigungsantrag aufgrund Erbfolge . . . . . . . . . . . . . . 903

M 46.10 Grundbuchberichtigungsantrag nach Einziehung eines Erbscheins . ......... 903

M 46.11 Berichtigung einer Eigentümereintragung zwecks Eintragung einer Sicherungs-

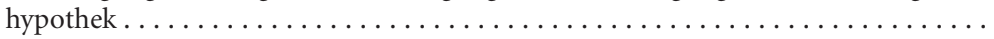

M 46.12 Grundbuchberichtigungsantrag - Firmenänderung $\ldots \ldots \ldots \ldots \ldots \ldots \ldots \ldots$

M 46.13 Grundbuchberichtigungsantrag - Ein- und Austritt bei BGB-Gesellschaft . . .....

M 46.14 Grundbuchberichtigungsantrag - Anwachsung.................. 906

M 46.15 Grundbuchberichtigungsantrag - Tod eines Gesellschafters . . . . . . . . . . . 906

\section{Dritter Teil. Besondere Arten von Grundbesitz}

\section{Abschnitt. Wohnungseigentum}

Kap. 47 Wohnungseigentum Leitzen/Schröders ......................

M 47.1 Begründung von Wohnungs- und Teileigentum nach $\$ 8$ WEG in Form einer notariellen Niederschrift (Große Teilungserklärung) $\ldots \ldots \ldots \ldots \ldots \ldots \ldots$

M 47.2 Teilungserklärung nach $\$ 8$ WEG durch unterschriftsbeglaubigte Erklärung (Kleine

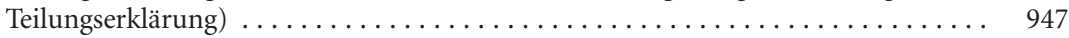

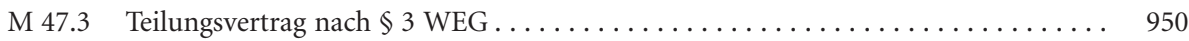

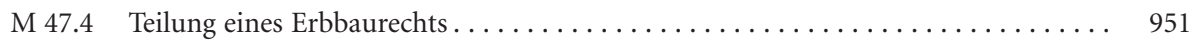

M 47.5 Besonderheiten für Wohnungseigentum an mehreren Gebäuden . . . . . . . . . . . . 954

M 47.6 Änderung einer Teilungserklärung - Änderung von Nutzungsart und Gemein-

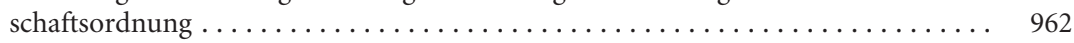

M 47.7 Änderung einer Teilungserklärung - Bildung weiteren Sondereigentums, Aufhebung von Sondereigentum $\ldots \ldots \ldots \ldots \ldots \ldots \ldots \ldots \ldots \ldots \ldots \ldots \ldots \ldots \ldots \ldots$

M 47.8 Änderung einer Teilungserklärung - Zuweisung von Pkw-Abstellplätzen . . . . . . 964

M 47.9 Tausch von Sondereigentum, Kellertausch $\ldots \ldots \ldots \ldots \ldots \ldots \ldots \ldots \ldots \ldots$

M 47.10 Nutzungsregelungen an Doppelstockgaragen .................... 967

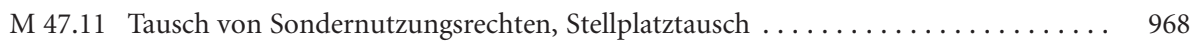

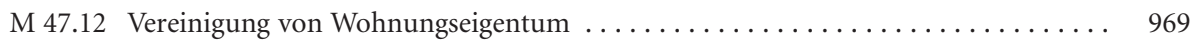

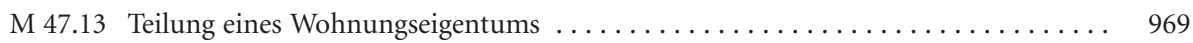

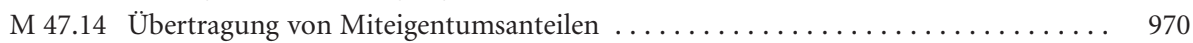

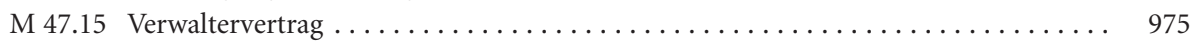

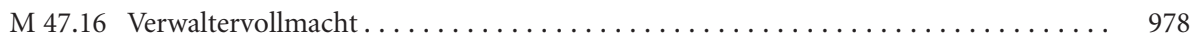

M 47.17 Veräußerungszustimmung des Verwalters ..................... 980

M 47.18 Antrag auf Gerichtsentscheidung bei Verweigerung der Veräußerungszustimmung 981 


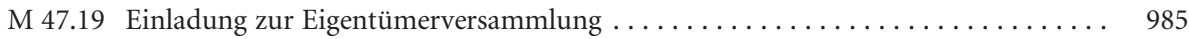

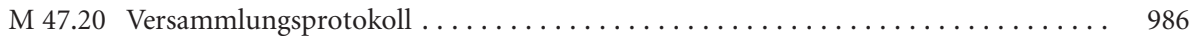

M 47.21 Antrag auf Bestätigung der Nichtanfechtung . . . . . . . . . . . . . . . . . . . 989

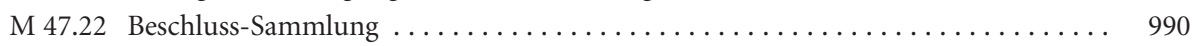

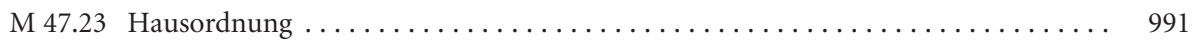

2. Abschnitt. Dauerwohn- und Dauernutzungsrecht

Kap. 48 Dauerwohn- und Dauernutzungsrecht Leitzen/Schröders . . . . . . . . . . . . 995

M $48.1 \quad$ Vertrag über die Bestellung eines Dauerwohnrechts . . . . . . . . . . . . . . 1001

M 48.2 Vertrag über die Bestellung eines Dauernutzungsrechts . . . . . . . . . . . . . . . 1004

\section{Abschnitt. Erbbaurecht}

Kap. 49 Erbbaurecht und Heimstätte Schumacher/Schröders... . . . . . . . . . . 1006

M 49.1 Bestellung eines Erbbaurechts - unbebautes Grundstück . . . . . . . . . . . . . . 1020

M 49.2 Bestellung eines Erbbaurechts mit Erwerb des vorhandenen Gebäudes . . . . . . . 1026

M 49.3 Anpassungsklausel für gewerbliches Erbbaurecht . . . . . . . . . . . . . 1031

M 49.4 Bestellung eines Erbbaurechts nach dem Sachenrechtsbereinigungsgesetz . . . . . . . 1034

M 49.5 Erbbauzinserhöhung, Vereinbarung. . . . . . . . . . . . . . . . . . . . . 1041

M 49.6 Erbbauzinserhöhung, Grundbucherklärung . . . . . . . . . . . . . . . . . 1041

M 49.7 Anpassung einer alten Erbbauzinsregelung, Vereinbarung . . . . . . . . . . . . . . . 1042

M 49.8 Anpassung einer alten Erbbauzinsregelung, Grundbucherklärung . . . . . . . . . . . 1043

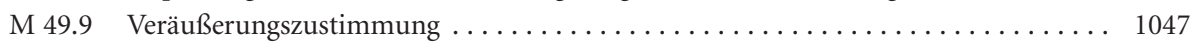

M 49.10 Antrag auf Ersetzung der Eigentümerzustimmung . . . . . . . . . . . . . . . . 1047

M 49.11 Belastungszustimmung und Rangrücktritt . . . . . . . . . . . . . . . . . . 1048

M 49.12 Stillhalteerklärung und Veräußerungszustimmung . . . . . . . . . . . . . . . . . . . . 1049

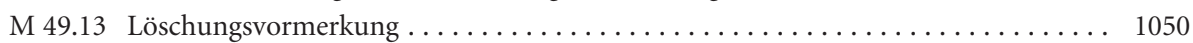

M 49.14 Erfüllung eines Heimfallanspruchs mit Erbbaurechtslöschung . . . . . . . . . . 1052

\section{Vierter Teil. Grundbuchrecht}

\section{Abschnitt. Grundbuch und Grundbucheintragungen}

Kap. 50 Grundbuchverfahren, Kataster Oertel . . . . . . . . . . . . . . . . . . 1059

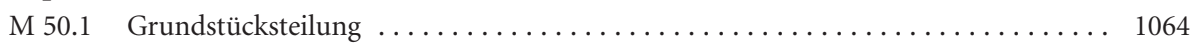

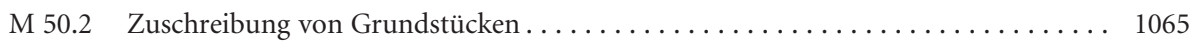

M 50.3 Vereinigung von Grundstücken mit Pfandrechtserstreckung und Zwangs-

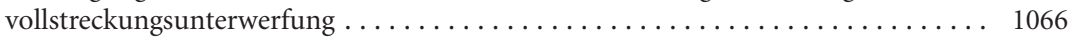

M 50.4 Antrag auf Erteilung eines Grundbuchauszugs . . . . . . . . . . . . . . . . . . . . 1069

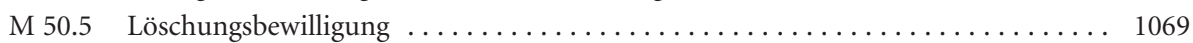

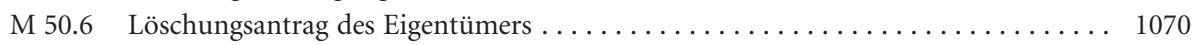

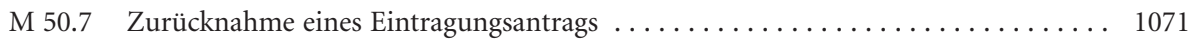

\section{Abschnitt. Eintragungen in Abt. II}

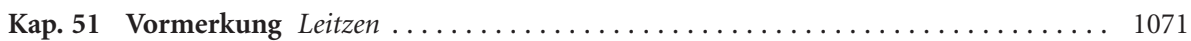

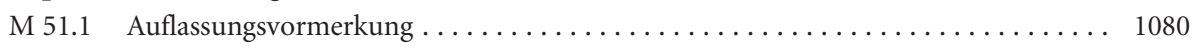

M 51.2 Vormerkung für bedingten Anspruch - Verpflichtung zur Nichtveräußerung -

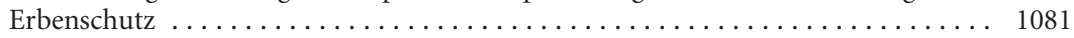

M 51.3 Antrag auf Eintragung einer Vormerkung aufgrund einer einstweiligen Verfügung. 1083 
M 51.4 Löschungsbewilligung für eine Auflassungsvormerkung . . . . . . . . . . . . 1083

Kap. 52 Rang der Grundstücksbelastungen Oertel ..................... 1084

M 52.1 Rangbestimmung (zB im Rahmen einer Grundschuldbestellung) . . . . . . . . 1088

M 52.2 Rangrücktrittserklärung eines Grundpfandgläubigers (zB zu M 52.1) . ....... 1089

M 52.3 Rangrücktrittserklärung eines Wohnungsberechtigten (zB zu M 52.1) . ....... 1089

M 52.4 Rangvorbehalt ( $\$ 881$ BGB) (im Rahmen einer Grundstücksbelastung) $\ldots \ldots \ldots .1090$

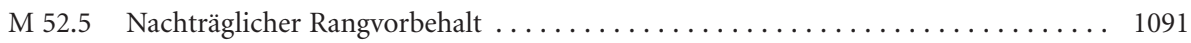

M 52.6 Rangbeilegung im Rahmen einer Grundschuldbestellung. . . . . . . . . . . . . . . 1091

M 52.7 Eigentümerzustimmung zu einem Rangrücktritt (zB zu M 52.2) . . . . . . . 1092

Kap. 53 Überbau und Notweg Oertel . . . . . . . . . . . . . . . . . . . . . . . . 1092

M 53.1 Verzicht auf gesetzliche Überbaurente unter Festlegung des Überbaus . . . . . . . . . . 1095

M 53.2 Vertragliches Überbaurecht unter Vereinbarung einer vertraglichen Überbaurente . 1096

M 53.3 Verzicht auf Notwegrente . . . . . . . . . . . . . . . . . . . . . . . . . . 1097

Kap. 54 Nutzungsrechte an Grundstücken Oertel/Schröders ................... 1097

M 54.1 Bestellung einer Grunddienstbarkeit - Weg- und Leitungsrecht . . . . . . . . . . 1105

M 54.2 Antrag auf Eintragung eines Herrschvermerks . . . . . . . . . . . . . . . . 1106

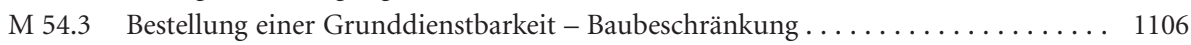

M 54.4 Grunddienstbarkeit und Reallast (Duldung von Stellplätzen und Unterhaltungs-

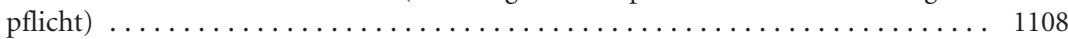

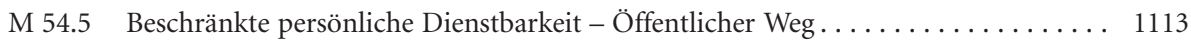

M 54.6 Beschränkte persönliche Dienstbarkeit - Getränkevertriebsverbot . . . . . . . . . 1114

M 54.7 Beschränkte persönliche Dienstbarkeit - Anlagenbetriebsrecht . . . . . . . . . 1115

M 54.8 Beschränkte persönliche Dienstbarkeit - Mieterdienstbarkeit . . . . . . . . . 1116

M 54.9 Wohnungsrecht im Rahmen eines Übergabevertrages (Form des Übergabe-

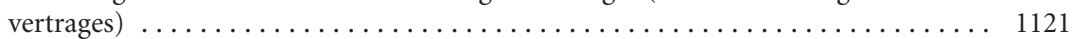

M 54.10 Bestellung eines Nießbrauchs an einem Grundstück ................ 1127

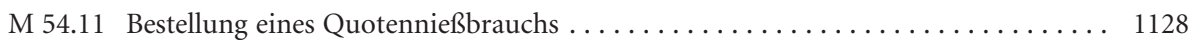

M 54.12 Nießbrauch für eine Gesamthandgemeinschaft .................... 1129

M 54.13 Nießbrauch an einer Briefhypothek ........................ 1131

M 54.14 Miteigentümervereinbarung $(\$ 1010$ BGB $\ldots \ldots \ldots \ldots \ldots \ldots \ldots \ldots \ldots \ldots \ldots \ldots \ldots \ldots \ldots$

Kap. 55 Dingliches Vorkaufsrecht Leitzen ......................... 1141

M 55.1 Bestellung eines dinglichen Vorkaufsrechts . . . . . . . . . . . . . . . . 1147

M 55.2 Bestellung eines dinglichen Vorkaufsrechts mit abweichenden Vereinbarungen ... 1147

Kap. 56 Reallast (mit Altenteil) Oertel/Schröders ........................ 1148

M 56.1 Bestellung einer subjektiv-persönlichen Reallast . . . . . . . . . . . . . . 1152

M 56.2 Leibgeding (zB im Rahmen eines Übergabevertrages) . . . . . . . . . . . . . 1155

3. Abschnitt. Eintragungen in Abt. III

Kap. 57 Hypothek, Grundschuld, Rentenschuld I: Bestellung und Änderung Schumacher ................................... 1158

M 57.1 Bestellung einer Briefhypothek $\ldots \ldots \ldots \ldots \ldots \ldots \ldots \ldots \ldots \ldots \ldots \ldots \ldots \ldots \ldots \ldots$

M 57.2 Antrag auf Erteilung eines gemeinschaftlichen Hypothekenbriefes . . . . . . . . 1164

M 57.3 Bestellung einer Buchhypothek mit Unterwerfung unter die sofortige Zwangsvoll-

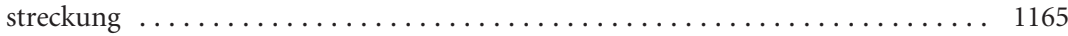

M 57.4 Widerspruch wegen unterbliebener Darlehensauszahlung . . . . . . . . . . . . 1166

M 57.5 Bestellung einer Sicherungshypothek ...................... 1168 
M 57.6 Bestellung einer Höchstbetragssicherungshypothek $\ldots \ldots \ldots \ldots \ldots \ldots \ldots \ldots \ldots \ldots$

M 57.7 Antrag auf Eintragung einer Zwangshypothek ..................... 1169

M 57.8 Antrag auf Eintragung einer Arresthypothek................... 1170

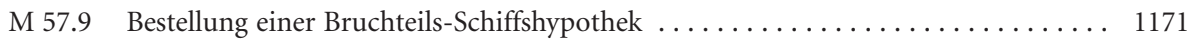

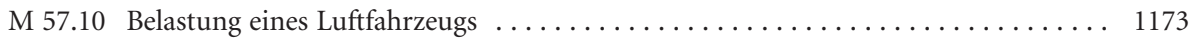

M 57.11 Belastung eines Luftfahrzeugs mit Zwangsvollstreckungsunterwerfung . . . . . . 1173

M 57.12 Bestellung einer Briefgrundschuld mit dinglicher und persönlicher Zwangsvoll-

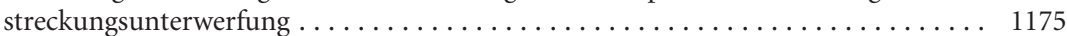

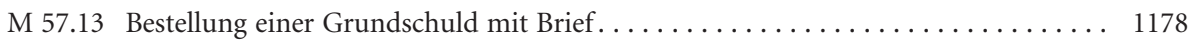

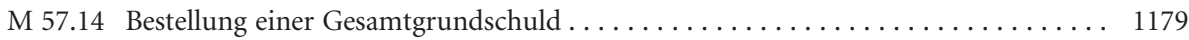

M 57.15 Verteilung einer Gesamtgrundschuld . . . . . . . . . . . . . . . . . . . . . 1180

M 57.16 Sicherungsvereinbarung zu einer Grundschuldbestellung . . . . . . . . . . 1181

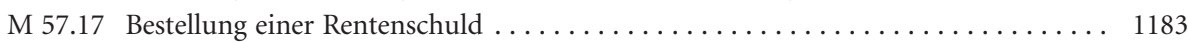

M 57.18 Umwandlung einer Buchhypothek in eine Briefgrundschuld (mit weiteren Inhalts-

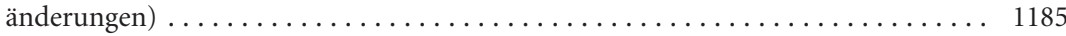

M 57.19 Umwandlung einer Grundschuld in eine Hypothek mit Zwangsvollstreckungs-

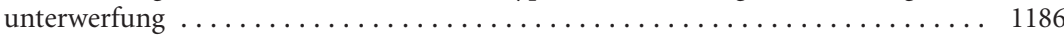

M 57.20 Umwandlung einer Zwangshypothek in eine Eigentümergrundschuld . . . . . . . . 1187

M 57.21 Pfandrechtserstreckung mit Unterwerfung unter die sofortige Zwangsvollstreckung 1188

M 57.22 Nachträgliche Unterwerfung unter die sofortige Zwangsvollstreckung......... 1189

M 57.23 Liegenbelassungsvereinbarung ............................. 1190

Kap. 58 Hypothek, Grundschuld, Rentenschuld II: Abtretung, Gläubigerbefriedigung und Löschung Schumacher.............................. 1190

M $58.1 \quad$ Abtretung einer Briefhypothek............................. 1193

M 58.2 Abtretung einer Buchhypothek ............................ 1194

M 58.3 Abtretung einer Höchstbetrags-Hypothekenforderung ohne Übergang der Hypothek ............................................ 1194

M 58.4 Abtretung einer Eigentümer-Briefgrundschuld . . . . . . . . . . . . . . . . 1195

M 58.5 (Teil-)Abtretung einer Briefgrundschuld ....................... 1196

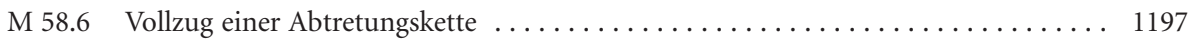

M 58.7 Abtretung einer vorläufigen Eigentümergrundschuld an den Baugeldgeber (Zwischenfinanzierer) ................................ 1197

M 58.8 Abtretung noch nicht fälliger Hypothekenzinsen . . . . . . . . . . . . . . . . . 1198

M 58.9 Abtretung rückständiger Hypothekenzinsen . . . . . . . . . . . . . . . . . . . . . 1199

M 58.10 Löschungsbewilligung für Briefhypothek........................ 1201

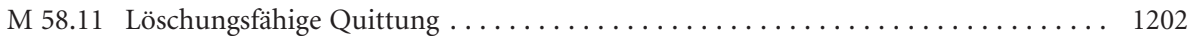

M 58.12 Umschreibungsantrag des Eigentümers . . . . . . . . . . . . . . . . . . . 1202

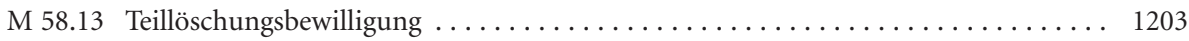

M 58.14 Quittung für Nichteigentümer mit Antrag auf Umschreibung der Hypothek . . . . 1203

M 58.15 Hypothekenverzicht .................................... 1204

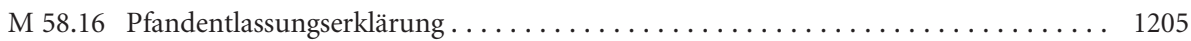

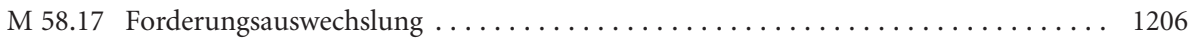

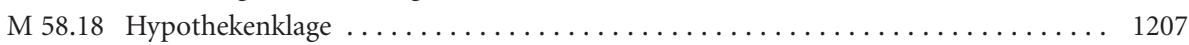




\section{Familien- und Erbrecht}

\section{Erster Teil. Familienrecht}

\section{Abschnitt. Name}

Kap. 59 Namensrecht Kesseler . . . . . . . . . . . . . . . . . . . . . . . . . . 1209

M 59.1 Erklärung über die Bestimmung des Ehenamens . . . . . . . . . . . . . . 1211

M 59.2 Erklärung über die Hinzufügung eines Begleitnamens . . . . . . . . . . . . . . . 1212

M 59.3 Widerruf der Hinzufügung eines Begleitnamens . . . . . . . . . . . . . . . . . 1213

M 59.4 Erklärung des Witwers über die Wiederannahme des Geburtsnamens oder des zum Zeitpunkt der Abgabe der Erklärung über den Ehenamen geführten Namens . 1213

M 59.5 Namensänderung nach Ehescheidung . . . . . . . . . . . . . . . . . . . . . 1214

M 59.6 Gemeinsame Bestimmung des Geburtsnamens des Kindes . . . . . . . . . . . . . . . 1215

M 59.7 Erteilung des Namens des anderen Elternteils als Geburtsname des Kindes . . . . . . 1215

M 59.8 Einwilligung des nicht sorgeberechtigten Elternteils in die Erteilung seines Namens

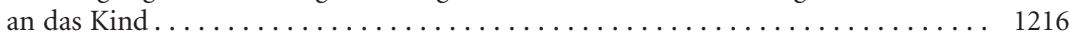

M 59.9 Einwilligung des Kindes in die Erteilung des Namens des anderen Elternteils . . . . 1216

M 59.10 Neubestimmung des Kindesnamens bei nachträglicher Begründung der

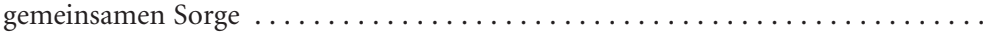

M 59.11 Anschließungserklärung des Kindes an die Neubestimmung seines Namens bei nachträglicher Begründung der gemeinsamen Sorge $\ldots \ldots \ldots \ldots \ldots \ldots \ldots$

M 59.12 Antrag des Kindes auf Erhalt des Mutternamens nach negativer Vaterschaftsfest-

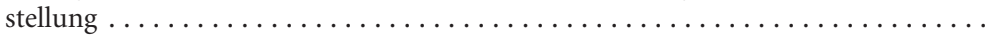

M 59.13 Antrag des gesetzlichen Vertreters des Kindes auf Erhalt des Mutternamens nach

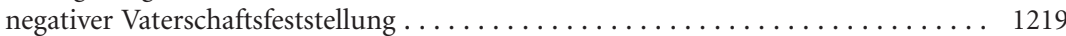

M 59.14 Antrag des vermeintlichen Kindsvaters nach negativer Vaterschaftsfeststellung auf Erteilung des Mutternamens an das Kind . . . . . . . . . . . . . .

M 59.15 Anschließung des Kindes - vertreten durch die Eltern - an den nachträglich bestimmten Ehenamen der Eltern . . . . . . . . . . . . . . . . . 1220

M 59.16 Anschließung des Kindes an den nachträglich bestimmten Ehenamen der Eltern . . 1220

M 59.17 Anschließung des Ehegatten des Kindes an dessen Namensänderung . . . . . . . . 1221

M 59.18 Erteilung des Ehenamens des sorgeberechtigten Elternteils und seines Ehegatten, der nicht Elternteil des Kindes ist, an das Kind . . . . . . . . . . . .

M 59.19 Einwilligung des anderen Elternteils in die Erteilung des Ehenamens des sorgeberechtigten Elternteils und dessen Ehegatten an das Kind $\ldots \ldots \ldots \ldots \ldots \ldots$

M 59.20 Einwilligung des Kindes in die Erteilung des Ehenamens des sorgeberechtigten

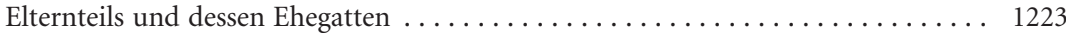

M 59.21 Namensänderung nach $\S 3$ NamÄndG . . . . . . . . . . . . . . . . . . . . . . . . 1224

M 59.22 Erklärung über die Rechtswahl nach Art. 10 Abs. 2 EGBGB . . . . . . . . . . . . . . 1224

M 59.23 Erklärung über die Rechtswahl nach Art. 10 Abs. 3 EGBGB . . . . . . . . . . . . . . 1225

\section{Abschnitt. Ehe}

Kap. 60 Ehewirkungen Kesseler/Schröders . . . . . . . . . . . . . . . . . . . . . . . 1225

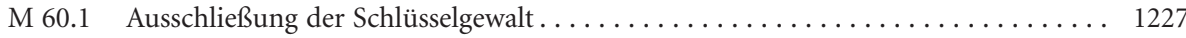

M 60.2 Antrag auf Aufhebung der Entziehung der Schlüsselgewalt . . . . . . . . . . 1227

M 60.3 Antrag auf Registerlöschung der Entziehung . . . . . . . . . . . . . . . . . . . 1228

M 60.4 Unterhaltsvereinbarung bei Getrenntleben . . . . . . . . . . . . . . . . . . . . 1231

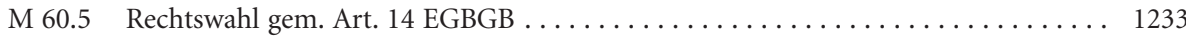


Kap. 61 Gesetzlicher Güterstand Kesseler/Schröders . . . . . . . . . . . . . . . . 1236

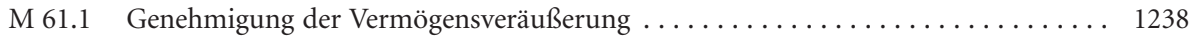

M 61.2 Wechselseitige Einwilligung beider Ehegatten . . . . . . . . . . . . . . . . 1238

M 61.3 Aufnahme eines Inventars des Anfangsvermögens . . . . . . . . . . . . . . . . 1240

M 61.4 Vereinbarung über den Ausgleich des Zugewinns . . . . . . . . . . . . . . . . . 1241

Kap. 62 Abwandlung des gesetzlichen Güterstands durch Ehevertrag Kesseler . . . . . . . 1243

M 62.1 Ehevertraglicher Ausschluss der Verfügungsbeschränkungen . . . . . . . . . . . . 1245

M 62.2 Ehevertragliche Festsetzung des Wertes des Anfangsvermögens und Limitierung

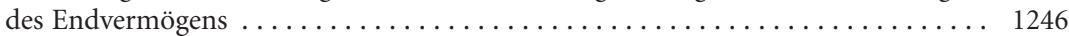

M 62.3 Vereinbarung über die Bewertung einzelner Gegenstände des Anfangs- und End-

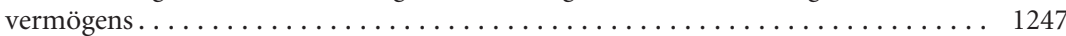

M 62.4 Herausnahme einzelner Vermögensgegenstände und des Betriebsvermögens aus

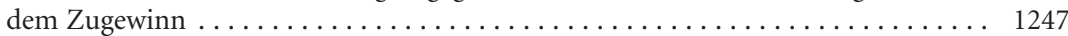

M 62.5 Neutralisierung des verzerrenden Effekts der Herausnahme einzelner Vermögens-

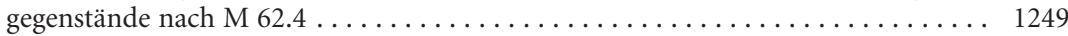

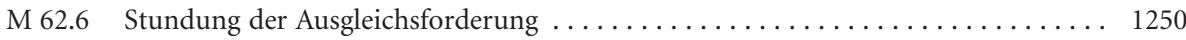

M $62.7 \quad$ Vereinbarung über die Ausgleichsquote . . . . . . . . . . . . . . . . . . . . . . 1250

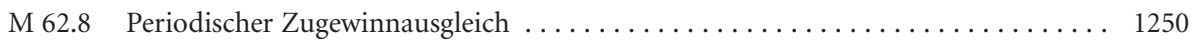

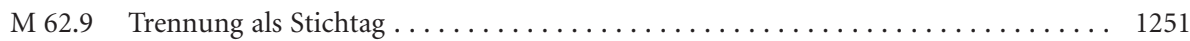

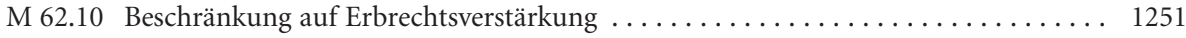

M 62.11 Einschränkung des Zugewinnausgleichs auf den Fall des Todes . . . . . . . . . . 1251

M 62.12 Zugewinnausgleich nur bei Eintritt einer Bedingung - Kinder . . . . . . . . . . . . 1252

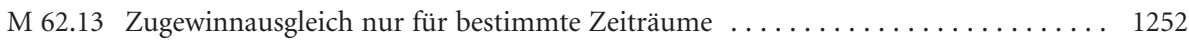

M 62.14 Wechsel in die Zugewinngemeinschaft mit Rückanknüpfung . . . . . . . . . . . 1252

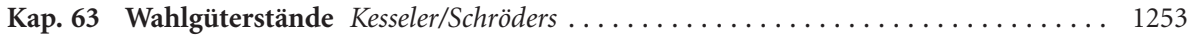

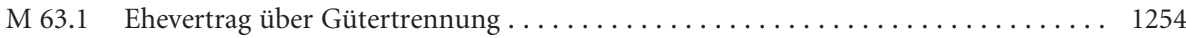

M 63.2 Ehevertragliche Vereinbarung der Gütergemeinschaft und Erbvertrag . . . . . . . . 1259

M 63.3 Nachträgliche Vereinbarung von Vorbehaltsgut . . . . . . . . . . . . . . . . . . . . 1260

M 63.4 Vereinbarung von Vorbehaltsgut im Sinne einer „Errungenschaftsgemeinschaft“ . 1260

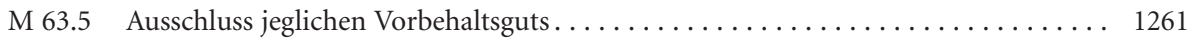

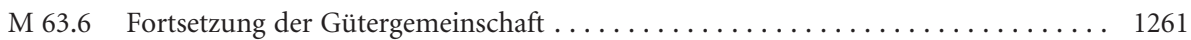

M 63.7 Ablehnung der Fortsetzung einer Gütergemeinschaft . . . . . . . . . . . . . . . 1261

M 63.8 Aufhebung der fortgesetzten Gütergemeinschaft . . . . . . . . . . . . . . . 1262

M 63.9 Bestimmung zum Vorbehaltsgut bei letztwilliger Verfügung oder Schenkung . . . . 1262

Kap. 64 Güterstand bei Auslandsberührung. Rechtswahl. Ausländische Güterstände

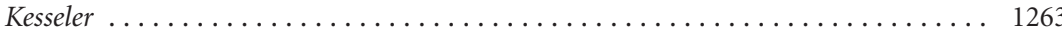

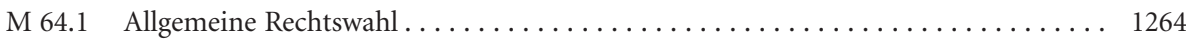

M 64.2 Rechtswahl gem. Art. 15 Abs. 2 Nr. 3 EGBGB . . . . . . . . . . . . . . . . . . . 1265

M 64.3 Ehevertragliche Vereinbarung der Gütertrennung ohne Rücksicht auf das

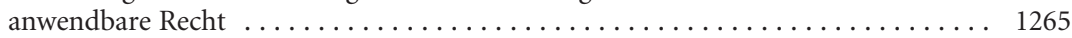

Kap. 65 Zuwendungen unter und an Ehegatten Kesseler/Schröders . . . . . . . . . . 1266

M 65.1 Ehebedingte Zuwendung mit Rückforderungsvorbehalt für den Fall der Scheidung 1271

M 65.2 Ausschluss der Rückforderung einer ehebedingten Zuwendung bei gleichzeitiger Regelung des Wertausgleichs beim Zugewinnausgleich . . . . . . . . . . . 1272

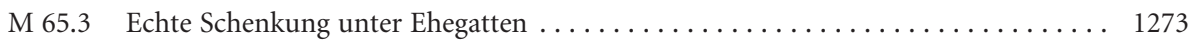

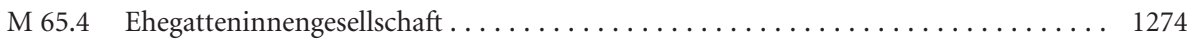


M 65.5 Auseinandersetzungsklausel zur Ehegattenaußengesellschaft $\ldots \ldots \ldots \ldots \ldots \ldots \quad 1275$

M 65.6 Darlehensvertrag zwischen Ehegatten zur Finanzierung eines Familienwohnheims. 1276

Kap. 66 Nachehelicher Unterhalt - Grundzüge Kesseler/Schröders ............... 1277

M 66.1 Aufforderung zur Unterhaltsauskunft $\ldots \ldots \ldots \ldots \ldots \ldots \ldots \ldots \ldots \ldots \ldots \ldots \ldots$

Kap. 67 Vorsorgende Unterhaltsvereinbarungen Kesseler ...................... 1284

M 67.1 Vertragsentstehungsdokumentation nebst Präambel eines Ehevertrages . . . . . . 1288

M 67.2 Unterhaltsvereinbarung eines Doppelverdienerpaares ohne Kinder, aber mit grundsätzlichem Kinderwunsch - auflösende Bedingung . . . . . . . . . . . . . . 1289

M 67.3 Unterhaltsvereinbarung auf Basis gesetzlicher Unterhaltstatbestände mit Höhen-

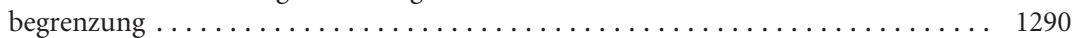

M 67.4 Ausschluss bestimmter gesetzlicher Unterhaltstatbestände . . . . . . . . . . . 1291

M 67.5 Ausschluss nur des $\S 1573$ Abs. 2 BGB . . . . . . . . . . . . . . . . . . . 1291

M 67.6 Zeitliche Begrenzung bestimmter Unterhaltstatbestände . . . . . . . . . . . . 1292

M 67.7 Differenzierte Unterhaltsregelung für bestimmte Ehe- bzw. Betreuungszeiten . . . . 1292

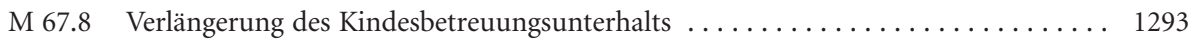

M 67.9 Regelung der Einsatzzeitpunkte für den Unterhalt . . . . . . . . . . . . . . . 1293

M 67.10 Begrenzung des Maßes des ehelichen Unterhalts . . . . . . . . . . . . . . . . 1294

M 67.11 Definition des angemessenen Unterhalts . . . . . . . . . . . . . . . . . . . 1294

M 67.12 Verzicht auf das Wiederaufleben des Unterhalts nach $\$ 1586 \mathrm{~b}$ BGB . . . . . . . . 1294

M 67.13 Vorgaben zur Ausübungskontrolle . . . . . . . . . . . . . . . . . . 1294

Kap. 68 Unterhaltsregelungen in Scheidungsvereinbarungen Kesseler .............. 1295

M 68.1 Gänzlicher Verzicht auf nachehelichen Unterhalt . . . . . . . . . . . . . . . . 1295

M 68.2 Ausgestaltung des nachehelichen Unterhalts . . . . . . . . . . . . . . . . . . 1296

M 68.3 Nachteilsausgleich bei Fehlverwendung des Vorsorgeunterhalts . . . . . . . . . . 1297

M 68.4 Vereinbarung zur Nichtberücksichtigung bestimmter Einkünfte des Pflichtigen und unterproportionaler Einbeziehung von Einkünften des Berechtigten . . . . . . 1297

M 68.5 Verzicht auf nachehelichen Unterhalt gegen Einräumung einer Leibrente . . . . . . 1298

Kap. 69 Versorgungsausgleich Reetz/Schröders ..................... 1298

M 69.1 Vorsorgliche Rechtswahl gem. Art. 17 Abs. 3 S. 1, 46d EGBGB iVm. Art. 5 Abs. 1 Rom-III-VO für nicht auszuschließenden „Wegzug“ aus Deutschland . . . . . . . 1305

M 69.2 Belehrung über die Folgen der internen Teilung von Betriebsrenten . . . . . . . 1312

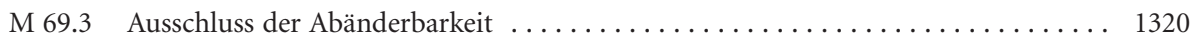

M 69.4 Auskunftsvereinbarung in vorsorgenden Eheverträgen . . . . . . . . . . . . 1322

M 69.5 Belehrung zur Tragweite eines gänzlichen Ausschlusses des Versorgungsausgleichs

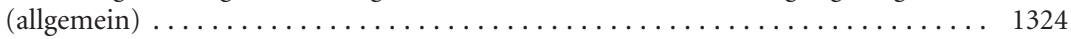

M 69.6 Sachverhaltsfeststellungen und Motive zur Modifikation des Versorgungsaus-

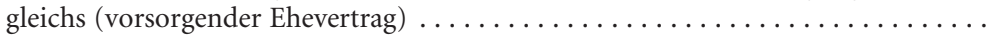

M 69.7 Sachverhaltsfeststellungen und Motive zur Modifikation des Versorgungsausgleichs (in einer Scheidungsvereinbarung) $\ldots \ldots \ldots \ldots \ldots \ldots \ldots \ldots \ldots \ldots \ldots \ldots \ldots \ldots$

M 69.8 Sachverhaltsfeststellungen nach Auskunft durch die Versorgungsträger (in einer

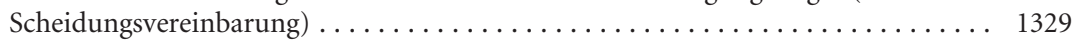

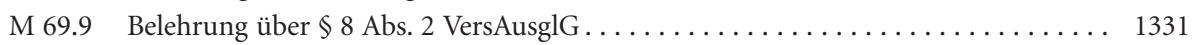

M 69.10 Versorgungsausgleich durch „vereinbarte Saldierung" und Verrechnung von Zugewinnausgleichsansprüchen (vorsorgende Vereinbarung) $\ldots \ldots \ldots \ldots \ldots$

M 69.11 Versorgungsausgleich innerhalb der ehelichen Vermögensverhältnisse (teilweiser Ausgleich, ,vereinbarte Saldierung “ und Abfindungsleistung durch Verrechnung mit Zugewinnausgleichsanspruch - Scheidungsvereinbarung) ............ 
M 69.12 Allgemeine Belehrung über Fehlvorstellungen der Vergleichbarkeit von Angaben des Kapitalwerts, des korrespondierenden Kapitalwerts, des Zeitwerts (Rückkaufwerts) usw.

M 69.13 Totalausschluss des Versorgungsausgleichs (mit Hinweis und Belehrung) . . . . . . 1335

M 69.14 Einseitiger Ausschluss des Versorgungsausgleichs (unter Hinweis auf eine Saldierung im Rahmen einer internen Teilung nach $\$ 10$ Abs. 2 VersAusglG) .....

M 69.15 Einseitiger Ausschluss in einer Scheidungsvereinbarung nach dem System der „einseitigen Ausgleichsrichtung" unter Verwendung der Wertangaben von

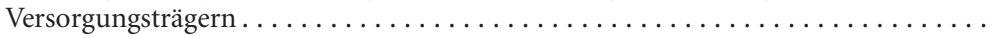

M 69.16 Einseitiger Ausschluss nach ,altem“ System der Vergleichbarmachung von Anrechten unter Verwendung der Wertangaben von Versorgungsträgern (Gutachter) .

M 69.17 Dynamische Lebensversicherung als Gegenleistung (ausführlich) . . . . . . . . .

M 69.18 Kapitalabfindung als Gegenleistung . . . . . . . . . . . . . . . . . .

M 69.19 Beitragsentrichtung nach $\$ 187$ Abs. 1 Nr. 2b) SGB VI durch Einmalzahlung in die

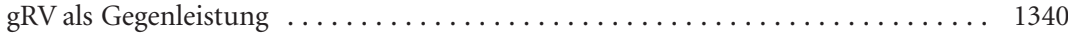

M 69.20 Ausgleich beschränkt auf „ehebedingte Nachteile“ in die gRV (vorsorgender

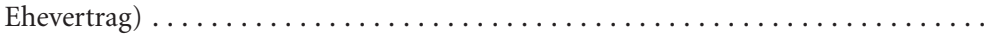

M 69.21 Ausschluss des Wertausgleichs einzelner Anrechte $\ldots \ldots \ldots \ldots \ldots \ldots \ldots \ldots$

M 69.22 Ausschluss des Wertausgleichs einzelner Anrechte gegen Zahlung eines Ausgleichsbetrags (Maßstab: korrespondierender Kapitalwert) in einer Scheidungs-

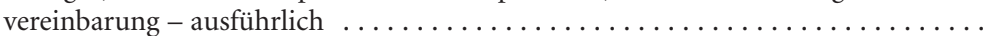

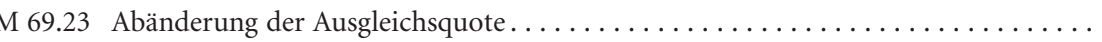

M 69.24 Auflösend bedingter Verzicht (ausscheidbarer Betreuungszeitraum für gemeinsame

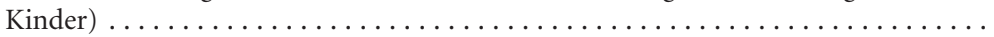

M 69.25 Festlegung eines sonstigen ausscheidbaren Ausgleichszeitraums (fiktives Ehezeit-

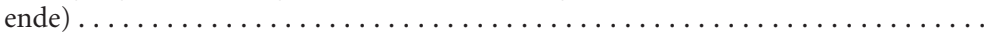

M 69.26 Belehrung über die Folgen der Festlegung des maßgeblichen Ausgleichszeitraums .

M 69.27 Auflösend bedingter Verzicht (Kinder, einverständliche Berufsaufgabe, Erwerbs-

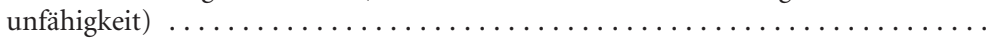

M 69.28 Aufschiebend bedingter Verzicht (Erbschaft) $\ldots \ldots \ldots \ldots \ldots \ldots \ldots \ldots \ldots \ldots$

M 69.29 Befristeter Verzicht (verlängerte „kurze Ehedauer“ nach $\$ 3$ Abs. 3 VersAusglG) . . .

M 69.30 Erweiterung: Mögliche Modifikation für Wartezeiterfordernis in der gRV . . . . . .

M 69.31 Erweiterung: Durchführung bei „kurzer Ehedauer“ trotz $\$ 3$ Abs. 3 VersAusglG ...

M 69.31a Verzicht mit einseitigem Rücktrittsvorbehalt (Kombination verschiedener

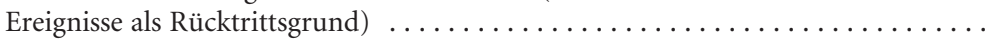

M 69.32 Verzicht mit einseitigem Rücktrittsvorbehalt (Kinderbetreuung als Rücktritts-

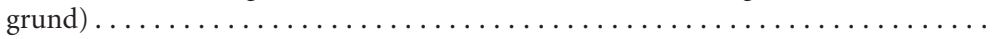

M 69.33 Verzicht mit einseitigem Rücktrittsvorbehalt (Wegfall eines Ehegatten-Mitarbeits-

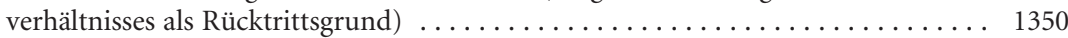

M 69.34 Vereinbarung schuldrechtlicher Ausgleichszahlungen ( $\$ 6$ Abs. 1 S. 2 Nr. 3

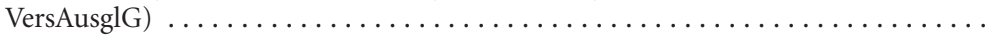

M 69.35 Vereinbarung schuldrechtlicher Ausgleichszahlungen für einzelnes Anrecht; hier:

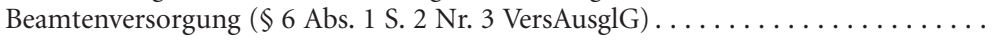

3. Abschnitt. Eingetragene Lebenspartnerschaft und nichteheliche Lebensgemeinschaft

Kap. 70 Eingetragene Lebenspartnerschaft Reetz/Schröders $\ldots \ldots \ldots \ldots \ldots \ldots \ldots$

M 70.1 Begründungserklärung - Lebenspartnerschaft . . . . . . . . . . . . . 1353

M 70.2 Ausschluss des Zugewinnausgleichs bei lebzeitiger Beendigung der Lebenspartner-

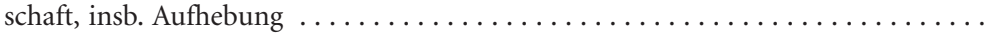


M 70.3 Gütertrennung durch Lebenspartnerschaftsvertrag zB zur Vorbereitung einer

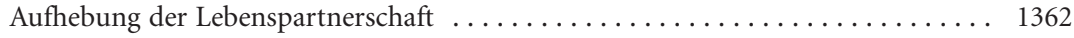

M 70.4 Regelung zum Güterrechtsregister - Lebenspartnerschaft .............. 1362

M 70.5 Regelung zur Befreiung von güterrechtlichen Verfügungsbeschränkungen -

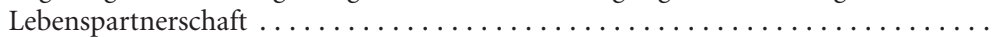

M 70.6 Vereinbarung zum Lebenspartnerschaftsnamen $\ldots \ldots \ldots \ldots \ldots \ldots \ldots \ldots \ldots \ldots$

M 70.7 Vollmacht (spezielle Bereiche des Sorgerechts - Beispiel: gesundheitliche Sorge) Lebenspartnerschaft .............................. 1366

M 70.8 Unterhaltsvereinbarung bei Getrenntleben der Lebenspartner . . . . . . . . . 1370

M 70.9 Vertragliche Vereinbarung zur Übernahme der gemeinsamen Mietwohnung -

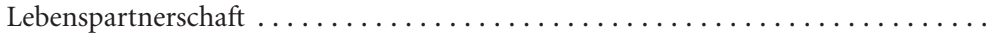

M 70.10 Gegenseitiger vollständiger Unterhaltsverzichtsvertrag (vorsorgende Vereinbarung; notarielle Form) - Lebenspartnerschaft . . . . . . . . . . . . . . . .

M 70.11 Eingeschränkter Unterhaltsverzicht; Beschränkung auf Existenzminimum nach der „Düsseldorfer Tabelle“ - Lebenspartnerschaft ....................

M 70.12 Teilweiser Unterhaltsverzicht unter Berücksichtigung der Kernbereichslehre des BGH (auch für Anschlusstatbestände) - Lebenspartnerschaft . . . . . . . . . . .

M 70.13 Begrenzung des Aufstockungsunterhalts (Höchstdauer und -grenze) - Lebens-

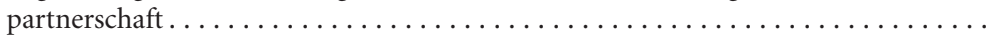

Kap. 71 Nichteheliche Lebensgemeinschaft Reetz/Schröders ......................

M 71.1 Klarstellende Vereinbarung zum Haftungsmaßstab - nichteheliche Lebensgemein-

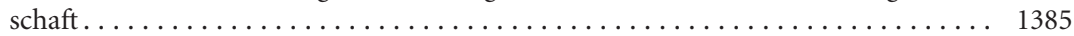

M 71.2 Beendigung der nichtehelichen Lebensgemeinschaft ................ 1386

M 71.3 Private Kapitallebensversicherung als Nachteilsausgleich für den Lebenspartner nichteheliche Lebensgemeinschaft $\ldots \ldots \ldots \ldots \ldots \ldots \ldots \ldots \ldots \ldots \ldots \ldots \ldots$

M 71.4 Vertragliche Vereinbarung zur Nutzung der gemeinsamen Wohnung, wenn bei Einzug lediglich ein Lebenspartner Mietvertragspartei ist (Aufnahmefall) - nicht-

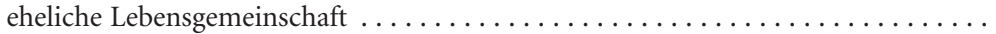

M 71.5 Aufschiebend bedingte Zuwendung eines Wohnungsrechts nach $\$ 1093$ BGB (ausführlich; notarielle Beurkundung) - nichteheliche Lebensgemeinschaft ........

M 71.6 Vormundbenennung durch Verfügung von Todes wegen - nichteheliche Lebens-

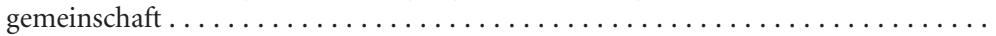

M 71.7 Erbvertragliche Besonderheiten: Fortgeltungsanordnung bei nachfolgender Ehe/ Lebenspartnerschaft, Rücktrittsvorbehalt, Anfechtungsausschluss, Klarstellungsregelungen - nichteheliche Lebensgemeinschaft $\ldots \ldots \ldots \ldots \ldots \ldots \ldots \ldots$

M 71.8 Vermögenszuordnung - nichteheliche Lebensgemeinschaft $\ldots \ldots \ldots \ldots \ldots \ldots$

M 71.9 Vermögenszuordnung; Herauszahlung bei Trennung angeknüpft an Bruchteil des Verkehrswerts eines Einfamilienhauses im Alleineigentum eines Partners, in dem die Lebensgemeinschaft gelebt wurde - nichteheliche Lebensgemeinschaft .......

M 71.10 Abwicklung von Zuwendungen, Leistungen und Aufwendungen für den Lebenspartner - nichteheliche Lebensgemeinschaft $\ldots \ldots \ldots \ldots \ldots \ldots \ldots \ldots \ldots$

\section{Abschnitt. Verwandtschaft}

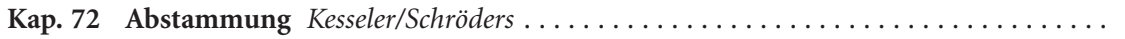

M 72.1 Vaterschaftsanerkennung durch einen Minderjährigen mit Zustimmung seiner Eltern und der volljährigen Kindesmutter . . . . . . . . . . . . . . . .

M 72.2 Vaterschaftsanerkennung für das Kind einer unverheirateten, minderjährigen, nicht sorgeberechtigten Frau mit ihrer Zustimmung, der ihres gesetzlichen Vertreters und der des gesetzlichen Vertreters des Kindes ................ 
M 72.3 Vaterschaftsanerkennung durch den neuen Partner einer verheirateten Frau während ihres Scheidungsverfahrens mit Zustimmung ihres Ehemannes .......

M 72.4 Antrag der Kindesmutter auf Feststellung der Vaterschaft durch das Familien-

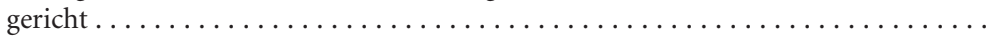

M 72.5 Antrag des gesetzlichen Vertreters eines geschäftsunfähigen Kindes auf Feststellung der Vaterschaft eines verstorbenen Mannes durch das Familiengericht .........

M 72.6 Anfechtung der Vaterschaft durch die Mutter als gesetzliche Vertreterin des

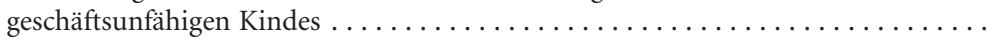

M 72.7 Anfechtung der Vaterschaft durch den biologischen Vater $\ldots \ldots \ldots \ldots \ldots \ldots \ldots$

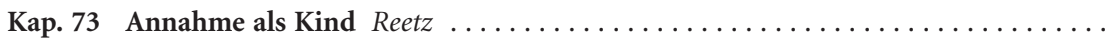

M 73.1 Antrag auf Annahme als Kind; alle erforderlichen Einwilligungen liegen vor

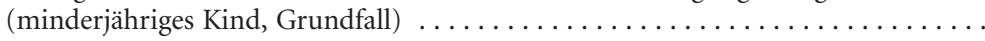

M 73.2 Notarielle Einwilligungen der leiblichen Eltern in Inkognito-Adoption . . . . . . . . .

M 73.3 Antrag auf Ersetzung der Einwilligung eines Elternteils nach $₫ 1748$ BGB ........

M 73.4 Antrag auf Ersetzung der Einwilligung der leiblichen Mutter (= Verweis im

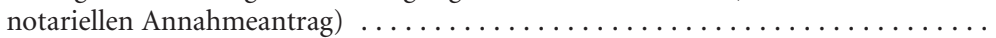

M 73.5 Notarielle Einwilligung in die Adoption und Verzichtserklärung des nichtehelichen Vaters auf Übertragung der Sorge nach $\$ 1671$ Abs. 2 BGB ................

M 73.6 Antrag auf Änderung des Vornamens im Rahmen eines Antrags auf Annahme als Kind (im Rahmen einer notariellen Urkunde) $\ldots \ldots \ldots \ldots \ldots \ldots \ldots \ldots \ldots$

M 73.7 Antrag des leiblichen Vaters auf Aufhebung der Annahme des minderjährigen Kindes; fehlende Einwilligung . . . ....................... 1429

M 73.8 Antrag auf Anerkennung einer Adoption nach $\$ 2$ AdWirkG . . . . . . . . . . 1431

M 73.9 Antrag auf Umwandlung einer Adoption nach $\$ 3$ AdWirkG . . . . . . . . . 1432

M 73.10 Antrag auf Annahme als Kind (volljähriges Kind - Grundfall); Namensänderung;

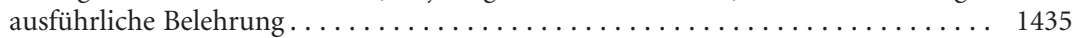

Kap. 74 Verwandten-, insbesondere Kindesunterhalt Reetz/Schröders ............ 1438

M $74.1 \quad$ Mehrbedarf neben dem Regelbedarf . . . . . . . . . . . . . . . . . 1444

M 74.2 Auskunft (im Rahmen einer notariellen Unterhaltsvereinbarung) . . . . . . . . 1450

M 74.3 Aufforderung zur Erteilung von Auskunft (Anwaltsschreiben) - Unterhalt . . . . . 1450

M 74.4 Obhut des Kindes ................................... 1451

M 74.5 Vertrag zu Gunsten Dritter (mit Freistellung für Überschüsse) - Unterhalt. . . . . . 1453

M 74.6 Berechnungsgrundlagen - notarielle Vereinbarung - Unterhalt . . . . . . . . . . . 1454

M 74.7 Vollstreckungsunterwerfung (statisch) - Unterhalt . . . . . . . . . . . . . . 1455

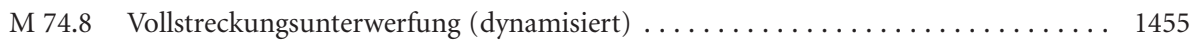

M 74.9 Vereinbarung über die Abänderung (klarstellend) - Unterhalt . . . . . . . . . . . 1455

M 74.10 Vereinbarung über die Abänderung (einschränkend) - Unterhalt . . . . . . . 1455

M 74.11 Belehrungshinweis zum (unzulässigen) Unterhaltsverzicht .............. 1456

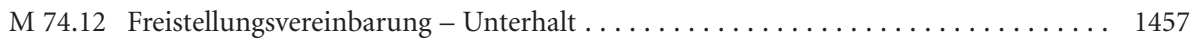

M 74.13 Privilegierter Volljähriger - Unterhaltsvereinbarung zwischen den Eltern

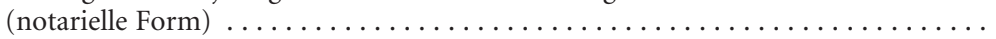

M 74.14 Privilegierter Volljähriger - Unterhaltsvereinbarung mit dem Kind (notarielle

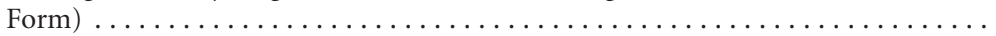

M 74.15 Kosten der privaten Krankenversicherung - Unterhalt ................ 1462

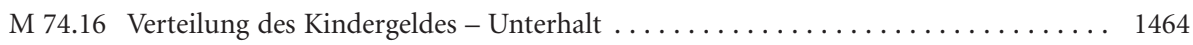

M 74.17 Dynamisierter Unterhalt für mehrere unverheiratete, minderjährige Kinder: notarielle Vereinbarung - Grundmuster kurze Fassung $\ldots \ldots \ldots \ldots \ldots \ldots \ldots$ 
M 74.18 Dynamisierter Unterhalt für mehrere unverheiratete, minderjährige Kinder: notarielle Vereinbarung - ausführliche Fassung $\ldots \ldots \ldots \ldots \ldots \ldots \ldots \ldots . \ldots \ldots$

M 74.19 Erweiterung (freigiebige, statische Zulage) $\ldots \ldots \ldots \ldots \ldots \ldots \ldots \ldots \ldots \ldots \ldots \ldots$

M 74.20 Dynamisierter Unterhalt für unverheiratete, minderjährige Kinder: Klage. . . . . . 1468

Kap. 75 Rechtsverhältnis zwischen den Eltern und dem Kind Kesseler .............. 1472

M 75.1 Sorgeerklärungen des Vaters und der beschränkt geschäftsfähigen Mutter mit Zustimmung des gesetzlichen Vertreters der Mutter ................ 1474

M 75.2 Antrag auf Änderung der elterlichen Sorge mit Zustimmung des anderen

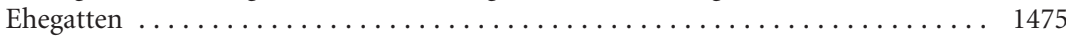

M 75.3 Antrag auf Übertragung der gemeinsamen elterlichen Sorge nach $\$ 1626$ Abs. 1

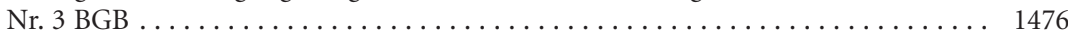

M 75.4 Antrag eines Elternteils auf Übertragung des Entscheidungsrechts............ 1477

M 75.5 Antrag der Eltern, die nicht miterben, auf Genehmigung einer Erbschafts-

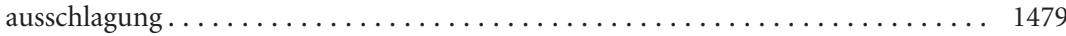

M 75.6 Antrag einer gemeinsam mit dem Vater sorgeberechtigten Mutter auf Beistandschaft des Jugendamts zur Geltendmachung von Unterhaltsansprüchen ........

\section{Abschnitt. Vormundschaft, Betreuung und Vorsorgevollmacht, Patientenverfügung, Pflegschaft}

Kap. 76 Vormundschaft Dorsel ................................. 1483

M 76.1 Benennung des Vormunds im Testament, Ausschließung bestimmter Personen . . 1485

M 76.2 Ablehnung der Übernahme einer Vormundschaft .................. 1486

M 76.3 Vorlage des Vermögensverzeichnisses durch Vormund und Gegenvormund . . . . . 1488

M 76.4 Antrag auf Genehmigung zum Abweichen von den Anordnungen des Erblassers . . 1489

M 76.5 Antrag auf familiengerichtliche Genehmigung der Anlegung von Mündelvermögen 1490

M 76.6 Gesuch um Genehmigung der Abhebung von Mündelgeld . . . . . . . . . . . 1491

M 76.7 Antrag des Vormunds auf Genehmigung eines Grundstückskaufvertrags . . . . . . 1493

M 76.8 Doppelbevollmächtigung des Notars in einem Kaufvertrag mit dem durch seinen Vormund vertretenen Mündel sowie Aktenvermerk des Notars . . . . . . . . . . . . . . 1494

M 76.9 Antrag auf Genehmigung eines Ausbildungsvertrags . . . . . . . . . . . . . . . . . . . 1494

M 76.10 Aufforderung an den Vormund zur Erklärung über die familiengerichtliche

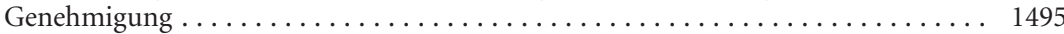

M 76.11 Anordnung der befreiten Vormundschaft ......................... 1495

M 76.12 Antrag auf Entlassung aus dem Amt als Vormund .................. 1496

M 76.13 Schlussrechnung des Vormunds nach Volljährigkeit des Mündels . . . . . . . . . . 1496

M 76.14 Entlastung des Vormunds durch Verzicht des Mündels . . . . . . . . . . . . . . 1497

M 76.15 Antrag auf Bewilligung einer Vergütung für den Vormund . . . . . . . . . . . 1498

Kap. 77 Pflegschaft Dorsel ................................. 1500

M 77.1 Antrag auf Bestellung eines (Ergänzungs-)Pflegers für eine Angelegenheit, an deren Besorgung der gesetzliche Vertreter verhindert ist . . . . . . . . . . . 1501

M 77.2 Mitteilung über die Notwendigkeit der Bestellung eines Pflegers für die Verwaltung von Vermögen, das ein Minderjähriger unter Ausschluss der Verwaltung durch den gesetzlichen Vertreter und Benennung eines Pflegers

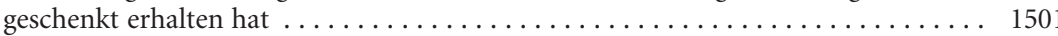

M 77.3 Anregung zur Bestellung eines Abwesenheitspflegers $\ldots \ldots \ldots \ldots \ldots \ldots \ldots \ldots$ 
Kap. 78 Betreuung und Betreuungsverfügung Dorsel .................. 1505

M 78.1 Anregung zur Bestellung eines Betreuers und Anordnung eines Einwilligungs-

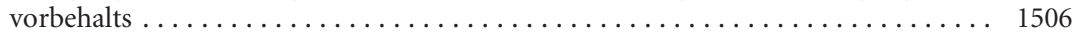

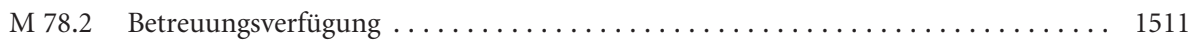

Kap. 79 Vorsorgevollmacht und Patientenverfügung Dorsel ................ 1513

M 79.1 Vorsorgevollmacht in Form einer Generalvollmacht .................... 1516

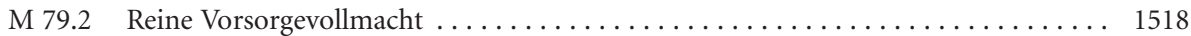

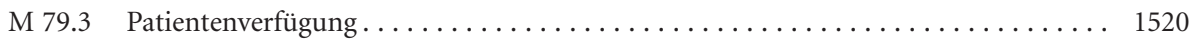

\section{Zweiter Teil. Erbrecht}

\section{Abschnitt. Erbrechtliche Grundzüge}

Kap. 80 Erbrechtliche Grundzüge und Rahmenurkunden Fröhler/Schröders ......... 1521

M $80.1 \quad$ Notarielles Testament - Urkundenmantel . . . . . . . . . . . . . . . . . 1543

M 80.2 Notarielles Testament durch Übergabe einer offenen/verschlossenen Schrift . . . . . 1544

M 80.3 Notarielles Testament bei Handicap des Erblassers (1) . . . . . . . . . . . . . 1546

M 80.4 Notarielles Testament bei Handicap des Erblassers (2) . . . . . . . . . . . . . 1547

M 80.5 Notarielles Testament bei Handicap des Erblassers (3) . . . . . . . . . . . . . . 1548

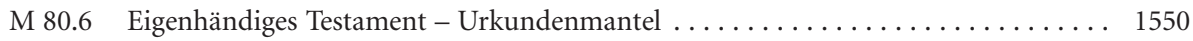

M 80.7 Nottestament vor dem Bürgermeister . . . . . . . . . . . . . . . . . 1551

M 80.8 Nottestament in besonderen Fällen (Dreizeugentestament) . . . . . . . . . . . 1552

Kap. 81 Erbausgleichung und Pflichtteilsanrechnung Fröhler ................ 1573

M $81.1 \quad$ Ausdrückliche Benennung der Zuwendungsart . . . . . . . . . . . . . . . . . . . 1576

M 81.2 Ausdrückliche Anordnungen zur Erbausgleichung ................. 1577

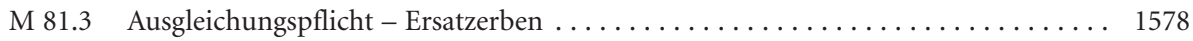

M 81.4 Anordnung einer Pflegeausgleichung mit hilfsweisem Vorausvermächtnis . . . . 1580

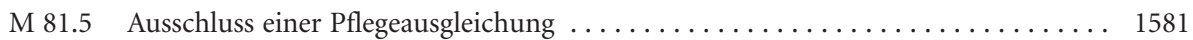

M 81.6 Ausgleichungsanordnung durch Vorausvermächtnis aufgrund Vorbehalts....... 1583

M 81.7 Aufhebung einer Ausgleichungspflicht durch Vorausvermächtnis aufgrund

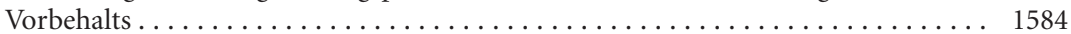

M 81.8 Nicht vorbehaltene Anordnung einer Ausgleichungspflicht durch Voraus-

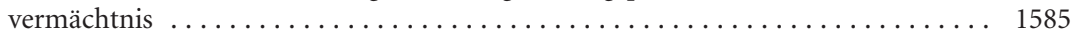

M 81.9 Nicht vorbehaltene Aufhebung einer Ausgleichungspflicht durch Voraus-

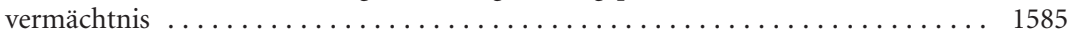

M 81.10 Nach Berufungsgrund differenzierte Ausgleichungsanordnung mit Vorbehalt . . . 1587

M 81.11 Ausdrückliche Anordnung der Pflichtteilsanrechnung . . . . . . . . . . . . . 1590

M 81.12 Ausdrückliche Klarstellung der Anordnungswirkung bei Wegfall des Zuwendungsempfängers ......................................... 1592

M 81.13 Nachträgliche vermächtnisweise Aufhebung einer Anrechnungspflicht ....... 1592

M 81.14 Anrechnungsbestimmung durch Verfügung von Todes wegen aufgrund Vorbehalts 1593

M 81.15 Vorrangbestimmung bei güter- und pflichtteilsrechtlicher Anrechnungspflicht... 1596

M 81.16 Bestimmung der Pflichtteilsanrechnung unter bedingtem Ausgleichungsvorbehalt. 1597

M 81.17 Bestimmung der Pflichtteilsanrechnung und bedingte Anordnung der Erb-

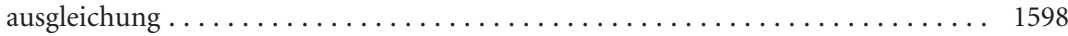

M 81.18 Pflichtteilsanrechnungsbestimmung des zuwendenden Ehegatten, Pflichtteilsergänzungsverzicht, Pflichtteilsverzichtsvertrag zwischen Zuwendungsempfänger und nichtzuwendendem Ehegatten sowie Vorbehalt der Erbausgleichung . . . . . . 1600 
M 81.19 Vorausvermächtnisweise Anordnung einer Ausgleichungspflicht durch den zuwendenden und den nichtzuwendenden Ehegatten .................

\section{Abschnitt. Gestaltung durch Verfügung von Todes wegen}

Kap. 82 Letztwillige Anordnungen Fröhler/Schröders.................... 1602

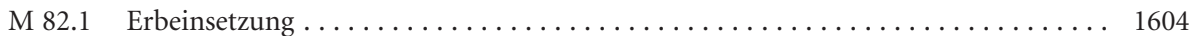

M 82.2 Miterbeneinsetzung auf gemeinschaftlichen Erbteil .................. 1604

M 82.3 Erbeinsetzung einer noch zu errichtenden Stiftung.................. 1605

M 82.4 Erbsatzerbeneinsetzung und Anwachsung ...................... 1607

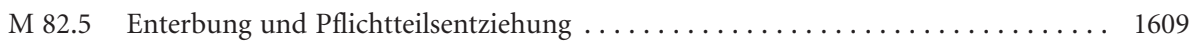

M 82.6 Vorausvermächtnis und Ersatzvorausvermächtnisnehmer .............. 1611

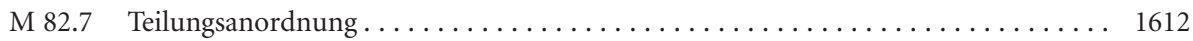

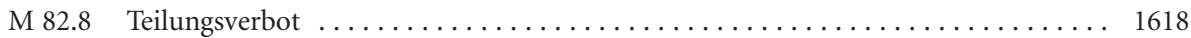

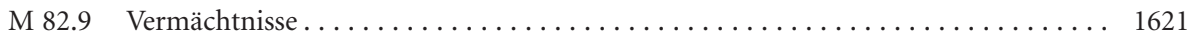

M 82.10 Vermächtnisweise mittelbare Verjährungsfristverlängerung für Pflichtteils-

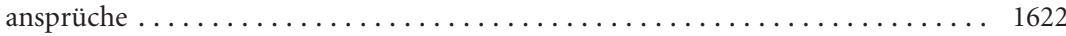

M 82.11 Vermächtnisweise Befreiung des Vermächtnisnehmers von der Pflichtteilslast..... 1623

M 82.11a Ausschluss des Kürzungsrechts des Hauptvermächtnisnehmers . . . . . . . . . . . . 1623

M 82.12 Auflage .............................................. 1624

M 82.13 Benennung eines Pflegers für nicht volljährige Kinder des Erblassers . . . . . . . 1625

M 82.14 Ausschluss der Sorgerechtsübertragung und Benennung eines Vormundes für nicht volljährige, nicht aus einer Ehe stammende Kinder . . . . . . . . . 1626

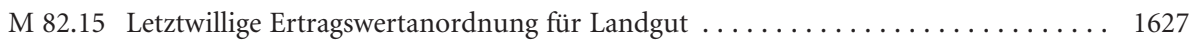

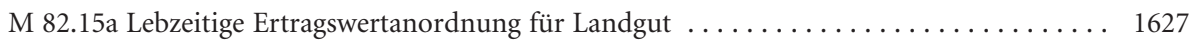

M 82.16 Einseitig erklärte Rechtswahl zur Bestimmung des Erbstatuts nach EGBGB . . . . 1628

M 82.16a Einseitig erklärte Rechtswahl zur Bestimmung des Erbstatuts nach EGBGB . . . . 1629

M 82.17 Einzeltestament einer ledigen kinderlosen Frau mit Nichten und Neffen . . . . . 1630

M 82.18 Einzeltestament eines ledigen kinderlosen Mannes mit Lebensgefährtin . . . . . . 1631

Kap. 83 Vor- und Nacherbschaft sowie Vor-, Nach- und Herausgabevermächtnis Fröhler 1632

M 83.1 Erbeinsetzung zum Vorerben mit Anordnung der Nacherbfolge . . . . . . . . . 1637

M 83.2 Weitere Nacherbfolge . . . . . . . . . . . . . . . . . . . . . . . . . . . 1639

M 83.3 Vorausvermächtnis an den Alleinvorerben .................... 1642

M 83.4 Gegenständlich beschränkte Nacherbeneinsetzung . . . . . . . . . . . . . . . . . . . 1642

M 83.5 Quotale Vollerbeneinsetzung des längstlebenden Ehegatten bei Wiederverheiratung 1644

M 83.6 Nacherbfolge unter auflösender Bedingung anderweitiger letztwilliger Verfügung • 1645

M 83.7 Anordnung eines Vor- und Nachvermächtnisses mit Testamentsvollstreckung . . . 1646

M 83.8 Erbeinsetzung und Herausgabevermächtnis auf den Tod des Erben . . . . . . . . . 1648

M 83.9 Ausscheidungsvereinbarung über Grundbesitz aus der Nacherbenbindung . . . . . . 1649

M 83.10 Übertragung der Gesamtheit der Nacherbenrechte durch den Nacherben an den Vorerben ......................................... 1650

M 83.11 Gemeinschaftliches Testament von Ehegatten, die sich gegenseitig zu befreiten Alleinvorerben und die gemeinsame Tochter zum Nacherben des Erstversterbenden und Ersatzerben des Längstlebenden einsetzen . . . . . . . . . . . . . 1651

Kap. 84 Testaments- und Vermächtnisvollstreckung Fröhler ................ 1654

M 84.1 Anordnung der Testamentsvollstreckung und Bestimmung der Person des

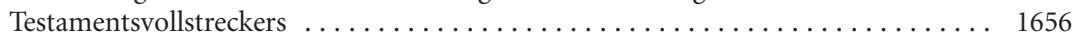


M 84.2 Anordnung der Vermächtnisvollstreckung und Bestimmung der Person des

Vermächtnisvollstreckers mit dessen Aufgabenbereich . . . . . . . . . . . . . . 1657

M 84.3 Bestimmung mehrerer Testamentsvollstrecker als Gesamtvollstrecker ......... 1658

M 84.4 Benennung der Aufgaben des Testamentsvollstreckers . . . . . . . . . . . . . 1660

M 84.5 Erweiterung der gesetzlichen Verfügungsmacht des Testamentsvollstreckers ...... 1662

M 84.6 Einschränkung der gesetzlichen Verfügungsmacht des Testamentsvollstreckers .... 1662

M 84.7 Anordnung von Vergütung und Auslagenersatz für den Testamentsvollstrecker ... 1663

M 84.8 Nacherbentestamentsvollstreckung/Nachnacherbentestamentsvollstreckung . . . . . 1665

M 84.9 Testamentsvollstrecker als Schiedsrichter und Schiedsgutachter . . . . . . . . . . 1666

M 84.10 Anordnungen hinsichtlich dem Testamentsvollstrecker gesondert erteilter

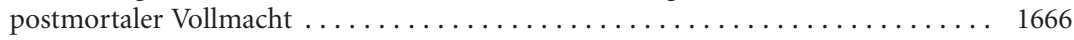

M 84.10a Vertretungsberechtigung des Bevollmächtigten im Falle einer Testamentsvoll-

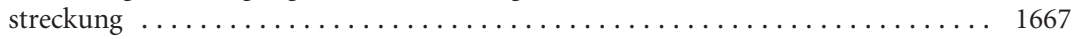

M 84.11 Testamentsvollstreckungsklausel für nichtbetriebliches Vermögen . . . . . . . . . 1668

M 84.12 Testamentsvollstreckungsklausel für betriebliches Vermögen . . . . . . . . . . 1668

Kap. 85 Gemeinschaftliches Testament und Erbvertrag Fröhler................ 1669

M 85.1 Eigenhändiges gemeinschaftliches Ehegattentestament - Urkundenmantel . . . . . 1674

M 85.2 Notarielles gemeinschaftliches Ehegattentestament - Urkundenmantel . . . . . . . . 1674

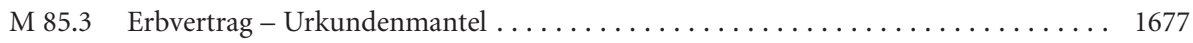

M 85.4 Gegenseitige Alleinerbeinsetzung des längstlebenden Ehegatten durch den

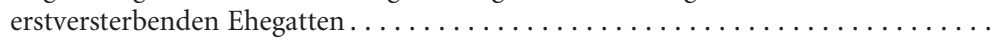

M 85.5 Vermächtnisanordnung bei Tod des erstversterbenden Ehegatten neben Alleinerbeneinsetzung des längstlebenden Ehegatten ....................

M 85.6 Supervermächtnis bei Tod des erstversterbenden Ehegatten zulasten des bestimmungsbefugten alleinerbenden Ehegatten ..................

M 85.7 Schlusserbeneinsetzung durch den Längstlebenden bei Vorhandensein von Abkömmlingen . . . . . . . . . . . . . . . . . . . . . . .

M 85.7a Herausgabevermächtnis durch den Erstversterbenden und Schlusserbeneinsetzung durch den Längstlebenden bei derzeitigem Nichtvorhandensein von

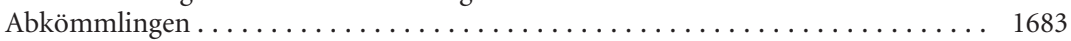

M 85.8 Vormundbenennung für minderjährige Kinder auf den Tod beider Eheleute . . . . 1685

M 85.9 Wiederverheiratungsklausel in Form auflösend bedingter Vollerbschaft bzw. aufschiebend bedingter Nacherbeneinsetzung . . . . . . . . . . . . . . 1687

M 85.10 Wiederverheiratungsklausel in Form eines aufschiebend bedingten Geldvermächtnisses zu Gunsten der gemeinschaftlichen Kinder . . . . . . . . . . . 1688

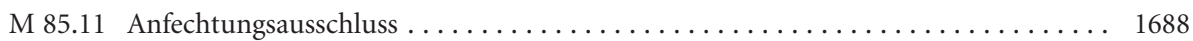

M 85.12 Einfache Verwirkungsklausel . . . . . . . . . . . . . . . . . . . . . 1690

M 85.13 Erweiterte Verwirkungsklausel nach Jastrow .................... 1691

M 85.14 Ausschlussermächtigungsklausel ........................... 1692

M 85.15 Abänderungsvorbehalt ................................. 1693

M 85.16 Rechtswahl gem. EGBGB zur Bestimmung deutschen Erbrechts durch Erbvertrag • 1695

M 85.16a Rechtswahl gem. EuErbVO durch Erbvertrag . . . . . . . . . . . . . 1696

M 85.17 Gemeinschaftliches Testament von Ehegatten, die sich gegenseitig zu Alleinvollerben und die gemeinsamen Kinder zu Schlusserben des Längstlebenden einsetzen (Berliner Testament) . . . . . . . . . . . . . . . . . . . . . . . . 1697

M 85.18 Gemeinschaftliches Testament gleichgeschlechtlicher Lebenspartner, die sich

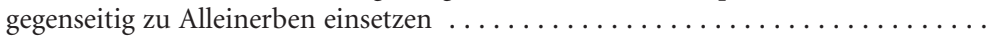

M 85.19 Erbvertragliche Zuwendung gegen Pflegeverpflichtung unter schuldrechtlichem durch Eintragung einer Erwerbsvormerkung abgesicherten Verfügungsverbot .... 
Kap. 86 Letztwillige Verfügungen von Unternehmern Fröhler/Schröders ........... 1702

M 86.1 Drittbestimmter Vermächtnisnehmer ........................ 1705

M 86.2 Drittbestimmte Teilungsanordnung . . . . . . . . . . . . . . . . . . . 1706

M 86.3 Pflicht zur Fortführung eines Einzelunternehmens in anderer Rechtsform . . . . . . 1710

M 86.4 Alleinerbeinsetzung eines Kindes zur Nachfolge am Kommanditanteil mit Unterbeteiligung des Ehegatten und des anderen Kindes . . . . . . . . . . 1712

M 86.5 Erbeinsetzung der Kinder zur Nachfolge am GmbH-Anteil mit durch Wiederverheiratung auflösend bedingtem Nießbrauchs- und dadurch aufschiebend bedingtem Rentenvermächtnis des Ehegatten samt Testamentsvollstreckung . ....

Kap. 87 Gestaltung in besonderen Problemfällen Fröhler.................... 1719

M 87.1 Gemeinschaftliches Testament in der Patchwork-Familie von Ehegatten, die sich gegenseitig zu Alleinvollerben und alle (gemeinsame sowie ausschließlich von einem von ihnen abstammende) Kinder zu Schlusserben des Längstlebenden

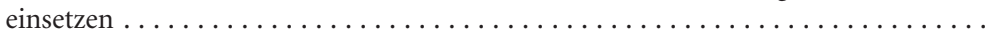

M 87.2 Geschiedenentestament - Kombination aus Vor- und Nacherbfolge mit Herausga-

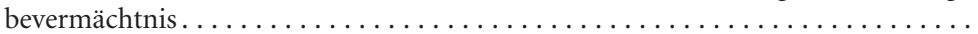

M 87.3 Verfügung von Todes wegen bei behinderten Abkömmlingen - sog. Behinderten-

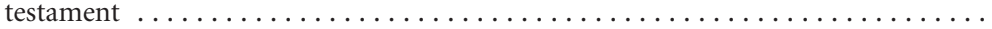

M 87.4 Pflichtteilsbeschränkung in guter Absicht $\ldots \ldots \ldots \ldots \ldots \ldots \ldots \ldots \ldots \ldots \ldots \ldots \ldots$

M 87.5 Verfügung von Todes wegen des Apothekeninhabers - sog. Apothekeninhabertestament (Ehemann als Apothekeninhaber, Ehefrau ohne Approbation) ........

Kap. 88 Widerruf und Anfechtung letztwilliger Verfügungen Fröhler ..............

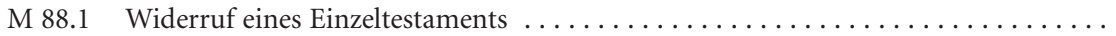

M 88.2 Widerruf einer einzelnen Testamentsverfügung aus einem Einzeltestament .......

M 88.3 Widerruf eines durch Einzeltestament erfolgten Widerrufs durch Einzeltestament . 1741

M 88.4 Widerruf einer einseitigen Verfügung aus einem gemeinschaftlichen Testament

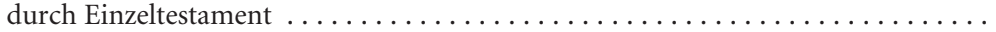

M 88.5 Widerruf eines gemeinschaftlichen Testaments durch gemeinschaftliches Wider-

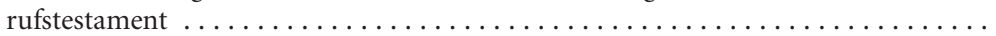

M 88.6 Widerruf einer wechselbezüglichen Verfügung aus einem gemeinschaftlichen Testament mit Änderungsvorbehalt durch Einzeltestament . . . . . . . . . . .

M 88.7 Widerruf eines gemeinschaftlichen Testaments durch einseitige Erklärung zu Lebzeiten beider Ehegatten . . . . . . . . . . . . . . . . . . . . .

M 88.8 Aufhebung einer vertragsmäßigen Verfügung aus einem Erbvertrag durch einseitiges Testament des längstlebenden Erblassers nach dem Tod des erstversterbenden Vertragsgegners wegen Verfehlungen des Bedachten ...........

M 88.9 Anfechtung eines gemeinschaftlichen Testaments/Erbvertrages durch den längstlebenden Ehegatten nach dem Tod des erstversterbenden Ehegatten ...........

3. Abschnitt. Gestaltung durch Vereinbarung unter Lebenden mit Wirkung auf den Tod

Kap. 89 Verträge über Erbverzicht, Pflichtteilsverzicht und Zuwendungsverzicht Fröhler 1760

M 89.1 Auflösend bedingter Pflichtteilsverzicht der volljährigen Kinder auf den Tod des erstversterbenden Elternteils . . . . . . . . . . . . . . . . . . . . . 1763

M 89.2 Auflösend bedingter Erbverzichtsvertrag ....................... 1764

M 89.3 Gegenständlich beschränkter Pflichtteilsverzichtsvertrag $\ldots \ldots \ldots \ldots \ldots \ldots \ldots$

M 89.3a Um Elternpflichtteilsgeltendmachung auflösend bedingter Pflichtteilsverzichtsverzicht (Notarielles Beurkundungsprotokoll - Auszug) . . . . . . . . . . . . . . 1769

M 89.3b Regelung zur Unterhaltspflicht im Pflichtteilsverzichtsvertrag ............. 1769 
M 89.3c Um Pflichtteilsergänzungsgeltendmachung auflösend bedingter Pflichtteils-

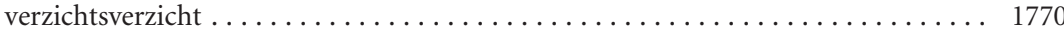

M 89.4 Vertrag über vollentgeltlichen Zuwendungsverzicht $\ldots \ldots \ldots \ldots \ldots \ldots \ldots \ldots . \ldots \ldots$

M 89.5 Vertrag über die Aufhebung eines Erb- und Pflichtteilsverzichtsvertrages . . . . . . 1779

Kap. 90 Schenkungen auf den Tod Fröhler ...................... 1779

M 90.1 Vertrag über eine erst auf den Tod des Übergebers zu erfüllende unbedingte

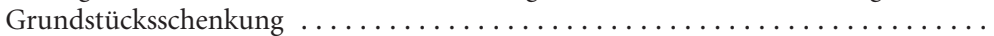

\section{Abschnitt. Nachlassverfahren}

Kap. 91 Erbscheins-, Testaments- bzw. Vermächtnisvollstreckerzeugnisanträge, Europäisches Nachlasszeugnis und Auslegungsvertrag Fröhler...............

M 91.1 Antrag auf Erteilung eines Alleinerbscheins nach gesetzlicher Erbfolge ohne Aus-

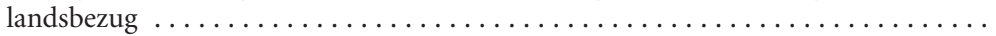

M 91.2 Antrag auf Erteilung eines gemeinschaftlichen Erbscheins bei gewillkürter Erbfolge ohne Auslandsbezug . . . . . . . . . . . . . . . . . . . . . . . .

M 91.3 Antrag auf Erteilung eines vorläufigen gemeinschaftlichen Erbscheins bei gesetz-

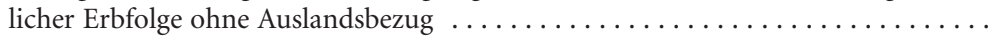

M 91.4 Antrag auf Erteilung eines Teilerbscheins ohne Auslandsbezug $\ldots \ldots \ldots \ldots \ldots$.

M 91.5 Antrag auf Erteilung eines Erbscheins bei angeordneter Nacherbfolge ohne Aus-

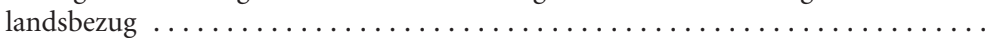

M 91.6 Antrag auf Erteilung eines Erbscheins bei angeordneter Nacherbfolge und dem Vorerben zugewendetem Vorausvermächtnis vor Eintritt des Nacherbfalls ohne

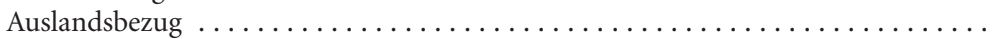

M 91.7 Antrag auf Erteilung eines Erbscheins bei eingetretener Nacherbfolge ohne Aus-

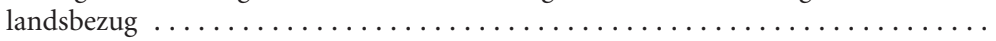

M 91.8 Antrag auf Erteilung eines Erbscheins bei durch Wiederverheiratung bedingter

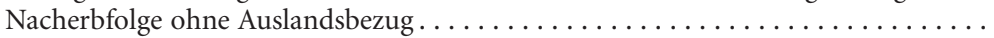

M 91.9 Antrag auf Erteilung eines gegenständlich beschränkten Vollerbscheins (Hauptantrag) bzw. eines Vorerbscheins mit Vermerk über Eintritt der Nacherbfolge (Hilfsantrag) bei angeordneter Nacherbfolge und dem Vorerben zugewendetem Vorausvermächtnis ab Eintritt des Nacherbfalls ohne Auslandsbezug .........

M 91.10 Antrag auf Erteilung eines Erbscheins bei eingetretener Nacherbfolge, wenn dem Vorerben ein Vorausvermächtnis zugewendet wurde ohne Auslandsbezug ......

M 91.11 Antrag auf Erteilung eines gegenständlich auf den im Inland befindlichen Nachlass beschränkten Eigenrechtserbscheins nach einem deutschen Erblasser mit Grundbesitz im Ausland

M 91.12 Antrag auf Erteilung eines gegenständlich auf den inländischen Spaltnachlass für unbewegliches Vermögen beschränkten Eigenrechtserbscheins nach einem aus-

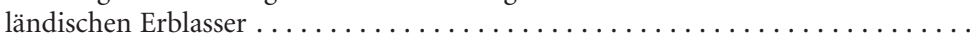

M 91.13 Antrag auf Erteilung eines gegenständlich auf den im Inland befindlichen Nachlass beschränkten Doppelerbscheins nach einem ausländischen Erblasser .........

M 91.14 Antrag auf Erteilung eines unbeschränkten Doppelerbscheins nach einem aus-

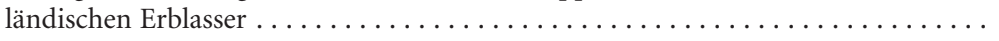

M 91.15 Antrag auf Erteilung eines Erbscheins, der gegenständlich auf im Gebiet der früheren DDR belegenen Grundbesitz beschränkt ist . . . . . . . . . . . . .

M 91.16 Antrag auf Erteilung eines gegenständlich auf den im Inland befindlichen Nachlass beschränkten Fremdrechtserbscheins nach einem ausländischen Erblasser mit

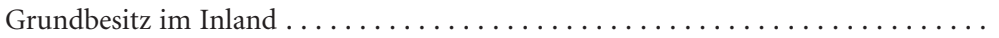

M 91.17 Antrag auf Berichtigung eines Erbscheins nach Wegfall der Testamentsvollstreckung infolge Aufgabenerledigung. 
M 91.18 Ernennung eines Nachfolgertestamentsvollstreckers durch die übrigen

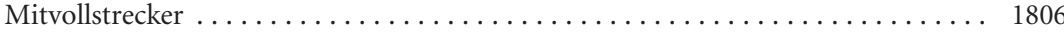

M 91.19 Annahme/Ablehnung des Testamentsvollstreckeramtes . . . . . . . . . . . . 1807

M 91.20 Antrag auf Erteilung eines Testamentsvollstreckerzeugnisses . . . . . . . . . . 1808

M 91.21 Antrag auf Erteilung eines Nacherbentestamentsvollstreckerzeugnisses . . . . . . . . 1809

M 91.22 Antrag auf Erteilung eines Vermächtnisvollstreckerzeugnisses . . . . . . . . . . . . . 1809

M 91.23 Haftungserklärung wegen Auszahlung des Sterbegeldes . . . . . . . . . . . . . . . 1810

Kap. 92 Ausschlagung von Erbschaft und Vermächtnis sowie Anfechtung von Annahme, Fristversäumnis, Ausschlagung und Anfechtung Fröhler.............. 1811

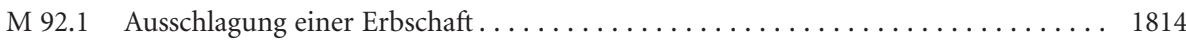

M 92.2 Ausschlagung einer Erbschaft durch den gesetzlichen Vertreter . . . . . . . . . 1820

M 92.3 Antrag auf familiengerichtliche/betreuungsgerichtliche Genehmigung der

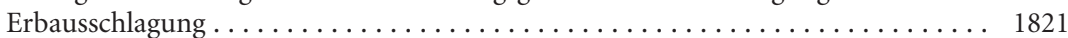

M 92.4 Ausschlagung einer Erbschaft aus ererbtem Ausschlagungsrecht . . . . . . . 1822

M 92.5 Ausschlagung einer Erbschaft als eingesetzter Erbe unter Annahme einer Erbschaft

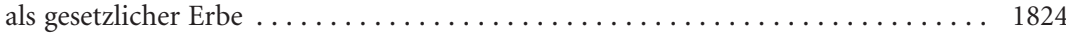

M 92.6 Ausschlagung einer Erbschaft bei Nachlassspaltung . . . . . . . . . . . . 1824

M 92.7 Anfechtung der Versäumnis der Ausschlagungsfrist unter Nachholung der

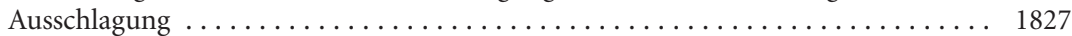

M 92.8 Anfechtung der Ausschlagung einer Erbschaft $\ldots \ldots \ldots \ldots \ldots \ldots \ldots \ldots \ldots \ldots 21827$

M 92.9 Anfechtung der Annahme einer Erbschaft ..................... 1828

M 92.10 Ausschlagung eines Vermächtnisses . . . . . . . . . . . . . . . 1830

Kap. 93 Notarielles Nachlassverzeichnis, Nachlasssicherung, Gläubigerbefriedigung und Haftungsbeschränkung Fröhler ......................... 1830

M 93.1 Nachlassverzeichnis für den Pflichtteilsberechtigten ................... 1832

M 93.2 Anregung der Anordnung einer Nachlasspflegschaft ............... 1835

M 93.3 Antrag eines Nachlassgläubigers auf Bestellung eines Nachlasspflegers zwecks gerichtlicher Geltendmachung einer Forderung . . . . . . . . . . . . 1837

M 93.4 Antrag eines Nachlassgläubigers auf Anordnung der Nachlassverwaltung . . . . . . 1839

M 93.5 Antrag eines Erben auf Aufgebot der Nachlassgläubiger . . . . . . . . . . . . . 1842

M 93.6 Antrag eines Nachlassgläubigers auf Fristsetzung zur Inventarerrichtung . . . . . . . 1842

M 93.7 Antrag eines Erben auf amtliche Aufnahme des Inventars . . . . . . . . . . . . . 1843

\section{Abschnitt. Gestaltung nach Eintritt des Erbfalls}

Kap. 94 Erbauseinandersetzung, Abschichtungsvereinbarung und Vermächtniserfüllung

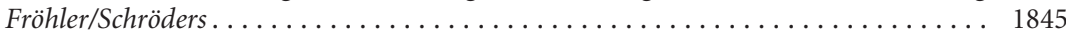

M 94.1 Vollständiges Ausscheiden eines Miterben aus der Erbengemeinschaft durch

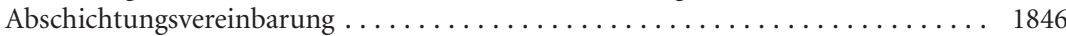

M 94.2 Vollständige Auseinandersetzung aller Miterben durch Erbauseinandersetzungs-

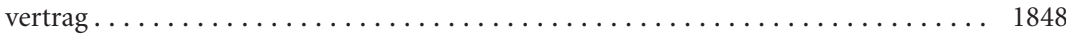

M 94.3 Auf bestimmte Nachlassgegenstände beschränkte Auseinandersetzung aller Miterben durch Teilerbauseinandersetzungsvertrag $\ldots \ldots \ldots \ldots \ldots \ldots \ldots \ldots 1850$

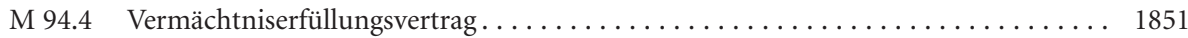

Kap. 95 Erbteilsübertragungs-, Erbteilsverpfändungs- und Erbschaftsvertrag Fröhler .. 1852

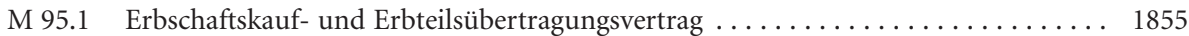

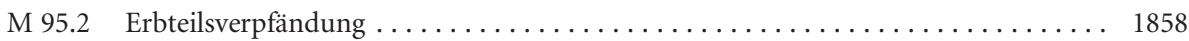

M 95.3 Erbschaftsvertrag - Verpflichtung zur Übertragung eines künftigen testamentarischen Erbteils, der die gesetzliche Erbquote nicht übersteigt . . . . . . . . . . . . 1860 


\section{Arbeitsrecht}

\section{Abschnitt. Arbeitsrechtliche Grundlagen}

Kap. 96 Grundlagen des Arbeitsrechts Vogel $\ldots \ldots \ldots \ldots \ldots \ldots \ldots \ldots \ldots \ldots \ldots$

\section{Abschnitt. Individualarbeitsrecht}

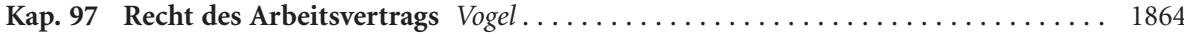

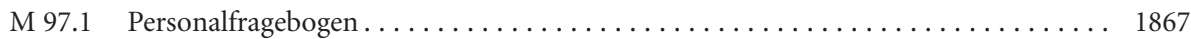

M 97.2 Einwilligung des Arbeitnehmers in eine Eignungsuntersuchung/ärztliche Untersu-

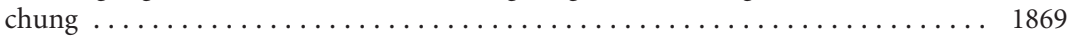

M 97.3 Einfacher Anstellungsvertrag ohne Bezugnahme auf Tarifvertrag . . . . . . . . . . 1872

M 97.4 Anstellungsvertrag mit Bezugnahmeklausel auf Tarifvertrag . . . . . . . . . . . . 1878

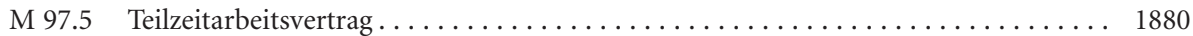

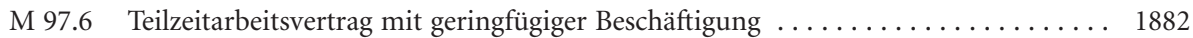

M 97.7 Teilzeitbeschäftigung nach betrieblichem Bedarf - Abrufarbeit . . . . . . . . . 1883

M $97.8 \quad$ Altersteilzeit-Vertrag . . . . . . . . . . . . . . . . . . . . . . . . . . 1885

M 97.9 Kalendarisch befristeter Arbeitsvertrag aus sachlichen Gründen . . . . . . . . . . . 1889

M 97.10 Zweckbefristeter Arbeitsvertrag aus sachlichen Gründen . . . . . . . . . . . . . . . . 1890

M 97.11 Mitteilung der Zweckerreichung nach $₫ 15$ Abs. 2 TzBfG . . . . . . . . . . . . 1890

M 97.12 Befristeter Arbeitsvertrag nach $\$ 14$ Abs. 2 TzBfG/sachgrundlose Befristung . . . . 1891

M 97.13 Ausführlicher Anstellungsvertrag mit Klauseln für Führungskräfte . . . . . . . . . 1892

M 97.14 Vertrag mit Außendienstmitarbeitern mit Provisionsvereinbarung . . . . . . . . . 1898

M 97.15 Anstellungsvertrag zwischen Verleiher und Arbeitnehmer mit Bezugnahme auf einen Tarifvertrag . . . . . . . . . . . . . . . . . . . . . . . . . . . . . 1904

M 97.16 Berufsausbildungsvertrag . . . . . . . . . . . . . . . . . . . . . . . 1907

M 97.17 Praktikantenvertrag . . . . . . . . . . . . . . . . . . . . . . 1912

M 97.18 Nachweis über die wesentlichen Vertragsbedingungen gemäß Nachweisgesetz . . . 1914

M 97.19 Vertrag mit einem freien Mitarbeiter . . . . . . . . . . . . . . . . . . . . 1917

Kap. 98 Vertragliche Nebenabreden und Erklärungen im laufenden Arbeitsverhältnis

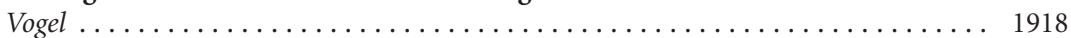

M 98.1 Fortbildungsvertrag mit Rückzahlungsklausel . . . . . . . . . . . . . . . . . . . 1920

M 98.2 Fortbildungsvertrag auf ausschließlichen Wunsch des Arbeitgebers . . . . . . . . . 1921

M 98.3 Auslandsentsendungsvereinbarung . . . . . . . . . . . . . . . . . . . 1921

M 98.4 Teilzeitvereinbarung gem. $\$ 8$ TzBfG bzw. $\$ 15$ BEEG . . . . . . . . . . . . . . . . . 1924

M 98.5 Antrag auf Verringerung der Arbeitszeit . . . . . . . . . . . . . . . . . . . . . 1925

M 98.6 Nachricht bei verspätet gestelltem Teilzeitverlangen . . . . . . . . . . . . . . . . 1925

M 98.7 Ablehnung des Teilzeitverlangens . . . . . . . . . . . . . . . . . . . . . . . . 1926

M 98.8 Urlaubsantrag des Arbeitnehmers mit formularmäßiger Bewilligung . . . . . . . . 1927

M 98.9 Erteilung von bezahltem und unbezahltem Urlaub . . . . . . . . . . . . . . . . . 1927

M 98.10 Vereinbarung unbezahlten Sonderurlaubs . . . . . . . . . . . . . . . . . . . 1928

M 98.11 Rahmenregelung für eine Zielvereinbarung . . . . . . . . . . . . . . . . . . . . . . . . 1929

M 98.12 Darlehensvertrag. . . . . . . . . . . . . . . . . . . . . . . . . . 1930

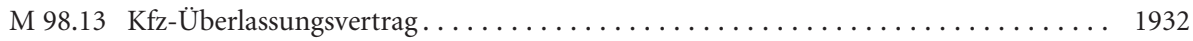

M 98.14 Geheimhaltungsklausel . . . . . . . . . . . . . . . . . . . . . 1936

M 98.15 Eingliederungsvertrag nach $\S 74$ SBG V . . . . . . . . . . . . . . . . 1937 
Kap. 99 Betriebliche Altersversorgung Vogel . ....................... 1937

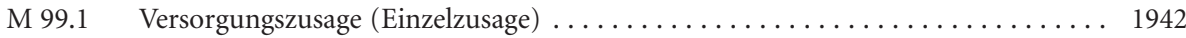

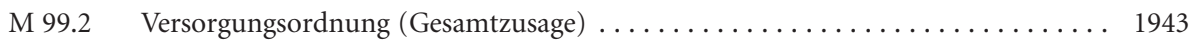

M 99.3 Verlangen des Arbeitnehmers auf Entgeltumwandlung gem. § 1a BetrAVG . . . . . 1946

M 99.4 Unverfallbarkeitsbescheinigung nach $\$ 4$ a Abs. 1 BetrAVG für unmittelbare Versorgungszusage ................................. 1947

M 99.5 Verlangen des Arbeitgebers nach Abfindung der Versorgungsanwartschaft nach $\$ 3$ BetrAVG . . . . . . . . . . . . . . . . . . . . . . . . . . . 1948

Kap. 100 Wettbewerbsverbot Vogel .............................. 1948

M $100.1 \quad$ Nachvertragliches Wettbewerbsverbot . . . . . . . . . . . . . . . . . 1951

M 100.2 Zusage erhöhter Karenzentschädigung $\ldots \ldots \ldots \ldots \ldots \ldots \ldots \ldots \ldots \ldots \ldots \ldots$

M 100.3 Berechnungsschema/Beispiel für Karenzentschädigung . . . . . . . . . . . . 1954

M 100.4 Einseitiger Verzicht des Arbeitgebers auf die Einhaltung des Wettbewerbsverbotes 1955

M 100.5 Lösungserklärung des Arbeitnehmers . . . . . . . . . . . . . . . . . . . 1955

M 100.6 Lösungserklärung des Arbeitgebers . . . . . . . . . . . . . . . . . . 1956

M 100.7 Aufforderung zur Auskunft über anderweitigen Erwerb . . . . . . . . . . . 1956

Kap. 101 Beendigung des Arbeitsverhältnisses Vogel .................... 1958

M 101.1 Außerordentliche Kündigung des Arbeitsverhältnisses durch den Arbeitnehmer

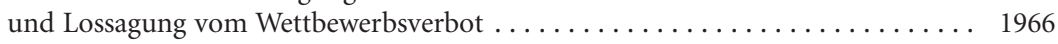

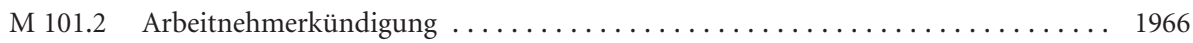

M 101.3 Aufforderung zur Mitteilung außerordentlicher Kündigungsgründe . . . . . . . 1967

M 101.4 Anfechtung einer Eigenkündigung oder eines Aufhebungsvertrages durch den Arbeitnehmer ..................................... 1967

M 101.5 Abmahnung ......................................... 1968

M 101.6 Außerordentliche Kündigung durch den Arbeitgeber . . . . . . . . . . . . . . . . . 1969

M 101.7 Außerordentliche, hilfsweise ordentliche Kündigung durch den Arbeitgeber . . . 1970

M 101.8 Ordentliche Kündigung durch den Arbeitgeber . . . . . . . . . . . . . . . 1970

M 101.9 Betriebsbedingte Kündigung mit Abfindungsangebot gem. $§ 1$ la KSchG . . . . . . 1972

M 101.10 Kündigungszurückweisung wegen fehlender Vollmachtsvorlage. . . . . . . . . . . 1972

M 101.11 Kündigungseinspruch beim Betriebsrat ...................... 1973

M 101.12 Ausübung des Direktionsrechts und vorsorgliche Änderungskündigung durch den Arbeitgeber . . . . . . . . . . . . . . . . . . . . . . . . . . . . . 1973

M 101.13 Änderungskündigung durch den Arbeitgeber . . . . . . . . . . . . . . . . . . . . 1974

M 101.14 Vorbehalt bei Änderungskündigung . . . . . . . . . . . . . . . . . . . . . . 1975

M 101.15 Anfechtung des Arbeitsvertrages mit Schwerbehindertem . . . . . . . . . . . 1976

M 101.16 Zustimmungsantrag des Arbeitgebers zur Kündigung eines schwerbehinderten Menschen/gleichgestellten behinderten Menschen ............... 1977

M 101.17 Antrag auf Zulassung der Kündigung nach dem MuSchG/BErzGG/PflegeZG an zB Gewerbeaufsichtsamt. . . . . . . . . . . . . . . . . . . . . . . . . . 1979

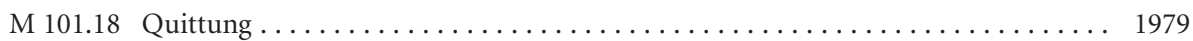

M 101.19 Einfacher Aufhebungsvertrag . . . . . . . . . . . . . . . . . . . . 1982

M 101.20 Aufhebungsvertrag mit Abfindungsregelung und Erledigungsklausel.......... 1982

M 101.21 Ausführlicher Aufhebungsvertrag . . . . . . . . . . . . . . . . . . . . . . 1984

M 101.22 Lohnsteueranrufungsauskunft . . . . . . . . . . . . . . . . . . . . . . 1990

M 101.23 Mitteilung an Geschäftsfreunde wegen Ausscheidens eines leitenden Angestellten

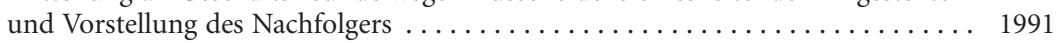

M 101.24 Presseerklärung beim Ausscheiden eines leitenden Arbeitnehmers . . . . . . . . 1991 


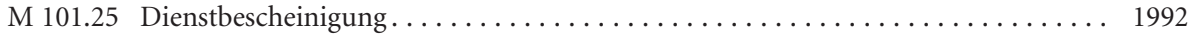

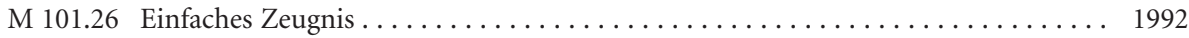

M 101.27 Qualifizierte Zeugnisse . . . . . . . . . . . . . . . . . . . . . . . . . . . 1992

M 101.28 Urlaubsbescheinigung bei Beendigung des Arbeitsverhältnisses . . . . . . . . . . 1993

Kap. 102 Unternehmensveräußerung und Arbeitsrecht Vogel . . . . . . . . . . . . . 2002

M 102.1 Unternehmenserwerb in Form des Anteilserwerbs (sog. Share Deal) . . . . . . . . 2003

M 102.2 Unternehmens-(Betriebs-)Kaufvertrag in Form der Übernahme von Wirtschafts-

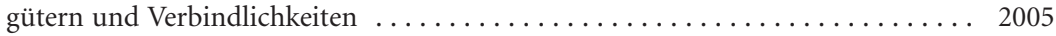

M 102.3 Vertragliche Überleitung der Arbeitsverhältnisse . . . . . . . . . . . . . . . . . . . . . 2007

M 102.4 Unterrichtung der Arbeitnehmer wegen Betriebsübergangs . . . . . . . . . . . . . 2009

M 102.5 Kündigung gegenüber einzelnen Arbeitnehmern in zeitlichem Zusammenhang mit einem Betriebsübergang . . . . . . . . . . . . . . . . . . 2010

M 102.6 Angaben der Folgen der Verschmelzung für die Arbeitnehmer und ihre Vertretungen sowie die insoweit vorgesehenen Maßnahmen im Rahmen eines

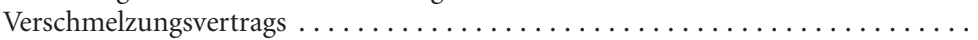

\section{Abschnitt. Betriebsverfassungsrecht}

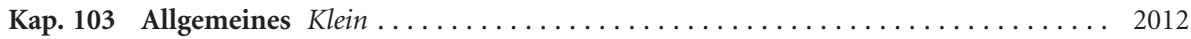

Kap. 104 Mitbestimmung in sozialen Angelegenheiten Klein . . . . . . . . . . . . . 2019

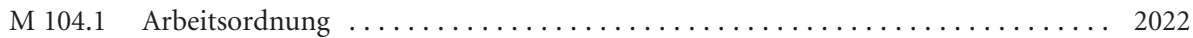

M 104.2 Betriebsvereinbarung zur Antidiskriminierung . . . . . . . . . . . . . . 2028

M 104.3 Betriebsvereinbarung zum Nichtraucherschutz . . . . . . . . . . . . . 2032

M 104.4 Betriebsvereinbarung zu Alkoholproblemen am Arbeitsplatz . . . . . . . . . . . 2033

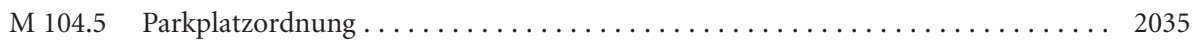

M 104.6 Betriebsvereinbarung zur Lage der Arbeitszeit und der Pausen . . . . . . . . . 2038

M 104.7 Gleitzeit-Betriebsvereinbarung . . . . . . . . . . . . . . . . . . . . . . . . 2039

M 104.8 Arbeitszeitkonto mit "Ampelregelung“ . . . . . . . . . . . . . . . . . . . . . . . . 2042

M 104.9 Betriebsvereinbarung zu Überstunden . . . . . . . . . . . . . . . . . . . . . . . . . . . . 2043

M 104.10 Betriebsvereinbarung zu Kurzarbeit . . . . . . . . . . . . . . . . . . . . . . . . . . 2045

M 104.11 Betriebsvereinbarung über Urlaubsgrundsätze und Betriebsferien . . . . . . . . . . 2046

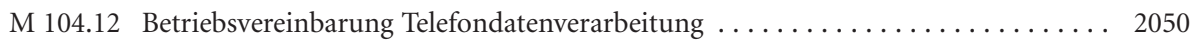

M 104.13 Betriebsvereinbarung Telefongebührenerfassung . . . . . . . . . . . . . . . 2051

M 104.14 Betriebsvereinbarung über die Nutzung von Internet und E-Mail . . . . . . . . . . 2052

M 104.15 Betriebsvereinbarung zur Arbeitszeiterfassung und Zugangskontrolle . . . . . . . . 2055

M 104.16 Betriebsvereinbarung Lohn- und Gehaltsabrechnung mit PAISY . . . . . . . . . . 2058

M 104.17 Betriebsvereinbarung zum betrieblichen Eingliederungsmanagement . . . . . . . 2060

M 104.18 Konzernbetriebsvereinbarung Mitarbeiterdarlehen . . . . . . . . . . . . . . . . . 2068

M 104.19 Betriebsvereinbarung über übertarifliche Zulagen . . . . . . . . . . . . . . . . . . 2070

M 104.20 Betriebsvereinbarung über eine Vergütungsgruppenordnung . . . . . . . . . . 2070

Kap. 105 Mitbestimmung in personellen Angelegenheiten Klein . . . . . . . . . . 2073

M 105.1 Betriebsvereinbarung innerbetriebliche Stellenausschreibung . . . . . . . . . . . . 2074

M 105.2 Betriebsvereinbarung Einführung eines Personalfragebogens . . . . . . . . . . . 2076

M 105.3 Betriebsvereinbarung zu Auswahlrichtlinien . . . . . . . . . . . . . . . . 2076

M 105.4 Unterrichtung des Betriebsrates nach $\S 99$ BetrVG bei beabsichtigter Einstellung

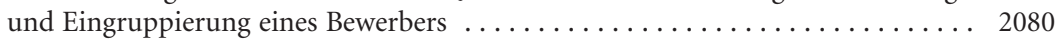

M 105.5 Stellungnahme des Betriebsrates bei Einstellung und Eingruppierung . . . . . . . 2081 
M 105.6 Unterrichtung des Betriebsrates nach $\$ 99$ BetrVG bei beabsichtigter Versetzung

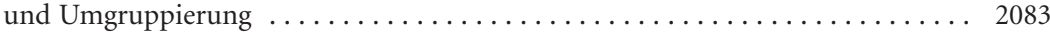

M 105.7 Stellungnahme des Betriebsrates bei Versetzung und Umgruppierung . . . . . . . 2083

M 105.8 Unterrichtung des Betriebsrates über eine vorläufige personelle Maßnahme . . . . 2084

M 105.9 Anhörung des Betriebsrates zu einer beabsichtigten ordentlichen Kündigung

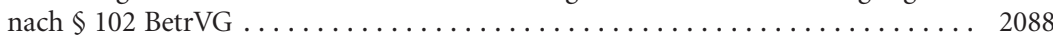

M 105.10 Anhörung des Betriebsrates zu einer beabsichtigten verhaltensbedingten fristlosen, hilfsweise ordentlichen Kündigung nach $\$ 102$ BetrVG . . . . . . . . . 2089

M 105.11 Anhörung des Betriebsrates zu einer beabsichtigten außerordentlichen Kündigung mit sozialer Auslauffrist bei ordentlich unkündbaren Arbeitnehmern 2090

M 105.12 Stellungnahme/Widerspruch des Betriebsrats . . . . . . . . . . . . . . 2092

M 105.13 Mitteilung über die Entlassung eines leitenden Angestellten nach $₫ 105$ BetrVG mit hilfsweiser Anhörung nach $\$ 102$ BetrVG ..................... 2093

M 105.14 Antrag auf Zustimmung zur beabsichtigten außerordentlichen Kündigung eines Betriebsratsmitglieds nach $\$ 103$ BetrVG . . . . . . . . . . . . . . . . . 2094

Kap. 106 Mitbestimmung in wirtschaftlichen Angelegenheiten Klein .............. 2095

M 106.1 Regelungsabrede über den Umfang von Mitteilungspflichten gegenüber dem Wirtschaftsausschuss ............................... 2096

M 106.2 Interessenausgleich bei Uneinigkeit über die durchzuführende Betriebsänderung . 2097

M 106.3 Interessenausgleich bei Einigkeit über die durchzuführende Betriebsänderung . . 2098

M 106.4 Interessenausgleich mit Namensliste nach $\$ 1$ Abs. 5 KSchG . . . . . . . . . . . . 2098

M 106.5 Interessenausgleich bei gleichzeitiger Festlegung des Sozialplanvolumens . . . . . . 2101

M 106.6 Sozialplan bei Betriebsschließung . . . . . . . . . . . . . . . . . . . . . . . 2102

M 106.7 Ergänzende Betriebsvereinbarung zu sog. „Turboprämien“ . . . . . . . . . . 2106

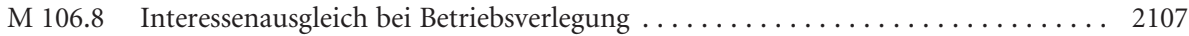

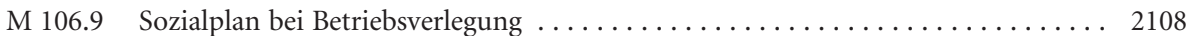

\section{E. Handels- und Gesellschaftsrecht}

\section{Erster Teil. Handelsrecht (ohne Gesellschaften)}

\section{Abschnitt. Prokura und Handelsvollmacht}

Kap. 107 Prokura und Handlungsvollmacht Leitzen ........................ 2113

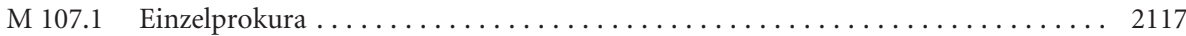

M 107.2 Ermächtigung zur Veräußerung und Belastung von Grundstücken ......... 2117

M 107.3 Beschränkung der Prokura auf den Betrieb einer Zweigniederlassung . . . . . . . . 2117

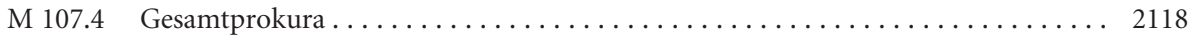

M 107.5 Gesamtprokura zur unechten Gesamtvertretung.................. 2118

M 107.6 Gesamtprokura zur echten und unechten Gesamtvertretung . . . . . . . . . . 2119

M 107.7 Anmeldung des Erlöschens der Prokura . . . . . . . . . . . . . . . . . 2119

\section{Abschnitt. Einzelkaufmann und eingetragener Kaufmann}

Kap. 108 Kaufmännisches Einzelunternehmen Leitzen/Schröders ................... 2120

M $108.1 \quad$ Erstanmeldung des Ist- oder Kannkaufmanns ..................... 2126

M 108.2 Anmeldung einer Firmenänderung . . . . . . . . . . . . . . . . . . . . . . . 2129

M 108.3 Anmeldung der Verlegung der Niederlassung eines Einzelunternehmens . . . . . 2130

M 108.4 Anmeldung der Errichtung einer Zweigniederlassung $\ldots \ldots \ldots \ldots \ldots \ldots \ldots .2131$ 
M 108.5 Anmeldung der Veräußerung des Einzelunternehmens mit Firma ........... 2132

M 108.6 Anmeldung der Verpachtung der Einzelfirma mit Haftungsausschluss . . . . . . . 2133

M 108.7 Anmeldung der Fortführung des Einzelunternehmens durch den Alleinerben . . . 2136

M 108.8 Anmeldung der Fortführung des Einzelunternehmens durch die Erbengemeinschaft. . . . . . . . . . . . . . . . . . . . . . . . . . . . 2137

M 108.9 Anmeldung der Fortführung des Einzelunternehmens durch den Vermächtnis-

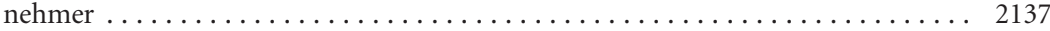

M 108.10 Anmeldung des Firmenerlöschens nach Veräußerung................. 2138

M 108.11 Anmeldung des Firmenerlöschens nach Aufgabe des Unternehmens . . . . . . . . 2138

M 108.12 Abmeldung der Firma eines Kannkaufmanns . . . . . . . . . . . . . . . . . . . . . . 2139

2. Teil. Personengesellschaften und Beteiligungen

\section{Abschnitt. Gesellschaft des Bürgerlichen Rechts}

Kap. 109 BGB-Gesellschaft Leitzen/Schröders ........................... 2140

M 109.1 Gesellschaftsvertrag einer Grundstücksverwaltungsgesellschaft ........... 2151

\section{Abschnitt. Offene Handelsgesellschaft}

Kap. 110 Gesellschaftsvertrag der OHG Leitzen/Schröders................... 2153

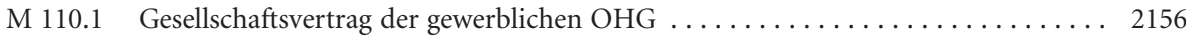

M 110.2 Allgemeine erbrechtliche Nachfolgeklausel . . . . . . . . . . . . . . . . . 2174

M 110.3 Qualifizierte erbrechtliche Nachfolgeklausel . . . . . . . . . . . . . . . . . 2174

M 110.4 Rechtsgeschäftliche Nachfolgeklausel . . . . . . . . . . . . . . . . . . 2175

Kap. 111 Handelsregisteranmeldungen zur OHG Leitzen .................... 2176

M 111.1 Anmeldung der Neuerrichtung einer OHG ................... 2177

M 111.2 Anmeldung der Errichtung einer OHG durch Eintritt eines Gesellschafters in das Einzelunternehmen ............................... 2177

M 111.3 Anmeldung der Fortführung des Einzelunternehmens durch Miterben in der

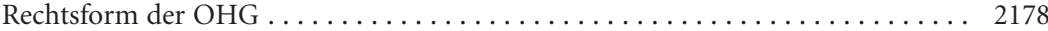

M 111.4 Anmeldung des Eintritts eines weiteren Gesellschafters in die OHG . . . . . . . . 2179

M 111.5 Anmeldung des Austritts eines Gesellschafters . . . . . . . . . . . . . . . . . . . 2179

M 111.6 Anmeldung des Ausscheidens eines Gesellschafters nebst Eintritt eines neuen Gesellschafters (auch: Abtretung) _........................ 2180

M 111.7 Anmeldung bei Fortsetzung nach Tod eines Gesellschafters . . . . . . . . . . . . . 2180

M 111.8 Anmeldung bei erbrechtlicher Nachfolgeklausel . . . . . . . . . . . . . . . . 2181

M 111.9 Anmeldung der Fortführung als Einzelfirma . . . . . . . . . . . . . . . . . . 2181

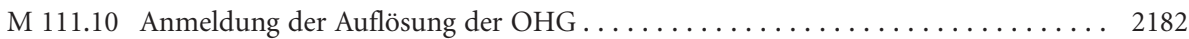

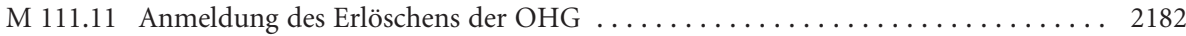

3. Abschnitt. Kommanditgesellschaft

Kap. 112 Gesellschaftsvertrag der KG Leitzen/Schröders ................... 2182

M 112.1 Gesellschaftsvertrag zur Gründung einer gewerblichen KG . . . . . . . . . . 2186

Kap. 113 KG-Familienpool Leitzen ............................... 2190

M 113.1 Vertrag der grundstücksverwaltenden Familien-KG . . . . . . . . . . . . 2190

Kap. 114 Handelsregisteranmeldungen zur KG Leitzen ...................... 2195

M $114.1 \quad$ Errichtung einer KG . . . . . . . . . . . . . . . . . . . . . . . . . . 2196

M 114.2 Aufnahme eines Kommanditisten in das Geschäft des Einzelkaufmanns . . . . . . 2196 
M $114.3 \quad$ Umwandlung einer OHG in eine KG durch Erbfolge . . . . . . . . . . . . . 2197

M 114.4 Änderung der Stellung eines Komplementärs in die eines Kommanditisten und umgekehrt .................................... 2198

M 114.5 Erhöhung und Herabsetzung von Hafteinlagen $\ldots \ldots \ldots \ldots \ldots \ldots \ldots \ldots \ldots . \ldots \ldots$

M 114.6 Eintritt eines weiteren Kommanditisten . . . . . . . . . . . . . . . . . . . . . . . . . 2199

M 114.7 Ausscheiden eines Kommanditisten .............................. 2199

M 114.8 Veräußerung einer Kommanditbeteiligung ..................... 2200

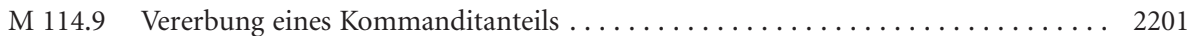

Kap. 115 GmbH \& Co. KG Leitzen/Schröders ........................ 2201

M $115.1 \quad$ Gesellschaftsvertrag der KG . . . . . . . . . . . . . . . . . . . . . . 2210

M 115.2 Gesellschaftsvertrag der Komplementär-GmbH . . . . . . . . . . . . . . . . 2212

M 115.3 Anmeldung der KG zum Handelsregister ...................... 2214

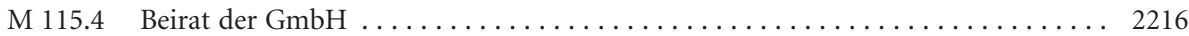

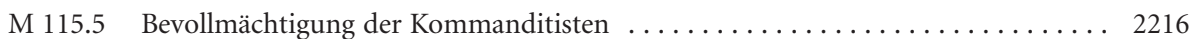

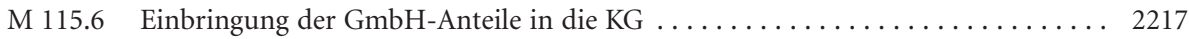

4. Abschnitt. Stille Gesellschaft und Unterbeteiligung

Kap. 116 Gesellschaftsvertrag der stillen Gesellschaft Leitzen/Schröders . . . . . . . . . 2218

M 116.1 Gesellschaftsvertrag einer stillen Gesellschaft (typische stille Gesellschaft) . . . . . 2253

M 116.2 Gesellschaftsvertrag über eine stille Beteiligung am Geschäftsbetrieb einer GmbH

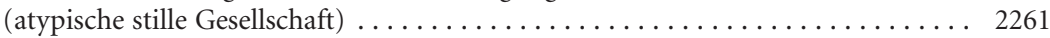

Kap. 117 Unterbeteiligung Leitzen/Schröders ....................... 2267

M 117.1 Unterbeteiligungs-Vertrag an dem Gesellschaftsanteil des persönlich haftenden Gesellschafters einer Kommanditgesellschaft . . . . . . . . . . . . . . . 2280

\section{Dritter Teil. Kapitalgesellschaften}

\section{Abschnitt. Gesellschaft mit beschränkter Haftung}

Kap. 118 GmbH: Gesellschaftstypen und Gesetzesentwicklung Dorsel . . . . . . . . . . 2286

Kap. 119 Die Gestaltung des Gesellschaftsvertrags der GmbH Dorsel . . . . . . . . . . . . 2292

M 119.1 Teilweise Einzahlung von Bareinlagen, Einforderungsregelung . . . . . . . . . . . 2298

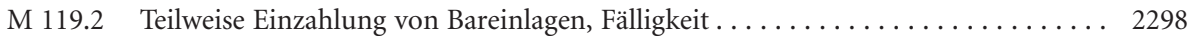

M 119.3 Abweichende Einforderungskompetenz bei Einlagen . . . . . . . . . . . . . . . . . 2298

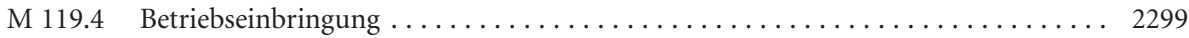

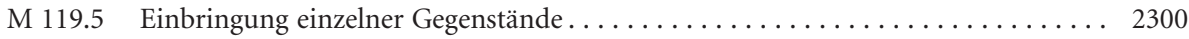

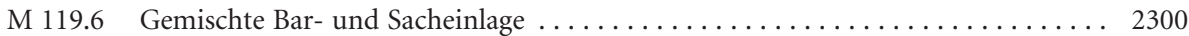

M 119.7 Zustimmungskatalog . . . . . . . . . . . . . . . . . . . . . . . . . . 2306

M 119.8 Abberufung von Gesellschafter-Geschäftsführern ................. 2308

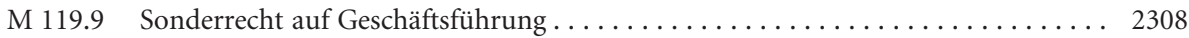

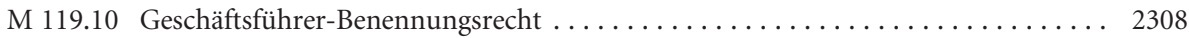

M 119.11 Niederlegung des Geschäftsführeramtes . . . . . . . . . . . . . . . . . . . . 2309

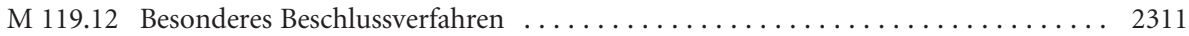

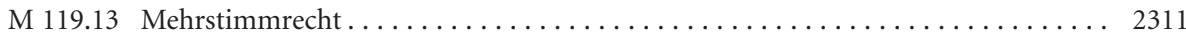

M 119.14 Stimmrechtsausschluss ............................... 2311

M 119.15 Protokoll ........................................... 2312

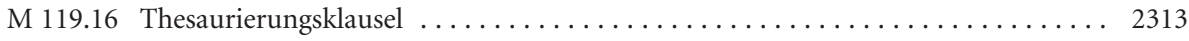

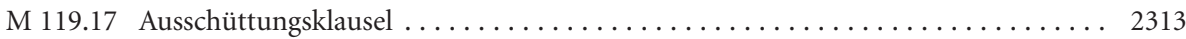


M 119.18 Rücklagenklausel ..................................... 2313

M 119.19 Kombinierte Ausschüttungs-/Thesaurierungsklausel ................. 2314

M 119.20 Steuerklausel . . . . . . . . . . . . . . . . . . . . . . . . . . . . . . . . . . . 2314

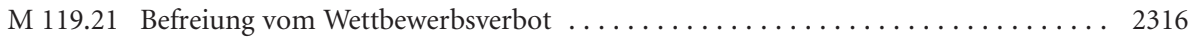

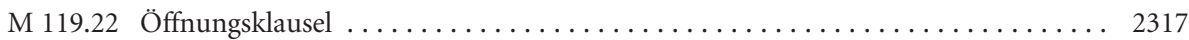

M 119.23 Zusammenlegung von Geschäftsanteilen durch Gesellschafterbeschluss ...... 2317

M 119.24 Zusammenlegung von Geschäftsanteilen ohne Gesellschafterbeschluss . . . . . . . 2318

M 119.25 Veräußerungsbeschränkung, Vorkaufsrecht ..................... 2319

M 119.26 Veräußerungsbeschränkung, Ankaufsrecht ................... 2320

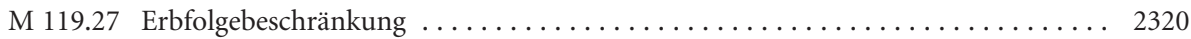

M 119.28 Hinauskündigungsklausel bei Unternehmensnachfolge . . . . . . . . . . . 2326

M 119.29 Hinauskündigungsklausel beim Managermodell ................. 2326

M 119.30 Abtretung mit Rückübertragungsverpflichtung .................. 2326

M 119.31 Buchwertklausel mit Schiedsgutachterklausel ................... 2328

M 119.32 Abfindung nach IDW-Bewertungsrichtlinien . . . . . . . . . . . . . . 2329

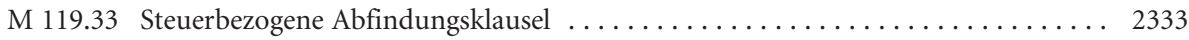

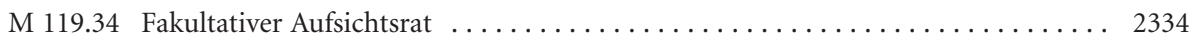

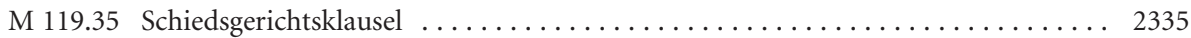

M 119.36 Mediationsklausel .................................... 2337

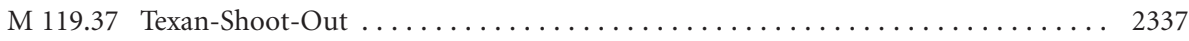

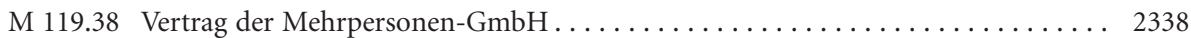

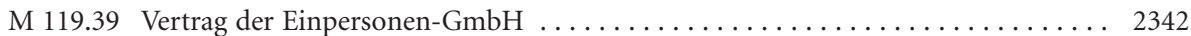

Kap. 120 Gründung und Anmeldung der GmbH und der UG (haftungsbeschränkt)

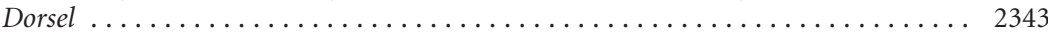

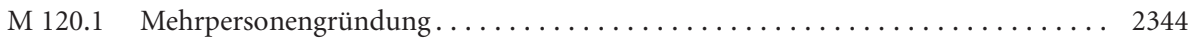

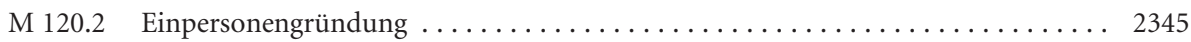

M 120.3 Anmeldung einer Mehrpersonen-GmbH ....................... 2351

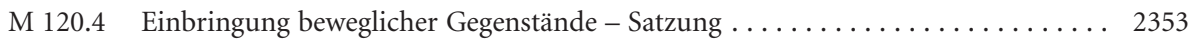

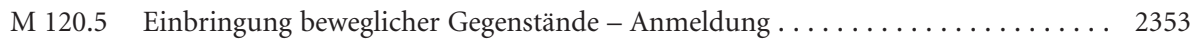

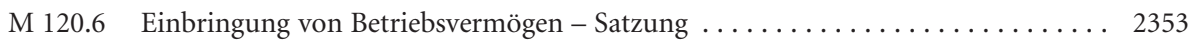

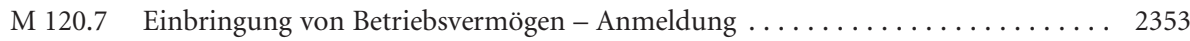

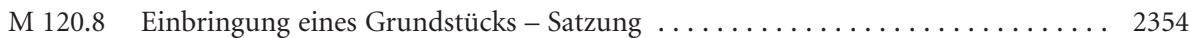

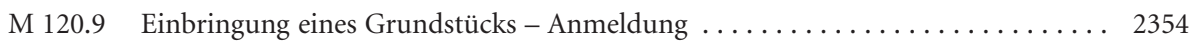

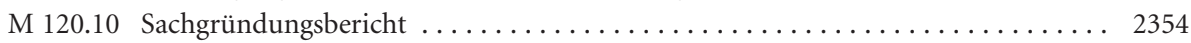

M 120.11 Musterprotokoll Einpersonengründung der $\mathrm{GmbH} \ldots \ldots \ldots \ldots \ldots \ldots \ldots \ldots . \ldots \ldots$

M 120.12 Registeranmeldung ................................. 2357

M 120.13 Vereinfachtes Verfahren zur Gründung einer Einpersonen-Unternehmer-

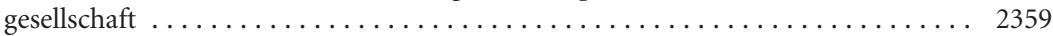

Kap. 121 Satzungsänderung, Kapitalmaßnahmen Dorsel ...................... 2360

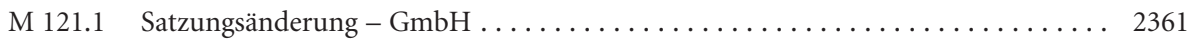

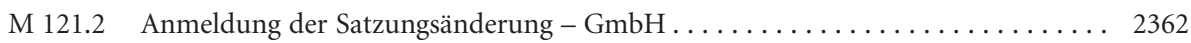

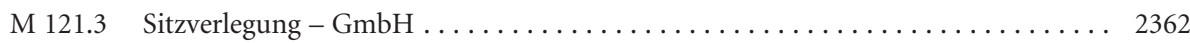

M 121.4 Kapitalerhöhung durch Bareinlage: Erhöhungsbeschluss, Übernahme - GmbH .. 2363

M 121.5 Anmeldung durch sämtliche Geschäftsführer - GmbH . . . . . . . . . . . 2364

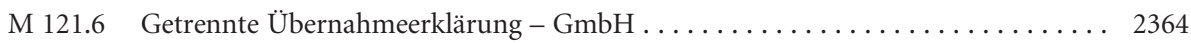

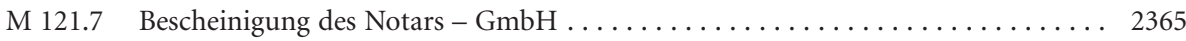


M 121.8 Liste der Übernehmer der neuen Stammeinlagen - GmbH . . . . . . . . . . . . 2365

M 121.9 Kostentragung in der Kapitalerhöhungsurkunde - GmbH . . . . . . . . . . . 2366

M 121.10 Einlageverpflichtung gem. $\$ 56$ GmbHG .................... 2366

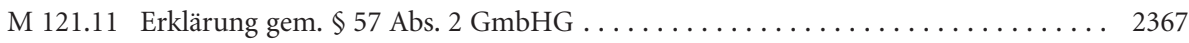

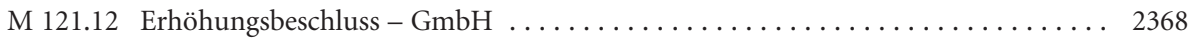

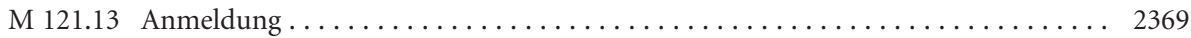

M 121.14 Kapitalerhöhung aus Gesellschaftsmitteln zum Übergang von der UG in die GmbH . . . . . . . . . . . . . . . . . . . . . . . . . . . . . 2370

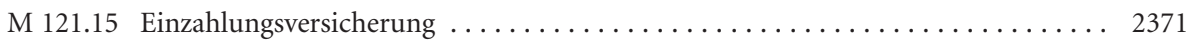

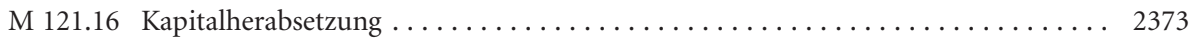

M 121.17 Kapitalherabsetzung nach Einziehung ........................... 2374

M 121.18 Kapitalherabsetzung bei Unterbilanz . . . . . . . . . . . . . . . . . . . . . . . 2374

M 121.19 Anmeldung der Kapitalherabsetzung . . . . . . . . . . . . . . . . . . . . 2374

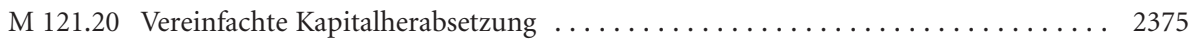

M 121.21 Anmeldung der vereinfachten Kapitalherabsetzung . . . . . . . . . . . . . . . 2376

M 121.22 Genehmigtes Kapital . . . . . . . . . . . . . . . . . . . . . . . . . . . . 2378

Kap. 122 Abtretung und Kauf von Geschäftsanteilen, Gesellschafterliste Dorsel . . . . . 2378

M 122.1 Aufschiebend bedingte Geschäftsanteilsabtretung - GmbH . . . . . . . . . . 2382

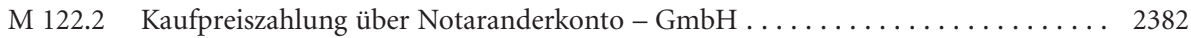

M 122.3 Kauf und Abtretung eines Geschäftsanteils - GmbH ................. 2385

Kap. 123 Treuhand, Mantelverwendung Dorsel ........................ 2390

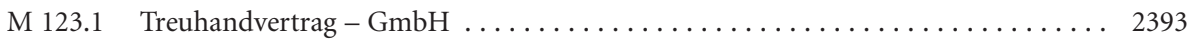

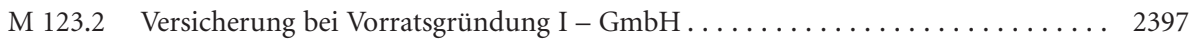

M 123.3 Versicherung bei Vorratsgründung II - GmbH . . . . . . . . . . . . . . . . . 2398

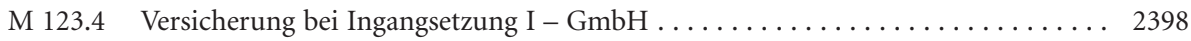

M 123.5 Versicherung bei Ingangsetzung II $-\mathrm{GmbH} \ldots \ldots \ldots \ldots \ldots \ldots \ldots \ldots \ldots \ldots$

Kap. 124 Bestellung und Anstellung des GmbH-Geschäftsführers Dorsel . . . . . . . . . 2399

M $124.1 \quad$ Vertretungsregelung mit Öffnungsklausel - GmbH . . . . . . . . . . . . . . . 2401

M 124.2 Erschwerung der Abberufung - GmbH . . . . . . . . . . . . . . . . . . . 2403

M 124.3 Anmeldung der Amtsniederlegung - GmbH . . . . . . . . . . . . . . . . . . 2404

M 124.4 Regelung der Amtsniederlegung in der Satzung . . . . . . . . . . . . . . 2404

M 124.5 Anstellungsvertrag eines Fremdgeschäftsführers - GmbH . . . . . . . . . 2408

Kap. 125 Auflösung und Liquidation der GmbH Dorsel .................... 2410

M 125.1 Gesellschafterbeschluss auf Auflösung einer GmbH $\ldots \ldots \ldots \ldots \ldots \ldots \ldots \ldots$

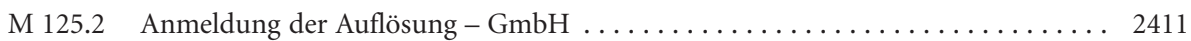

M 125.3 Bekanntmachung der Auflösung im Veröffentlichungsorgan der GmbH ....... 2411

M 125.4 Anmeldung der Beendigung der Liquidation $-\mathrm{GmbH} \ldots \ldots \ldots \ldots \ldots \ldots \ldots \ldots$

Kap. 126 Beherrschungs- und Gewinnabführungsvertrag zwischen zwei GmbHs Dorsel 2412

M 126.1 Beherrschungs- und Gewinnabführungsvertrag (Organschaftsvertrag) zwischen

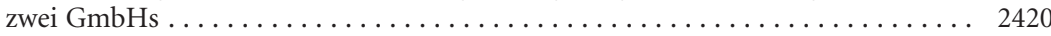

M 126.2 Protokoll einer Gesellschafterversammlung - Zustimmung der Gesellschafter der

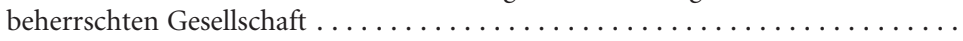

M 126.3 Anmeldung des Bestehens eines Unternehmensvertrags zum Handelsregister der beherrschten Gesellschaft ................................. 2424 


\section{Abschnitt. Aktiengesellschaft}

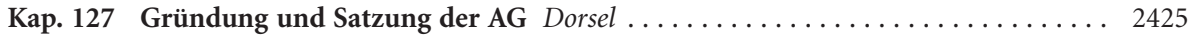

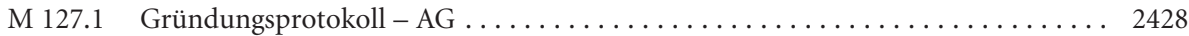

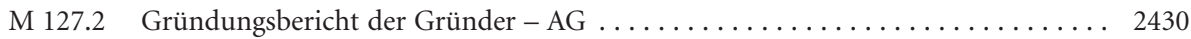

M 127.3 Gründungsprüfungsbericht der Mitglieder des Vorstands und des Aufsichtsrats AG . . . . . . . . . . . . . . . . . . . . . . . . . . . . . . 2431

M 127.4 Niederschrift über die Sitzung des Aufsichtsrats vom . . - AG . . . . . . . . . . 2431

M 127.5 Anmeldung der AG zum Handelsregister . . . . . . . . . . . . . . . . . . 2432

M 127.6 Prüfungsbericht des beauftragten Notars - AG . . . . . . . . . . . . . . . 2434

M 127.7 Gründungssatzung - Vorzugsaktien . . . . . . . . . . . . . . . . . . . . . . . 2440

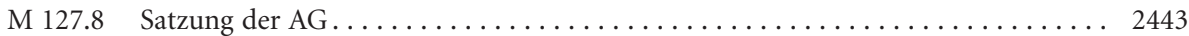

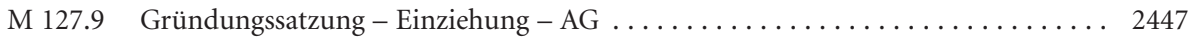

M 127.10 Gründungssatzung - Vinkulierte Namensaktien .................. 2448

Kap. 128 Rechtsstellung, Bestellung und Anstellung von Vorstandsmitgliedern Dorsel . 2449

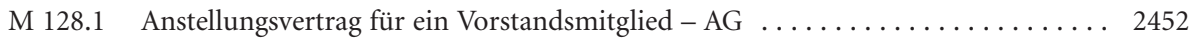

Kap. 129 Satzungsänderungen, Kapitalmaßnahmen Dorsel . . . . . . . . . . . . . . 2454

M 129.1 Hauptversammlungsbeschluss (zu Muster M 127.8) - AG . . . . . . . . . . . 2454

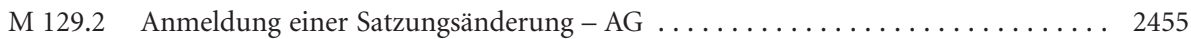

M 129.3 Erhöhungsbeschluss Bareinlage - AG . . . . . . . . . . . . . . . 2457

M 129.4 Anmeldung der Durchführung einer Erhöhung verbunden mit der Anmeldung des Erhöhungsbeschlusses - AG . . . . . . . . . . . . . . . . . 2457

M 129.5 Beschluss einer Kapitalerhöhung gegen Einlage von GmbH-Geschäftsanteilen -

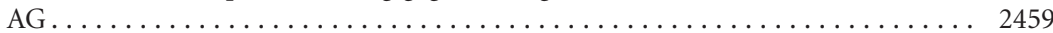

M 129.6 Zeichnungsvertrag und Geschäftsanteilsabtretung - AG . . . . . . . . . . . . 2459

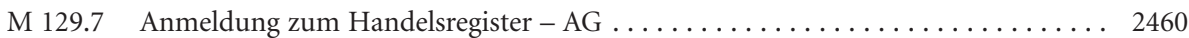

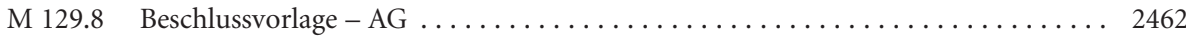

M 129.9 Beschlussvorschlag über eine bedingte Kapitalerhöhung nach $\$ 192$ Abs. 1, Abs. 2

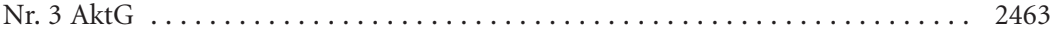

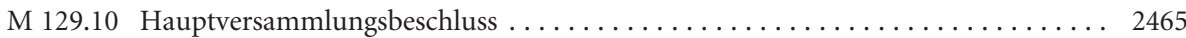

M 129.11 Beschluss über eine vereinfachte Kapitalherabsetzung - AG . . . . . . . . . . 2466

Kap. 130 Die Hauptversammlung der AG Dorsel......................... 2467

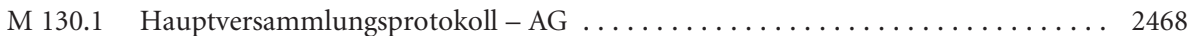

M 130.2 Privatschriftliche Niederschrift - Hauptversammlung AG . . . . . . . . . . . 2476

\section{Abschnitt. Private Limited Company}

Kap. 131 Private Limited Company Dorsel/Schröders...................... 2477

M 131.1 Memorandum of Association - Private Limited Company ................. 2499

M 131.2 Articles of Association - Private Limited Company . . . . . . . . . . . . . . . . . 2499

M 131.3 Form 10 - Private Limited Company ......................... 2500

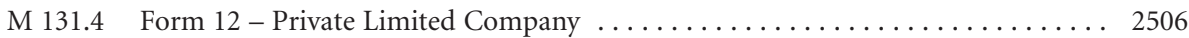

M 131.5 Handelsregisteranmeldung - Private Limited Company . . . . . . . . . . . . . 2507

\section{Abschnitt. Eingetragene Genossenschaft}

Kap. 132 Eingetragene Genossenschaft Leitzen/Schröders ...................... 2508

M 132.1 Satzung einer eingetragenen Genossenschaft mit Generalversammlung . . . . . . . 2512

M 132.2 Gründungsprotokoll - Eingetragene Genossenschaft . . . . . . . . . . . . . . . . 2517 
M 132.3 Anmeldung der Neugründung zum Genossenschaftsregister - Eingetragene

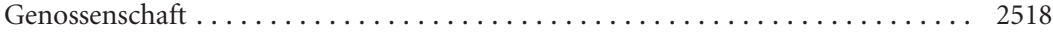

M 132.4 Beschluss der Generalversammlung über Vorstandswechsel - Eingetragene Genossenschaft .................................... 2519

M 132.5 Anmeldung eines Vorstandswechsels - Eingetragene Genossenschaft. . . . . . . . 2519

M 132.6 Beitrittserklärung zu einer eingetragenen Genossenschaft . . . . . . . . . . . . 2520

M 132.7 Übertragung des Geschäftsguthabens - Eingetragene Genossenschaft . . . . . . . 2521

M 132.8 Kündigung der Mitgliedschaft - Eingetragene Genossenschaft . . . . . . . . . . 2522

M 132.9 Aufkündigung durch einen Privatgläubiger - Eingetragene Genossenschaft . . . . 2522

\section{F. Sozietätsverträge}

Kap. 133 Sozietätsverträge Römermann ......................... 2525

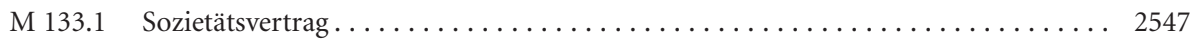

M 133.2 Varianten zur Vertragsklausel über eine Gewinnbeteiligung (M 133.1 $\$ 12$ Abs. 1) - Sozietätsvertrag ............................... 2553

M 133.3 Varianten zu nachvertraglichen Wettbewerbsklauseln ( M 133.1 $\$ 14)$ - Sozietäts-

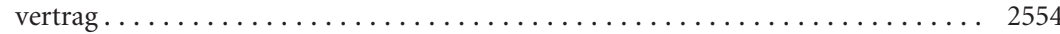

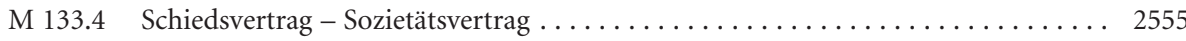

Kap. 134 Partnerschaftsgesellschaft mit beschränkter Berufshaftung Römermann/Zimmermann ......................... 2556

M 134.1 Vertrag einer Partnerschaftsgesellschaft mit beschränkter Berufshaftung . . . . . . 2571

\section{G. Mediation}

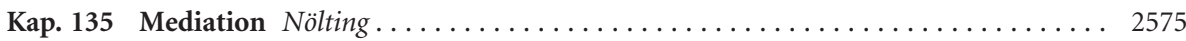

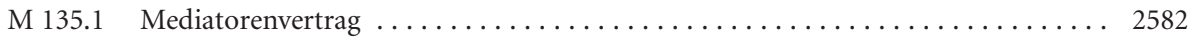

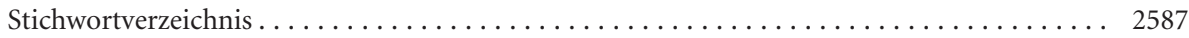

